Document downloaded from:

http://hdl.handle.net/10251/103260

This paper must be cited as:

Bertolesi, E.; Milani, G.; Lopane, FD.; Acito, M. (2017). Augustus Bridge in Narni (Italy): Seismic Vulnerability Assessment of the Still Standing Part, Possible Causes of Collapse, and Importance of the Roman Concrete Infill in the Seismic-Resistant Behavior. International Journal of Architectural Heritage. 11(5):717-746. doi:10.1080/15583058.2017.1300712

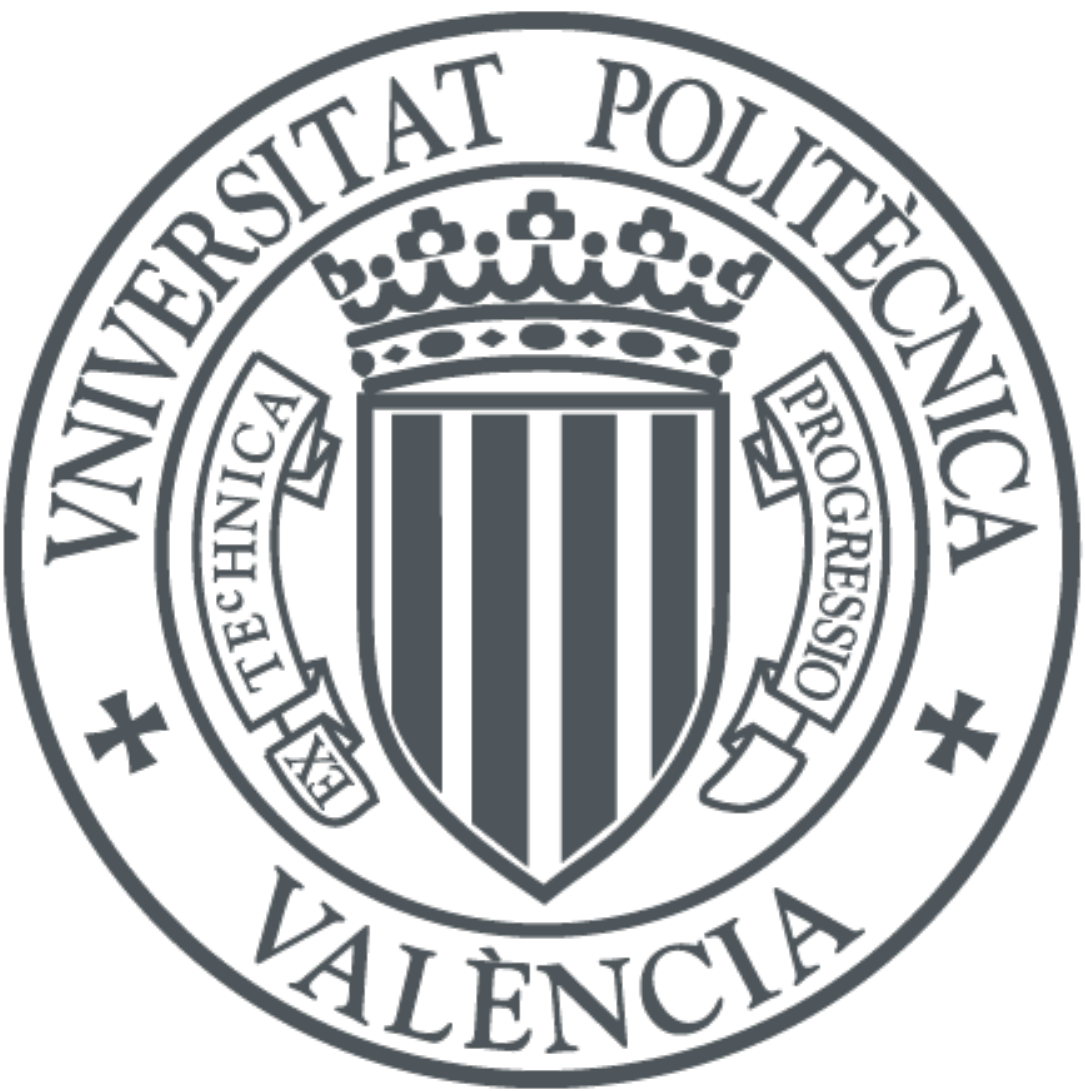

The final publication is available at

https://doi.org/10.1080/15583058.2017.1300712

Copyright Taylor \& Francis

Additional Information 


\title{
Augustus Bridge in Narni (Italy): Seismic vulnerability assessment of the still standing part, possible causes of collapse and importance of the Roman concrete infill in the seismic- resistant behavior
}

\author{
Elisa BERTOLESI ${ }^{1}$, Gabriele MILANI*2, Fulvio Domenico LOPANE ${ }^{3}$, Maurizio \\ $\mathrm{ACITO}^{4}$
}

1. Post Doctoral Fellow, Dept. of Architecture, Built Environment and Construction Engineering, Technical University of Milan, Piazza Leonardo da Vinci 32, 20133, Milan, Italy

3. PhD student, University of Newcastle, UK

2. Associate Professor, Dept. of Architecture, Built Environment and Construction Engineering, Technical University of Milan, Piazza Leonardo da Vinci 32, 20133, Milan, Italy

3. PhD Student, University of Newcastle Upon Tyne, Department of Civil Engineering, Newcastle NE1 7RU UK

4. Assistant Professor, Dept. of Architecture, Built Environment and Construction Engineering, Technical University of Milan, Piazza Leonardo da Vinci 32, 20133, Milan, Italy

* Author to whom all correspondence should be addressed. E-mail: gabriele.milani@polimi.it Phone: +39 3495516064

Keywords: masonry arch Roman bridges; Roman concrete; earthquake; spectral response analysis; non-linear static analysis (pushover); non-linear dynamic analysis.

\begin{abstract}
The final results of advanced FE analyses performed on a Roman arch bridge, namely the Augustus Bridge (Ponte di Augusto) in Narni, center Italy are presented. The bridge, one of the most impressive Roman artworks, has been injured by several traumatic events during the millennia, the result of which is its present ruin condition.

The aims are manifold, starting from a better understanding of the causes at the base of the partial collapse occurred on the central pier, passing through a seismic assessment of the ruined still standing part and ending with a discussion on the role played by Roman concrete on the stability against horizontal actions. An advanced material model exhibiting damage, plastic deformation and softening in both tension and compression is adopted for Roman concrete. Both the case of a foundation settlement of the central pier and the application of a seismic excitation are investigated, by means of non-linear static and non-linear dynamic analyses. Numerical simulations are carried out within the FE code ABAQUS by means of detailed 3D models, using historical documentation and previous results of the latest research carried out on materials, assuming realistic models on both the uniaxial stress-strain relationships under nonlinear load-unload conditions by using independent damage parameters in tension and compression, and the multiaxial behavior ruled by a regularized Drucker-Prager strength criterion. The methodological approach turns out to be potentially valid for all existing Roman bridges.

Results highlight the vulnerability of the ruins, that the collapse of the central part was probably due to settlement of the central pier and that Roman concrete plays a crucial role in increasing the stability against earthquake actions.
\end{abstract}




\section{1 - Introduction}

The Ponte di Augusto (Italian for "Bridge of Augustus") in Narni, Italy is one of the most important artworks ever built by the Romans, most of which are still in service nowadays.

Roman bridges were an essential part of the great road system of ancient Rome, which at the time of Diocletian reached a length of about 53000 miles (approximately 80000 kilometers - hence the saying "all roads lead to Rome"), and which gave rise to several road systems of many modern nations around the Mediterranean sea.

Several historical sources, as Cecchi (2003) and Galliazzo (1994), indicate the Ponte Emilio as the first artifact of stone built in Rome in 179 BC. Most probably, the bridge initially had a mixed structure, with stone piers and wooden superstructure, which was replaced with stone arches in 142 BC.

This was not the only bridge built in the second century BC. Such century was without any doubt a period of great works, many streets were paved with flint in Rome, graveled and fixed out of the cities and many arch bridges were built in many places. The Ponte Milvio belongs also to this period: it was built, using stone, in $109 \mathrm{BC}$.

The construction of bridges and viaducts grew and extended gradually to the entire Roman Empire during the first century BC. With Caesar's death in $44 \mathrm{BC}$ and the rise of Augustus, and the consequential beginning of the Imperial Age, there has been, in Rome and throughout the Empire, an impressive reorganization of many urban plants and energetic restoration of numerous road layouts with the resulting construction or rebuilding of many bridges.

From the late Republican bridge, meant as civil structure of crossing, in the Augustan age the bridge started to be considered as a monument, a tangible expression of unity and power of the Roman Empire. From this period is the Bridge over the Nera river at Narni on the Via Flaminia, which numerous historical references, as Cecchi (2003) and Galliazzo (1994), describe as one of the marvels of Roman engineering.

By way of example Figure 1 shows the images and the relative sizes of some of the main and most important Roman arch bridges with a Roman concrete filling, which clarify the high level of engineering reached by the Romans in the construction of bridges, with works that were overcome only in the modern era, when the construction of bridges has been able to rely on materials such as steel and reinforced concrete.

In Figure 2 the Ponte di Augusto is illustrated, in the most reliable reconstruction of the original configuration (Cecchi 2003 and Galliazzo 1994). 


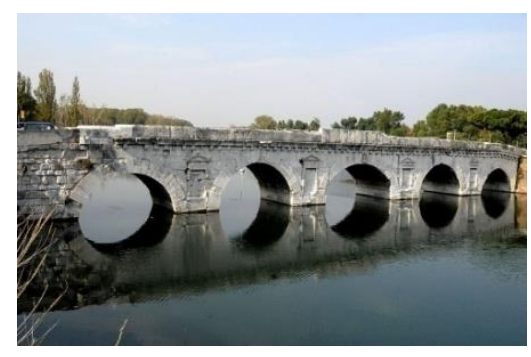

a)

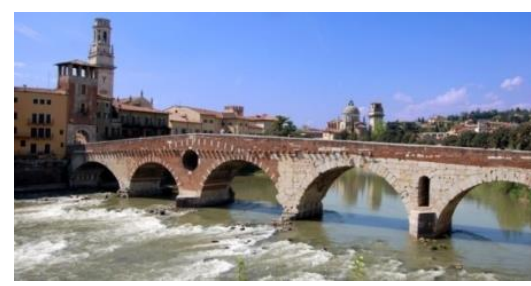

d)

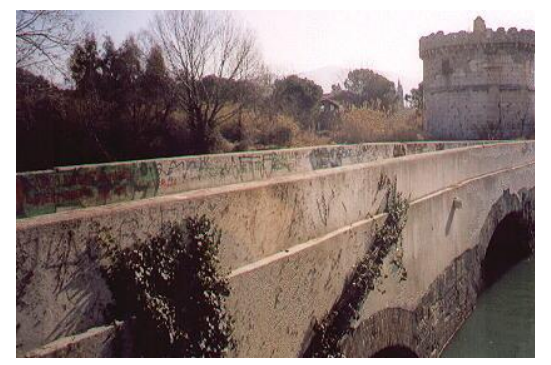

g)

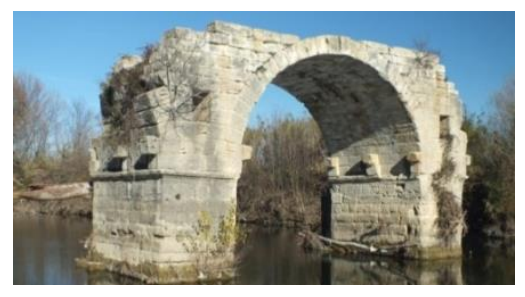

1)

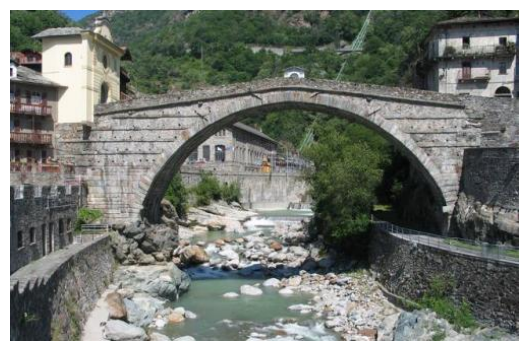

b)

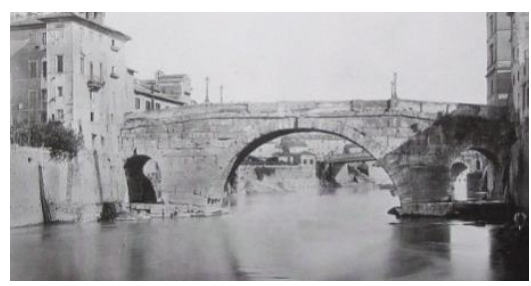

e)

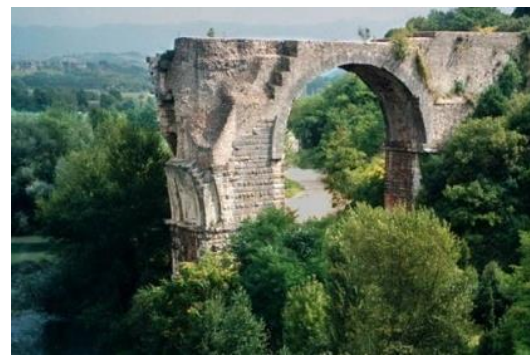

h)

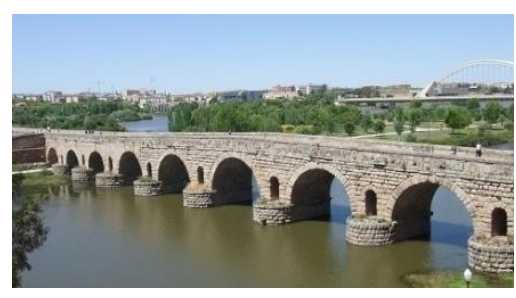

$\mathrm{m})$

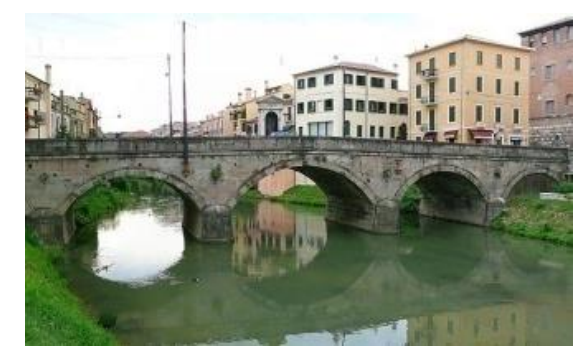

c)

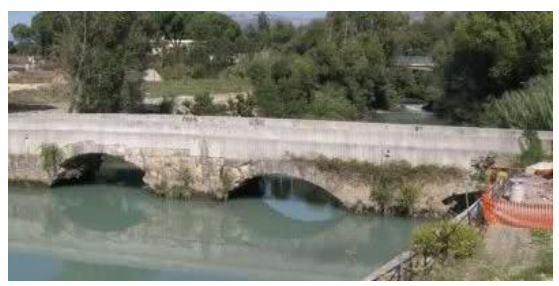

f)

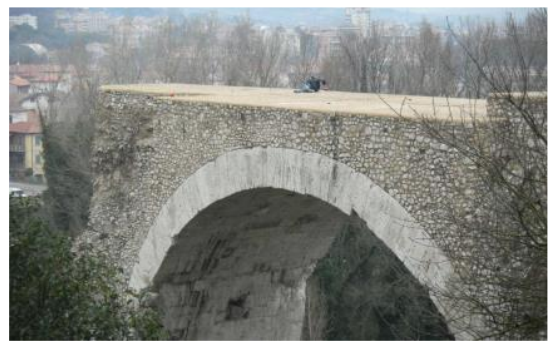

i)

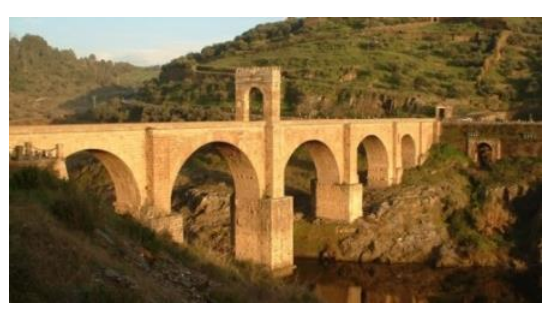

n)

\begin{tabular}{|lccccccc|}
\hline \multicolumn{1}{|c}{ Bridge } & Place & Country & Year of construction & Length & Width & Main span & References \\
\hline a) Ponte di Tiberio & Rimini & Italy & 14-21 AD & $74.00 \mathrm{~m}$ & $8.45 \mathrm{~m}$ & $10.70 \mathrm{~m}$ & Galliazzo (1994) \\
\hline b) Pont-Saint-Martin & $\begin{array}{c}\text { Pont } \\
\text { Saint Martin }\end{array}$ & Italy & $\begin{array}{c}\text { 70-40 BC lower part, } \\
\text { Augustan age upper part }\end{array}$ & $36.00 \mathrm{~m}$ & $5.80 \mathrm{~m}$ & $35.64 \mathrm{~m}$ & Galliazzo (1994) \\
\hline c) Ponte Molino & Padova & Italy & 30-40 BC & $50.54 \mathrm{~m}$ & $9.21 \mathrm{~m}$ & $11.47 \mathrm{~m}$ & Galliazzo (1994) \\
\hline $\begin{array}{l}\text { d) Ponte Pietra over the } \\
\text { Adige river }\end{array}$ & Verona & Italy & $\begin{array}{c}\text { Probably first half of first } \\
\text { century BC }\end{array}$ & $91.36 \mathrm{~m}$ & $7.20 \mathrm{~m}$ & $18.14 \mathrm{~m}$ & Galliazzo (1994) \\
\hline e) Ponte Cestio & Roma & Italy & Probably around 62 BC & $48.00 \mathrm{~m}$ & $8.95 \mathrm{~m}$ & $23.97 \mathrm{~m}$ & Galliazzo (1994) \\
\hline f) g) Ponte Lucano & Tivoli & Italy & First century BC & $75.00 \mathrm{~m}$ & $6.90 \mathrm{~m}$ & $11.00 \mathrm{~m}$ & Galliazzo (1994) \\
\hline h) i) Ponte di Augusto & Narni & Italy & $27 \mathrm{BC}$ & $180.00 \mathrm{~m}$ & $8.00 \mathrm{~m}$ & $32.10 \mathrm{~m}$ & $\begin{array}{c}\text { Cecchi (1993) and } \\
\text { Galliazzo (1994) }\end{array}$ \\
\hline I) Pont Ambroix & Villetelle & France & First century BC & $100.00 \mathrm{~m}$ & $6.60 \mathrm{~m}$ & $10.40 \mathrm{~m}$ & Galliazzo (1994) \\
\hline m) Puente Romano & Mérida & Spain & First century BC & $832.00 \mathrm{~m}$ & $7.20 \mathrm{~m}$ & $11.35 \mathrm{~m}$ & Galliazzo (1994) \\
\hline n) Puente de Alcántara & Alcántara & Spain & $103-104 \mathrm{AD}$ & $190.00 \mathrm{~m}$ & $8.60 \mathrm{~m}$ & $28.80 \mathrm{~m}$ & Galliazzo (1994) \\
\hline
\end{tabular}

Figure 1: Some of the most important Roman bridges with concrete filling (images from the web). 


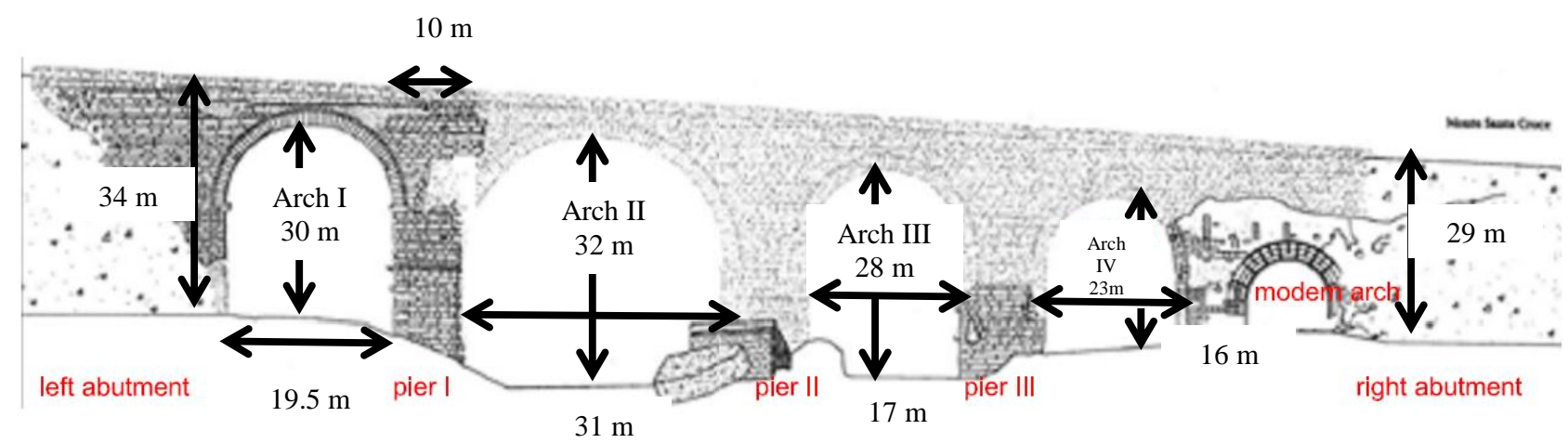

Figure 2: Front of the bridge from East (from upstream): the existing parts of the bridge are darker, while the hypothetical configuration of the original bridge is clearer (picture taken from Cecchi 2003).

The numeration of piers and arches is done in ascending order from left to right (or from South to North).The existing parts of the bridge are darker, while the hypothetical reconstruction of the original bridge is clearer. The right arch is modern, the abutment was perforated to allow the passage of the railway line Rome-Ancona.

The bridge now presents a ruin configuration (Figure 1 and Figure 2), with a single arch survived, very similar to the one celebrated in past centuries by important artists (among them Jean-BaptisteCamille Corot (1796-1875), who depicted the bridge over the years 1826-1827 in a painting exhibited in the Louvre Museum- Paris). In this, and in other images that depict the bridge in the seventeenth century, the bridge appears as shown in the dark part of Figure 2, except for the hole for the passage of the railway of the twentieth century, and the final collapse of the pier II, occurred in 1885 .

In addition to the impressive majesty and dimension of the bridge, to determine the significant structural interest to the Ponte di Augusto is its state of ruin, which allowed an in-depth study. Considerably interesting, from the structural point of view, are the geometrical and mechanical insights reported in Cecchi (2003), concerning the concrete filling and the travertine coating. With this information it was possible to have an appropriate level of knowledge to identify the vulnerability of the structure, both in the current ruin configuration and in the plausible original configuration (as will be reported in a subsequent work), which enabled the bridge to be in service for more than 1000 years after the construction.

Although there had already been a partial collapse in the seventh century AD, followed by a reconstruction which allowed the use of the bridge, in the first half of the eleventh century the bridge was described in the chronicles as "Broken Bridge". Some historians (see Cecchi 2003 and Galliazzo 1994) trace the cause of the collapse of the II, III and IV arch, to a flood of the Nera river, that swept the bridge following the collapse of a dam upstream.

In Cecchi (2003), however, based on analyses and studies conducted on the bridge, the author traces the causes of the collapse to a progressive foundation settlement of the pier II. As a matter of fact, on the basis of geometrical surveys and historical constructive considerations, it is believed that the original configuration was the one with 4 arches with the springers of circular arch II at the same height. The lowering of about 2.9 meters of the dosseret block of pier II, according to Cecchi (2003), is due to the foundation settlement of the pier itself occurred during two thousand years. 
At present, a large amount of technical literature dealing with the historical/structural analysis of masonry arch bridges and masonry arches in general is at disposal, as Oliveira et al. (2010), Cavicchi \& Gambarotta (2005), Cavicchi \& Gambarotta (2006), Reccia et al. (2014), Milani \& Lourenço (2012), Audenaert \& Beke (2010), Fanning et al. (2001), Martín-Caro \& Morales (2007), Pelà et al. (2009), Pippard (1948), Gilbert \& Melbourne (1994), Gilbert (2006), De Felice \& De Santis (2010), Audenaert et al. (2008), Drosopoulos et al. (2006), Fanning \& Boothby (2001) and Zeman et al. (2008). Sometimes, to be practically more efficient, such literature simplifies either the real 3D geometry to $1 \mathrm{D} / 2 \mathrm{D}$ problems or uses inadequate material models. Obviously, such structural models involve varying levels of accuracy and simplifications, which limit their range of applicability to specific cases. The most common idealizations of masonry material behavior are elastic, plastic and nonlinear (for a detailed discussion the reader is referred to e.g. Reccia et al. 2014 and Milani \& Lourenço 2012), but the most diffused theoretical approach, particularly in the case of masonry arch bridges, still remains limit analysis (Cavicchi \& Gambarotta 2005, Cavicchi \& Gambarotta 2006, Gilbert 2006, Drosopoulos et al. 2006). Limit analysis provides very quickly failure mechanisms and an estimation of the load carrying capacity of the structure. Besides the historic rules, the classic approach to determine the stability of arch bridges is probably due to Pippard (1948), but nothing is said about the role played by out-of-plane horizontal loads.

Transversal effects may be very important from a practical point of view, playing a crucial role in the decrease of the load bearing capacity or in case of earthquakes (Milani \& Lourenço 2012 and Pelà et al. 2009). For complex geometries, FEs models are sometimes constituted by many elements and variables, making the solution of the incremental problem difficult even for small bridges, particularly in presence of softening behavior for the constituent materials, which is normally required for masonry (Audenaert et al. 2008, Fanning \& Boothby 2001, Zeman et al. 2008).

From the above considerations, it appears clear that, in general, to properly take into account all the aspects influencing masonry bridges behavior, such as non-linearity of the materials, arch-fill interaction, transversal effects, actual geometry, etc., is not an easy task.

In this study, starting from the historical documentation and the results of the latest research carried out on materials of the bridge, but also on the basis of experimental tests of identification of the dynamic behavior of the remaining part of the ruins of the bridge, carried out during the present work, a series of advanced non-linear numerical analyses are conducted, critically compared and discussed.

The key issues tackled are manifold. In particular, several numerical approaches are utilized for a better understanding of the causes at the base of the partial collapse occurred. An advanced material model exhibiting damage, plastic deformation and softening in both tension and compression is adopted for Roman concrete. Both the case of a foundation settlement of the central pier and the application of a seismic load are dealt with, the former by means of non-linear static and the latter through non-linear dynamic analyses. Numerical simulations are conducted by means of the commercial code ABAQUS, which allows a realistic reproduction of the actual material behavior under nonlinear load-unload conditions by using independent damage parameters in tension and compression, and a 3D behavior ruled by a regularized Drucker-Prager strength criterion.

Another important topic discussed in the paper is the seismic vulnerability of the still standing part, i.e. the bridge in the present configuration, which again is estimated by means of both non-linear static (pushover) and non linear dynamic analyses. 
Furthermore, in order to have an insight into the role played by Roman concrete on the stability of masonry arch bridges in general, different hypotheses on its constitutive behavior are formulated, taking as reference data those provided either by Cecchi (2003), which assumes constant properties along the height of the bridge, or by Drdácký et al. (2013), which sampled -by probing along the height of pier I- several specimens then tested in the lab and made the hypothesis of a stratigraphy constituted by four layers of concrete with sensibly different mechanical properties. The compared results help in having an insight into the most realistic mechanical properties to adopt for the Roman concrete to realistically reproduce the behavior of such kind of structures during centuries and against possible seismic events.

From an overall analysis of the many numerical simulations performed, the idea that Roman concrete increases the overall strength of the structure, also against earthquakes, is corroborated. The utilization of weaker mechanical properties, indeed, assuming for instance values suggested by the Italian code for existing masonry, results into a largely insufficient capacity of the whole bridge to cope with transversal actions mimicking an earthquake, and even important damages for gravity loads. Pushover simulations seem to confirm the outcome provided by non-linear dynamic simulations, suggesting that the collapse of the central part could be a consequence of a seismic event, but only under the hypothesis of mechanical strength for the Roman concrete much smaller than that found experimentally on the still standing part.

\section{2 - Notes on construction techniques of Roman bridges}

The mortar and the concrete (or opus caementicium), occupy a prominent position in the Roman bridges (Lamprecht 1986, Cantisani et al. 2002, Drdácký et al. 2013), because the mortar appears in bridges as a binder between the stone elements of each type of masonry or between brick in the opus testaceum (adobe brickwork); and the concrete is almost always present in direct foundations or on the head of indirect foundations, as well as in the nucleus of the abutments, in piers and superstructures of the bridges.

Other plastic mixtures like opus signinum or clay packed with gravel or stones or clay mixed with marsh grasses, rarely appear in bridges and however they are quite exceptional techniques.

Concerning the mechanical properties of the opus caementicium, the extended campaigns of resistance to compression tests and bulk density (such as in Lamprecht 1986), carried out on samples coming from Roman buildings such as walls, theaters, amphitheaters, domes etc., mainly localized in Italy and Germany), have shown that the Roman concrete has resistance properties and density similar to those possessed by a modern concrete (with Portland cement) of low/medium strength class.

The construction techniques, even if closely related to the materials in the vicinity of the building, were generally based on the use of lime mortar with the addition of pebbly, sands of volcanic origin and/or dust and shards of terracotta, which gave a considerable compressive strength to the material with a hydraulic reaction. For this reason the structures were shaped to work with prevailing states of compression.

From mineralogical investigations carried out on samples of Roman concrete, it has been detected that hydraulicity was mainly given by the addition of dust and shards of terracotta and/or by the addition of sand and pebbles of volcanic origin (pozzolan). Though, as appears from the investigations carried out on samples of concrete from the Ponte di Augusto (Cecchi 2003, Cantisani et al. 2002, Drdácký et al. 2013), in this case the hydraulicity in the conglomerate is attributable to calcification of stones of impure limestone, and not by inserting any particular 
additives (Cantisani et al. 2002). We are therefore dealing with a technique that was then taken up purely by chance in Great Britain, and that led, about eighteen centuries later, to the discovery of modern Portland cement. The importance of the artwork and the proven construction techniques used for centuries by the Romans suggests a possible awareness of who has made the construction of the Ponte di Augusto, though not historically documented.

From the structural point of view, the Roman bridges are almost entirely shaped with reference to circular arches, whose size depended mostly on the opportunities offered by the foundational area of the crossing riverbed.

Figure 1 shows some pictures of Roman bridges, from which it can be appreciated the recurring use of round arches, although in rare cases, in relation to orographic conditions, they can appear segmental arches (Galliazzo 1994).

Also in this case, there are not historical elements that allow an assumption about the awareness by Roman engineers of the static behavior of arch structures, in particular round arches; according to historians, however, it is unquestionable the knowledge of the Romans of the techniques and constructive advantages for the realization of circular centering (Galliazzo 1994) and especially in the preparation of the blocks of stone constituting arches and vaults of the arcades; probably arranged with shapes and sizes obtainable with simple proportionality rules, as a function of the span of the arches.

\section{3 - The Ponte di Augusto in Narni}

In the present section, a brief overview of the case study the paper deals with is provided. A preliminary historical sketch is reported, followed by a mechanical characterization of the materials used.

\section{1 - History of the bridge}

The Ponte di Augusto is located next to the city of Narni, an Umbrian town of about twenty thousand inhabitants in the province of Terni (Central Italy) (Cecchi 2003, Galliazzo 1994, Salvatore et al. 2005).

The bridge was built to cross the river Nera. The river Nera is a $116 \mathrm{~km}$ long river that flows mainly in Umbria and it is the main tributary of the river Tevere. The Ponte di Augusto is located just at the beginning of the gorge that the river Nera runs through after leaving the wide valley of the city of Terni, at the limit of which there is, on a hill, the city of Narni. The banks are: the slopes of Monte Maggiore (South bank), on which stands Narni, and the lower ledge of Mount Santa Croce (North bank).

It can be stated that the Ponte di Augusto in Narni is one of the most impressive bridges of the whole Roman Italy, and one of the most interesting of the Roman Empire due to its technical and architectural features.

It was probably built in $27 \mathrm{BC}$ during the seventh consulate of Augustus, during a restoration of the Via Flaminia (Figure 3) motivated by military reasons. Probably the bridge was already partially collapsed, because of not well known reasons, in the seventh century, and it had been rebuilt 
reusing the materials recovered from the collapse and following the example of the previous design. Later, in 1053 or $1054 \mathrm{AD}$, according to many scholars, it seems that an overflow of the river (caused by the collapse of a dam upstream) has definitely brought down the superstructure of the bridge that was not rebuilt anymore. It happened probably because the knowledge and the techniques of that period did not allow a reconstruction in the original configuration, and so the function of crossing the valley was taken from the medieval bridge built a little further upstream (before 1217 AD according to historical sources, see Cecchi 2003) whose piers was made with salvaged materials (and not only) coming from the collapse of the Ponte di Augusto of XI century.

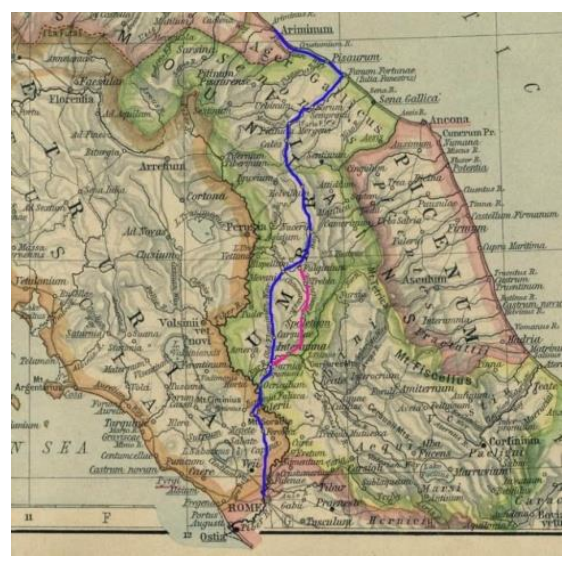

Figure 3: Via Flaminia (image from the web).

From that moment, the Ponte di Augusto appears in medieval documents as "Ponte Rotto" (Broken Bridge). In the nineteenth century there was a real working plan of restoration of the Ponte di Augusto, after the collapse of medieval bridge, in 1819 AD. But the situation changed only in 1885 $\mathrm{AD}$, when a flood of the river Nera overthrew the second pier from left, reducing it into pieces (the number of piers and arches is conventionally performed by referring to the prospect of the bridge seen from upstream, or from the East).

The right abutment of the bridge was then perforated by an arch to allow the passage of the railroad Rome-Ancona (Figure 2, Figure 4); finally in 1949 AD several voussoirs of the left arch, fallen down long before, were reinstalled.

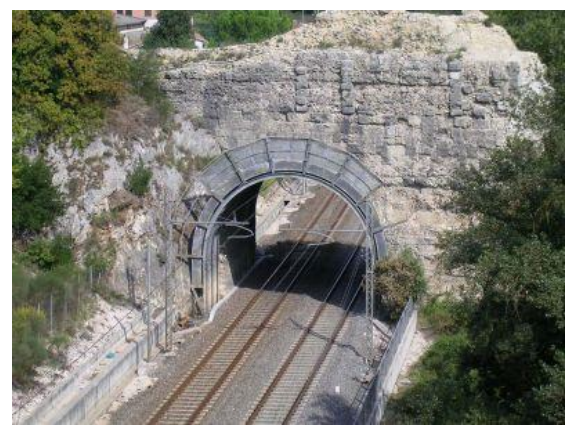

Figure 4: Right abutment perforated to allow the passage of the railroad.

The front shown in Figure 2 is the bridge seen from upstream (i.e. from East) in order to make unequivocal the identification of the parts of the bridge through the enumeration of piers, arches and abutments. 


\section{2 - Materials properties}

The arches, the piers and the bridge abutments have an outer coating made of masonry blocks of travertine disposed in opus quadratum, the filling of the bridge is instead in Roman concrete (Cecchi 2003, Galliazzo 1994, Cantisani et al. 2002, Drdácký et al. 2013).

The "opus quadratum" is a Roman construction technique that consists of a dry stone having regular parallelepiped ashlars positioned mostly in horizontal rows (Figure 5).

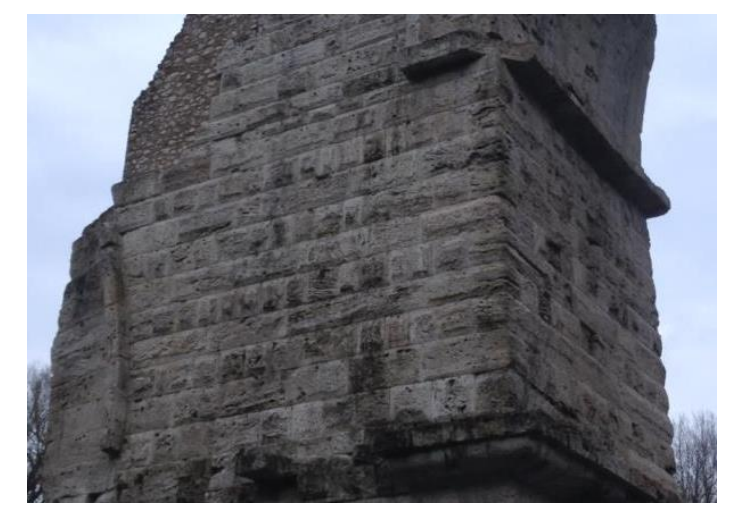

Figure 5: Example of opus quadratum (Ponte di Narni).

\subsection{1 - Travertine}

For the mechanical characterization of travertine, reference is made to the results of tests performed on materials during the restoration of the bridge (Cecchi 2003, Salvatore et al. 2005), which took place after an earthquake in 2000 which endangered the stability of the bridge.

Compression tests on travertine were performed by Cecchi (2003) on 10 cubic specimens with side of $50 \mathrm{~mm}, 7$ of them valid. The experimental average strength so evaluated was equal to 21.20 MPa.

Still in Cecchi (2003) bending tests were carried out on 10 specimens of length $120 \mathrm{~mm}$ having a cross section of $30 \mathrm{~mm}$ (width) by $20 \mathrm{~mm}$ (height). The average strength found was $8.53 \mathrm{MPa}$.

Whilst numerical data to adopt for tensile strength, according to consolidated literature in the field of softening materials, should be the average flexural strength divided by 3 , data present a wide scatter and the connection of travertine with internal layer is questioned by Cecchi (2003), who suggests to adopt a peak tensile strength equal to $0.1 \mathrm{MPa}$. In the present paper, also considering that the travertine layer has limited thickness and hence little importance on the overall behavior of the structure, a safe reduction by 6 of the flexural strength is applied, i.e. higher values of tensile strength are adopted. Such choice is also justified by direct in-situ inspection, revealing that travertine connects well with the internal concrete (without relative sliding). Such hypothesis, moreover, is quite consistent with Roman construction techniques, which, as is in the case of the Ponte di Augusto, provided the anchoring of the blocks of travertine between themselves and with the concrete filling using metal stirrups (Cecchi 2003).

Bending tests allowed deducing also the travertine elastic modulus. In particular in Cecchi (2003) the elastic modulus of the travertine was estimated equal to $10006 \mathrm{MPa}$. 
Finally, an average specific weight $\rho_{\mathrm{m}}=2117 \mathrm{~kg} / \mathrm{m}^{3}$ again according to Cecchi (2003) is adopted.

\subsection{2 - Roman concrete}

With regard to the mechanical characterization of the Roman concrete, reference is made, in addition to the mechanical tests carried out in the occasion of the restoration (Cecchi 2003, Salvatore et al. 2005), also to Cantisani et al. (2013) and Drdácký et al. (2013).

In particular, in Cecchi (2003) compression tests were conducted on 4 cubic specimens, 2 with side $22 \mathrm{~cm}$ and the other 2 with side $10 \mathrm{~cm}$. Here, it is worth pointing out that it would be appropriate to use specimens of greater size because of the highly variable size of the aggregates inside the mixture. Unfortunately it was not possible in this case because of the difficulties of sampling large specimens. By means of the extensometers it was also possible to estimate a Poisson's ratio $v=$ 0.15 , averaging the values obtained for the first two samples.

The Young's modulus E was evaluated by the average of the angular coefficient of the stress-strain curves for the first load cycles, i.e. where it was supposed that the material was still in the elastic range. The average value of cubic compressive strength found by Cecchi (2003) is equal to 24.62 $\mathrm{MPa}$, whereas the Young modulus to 12230 . Specific weight was estimated equal to $2223 \mathrm{~kg} / \mathrm{m}^{3}$.

\section{4 - Dynamic test}

Thanks to 4 EMME Service S.p.A. Company, it has been possible to perform a series of surveys with the aim to characterize the dynamic behavior of the Ponte di Augusto in Narni and to properly calibrate the numerical model. The dynamic test for the identification of the natural frequencies of the structure were conducted under the supervision of the authors and the elaboration of the experimental data was conducted by the authors themselves. The purpose of the dynamic analysis is to identify the free frequencies of vibration.

The measurement of the natural frequencies of the structure was performed using, in various configurations, 2 digital tromographs Microsismic 6S consisting in 3 accelerometer terns and 3 geophonic terns. Full scale accelerometers have the following technical characteristics: $\pm 3 \mathrm{~g}$ in the band $0.5 \mathrm{~Hz}-1600 \mathrm{~Hz}$ for $\mathrm{X}$ and $\mathrm{Y}$ axes and $0.5 \mathrm{~Hz}-550 \mathrm{~Hz}$ for the $\mathrm{Z}$ axis. The devices were connected each other via radio to allow the synchronization of the signal. The sampling was of 512 $\mathrm{Hz}$ for periods of 240 seconds.

The Microsismic devices were placed in 6 different configurations which will be described below in Figure 6, the excitation was of the natural kind. 


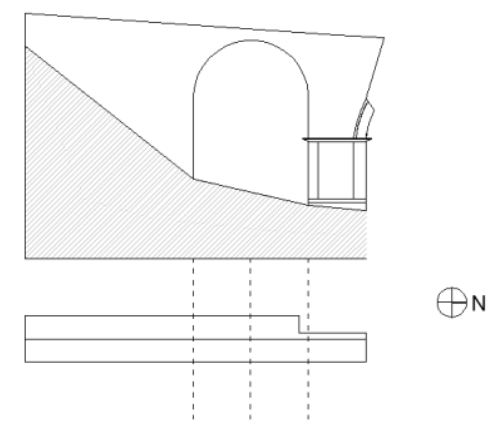

a) Scheme of the bridge

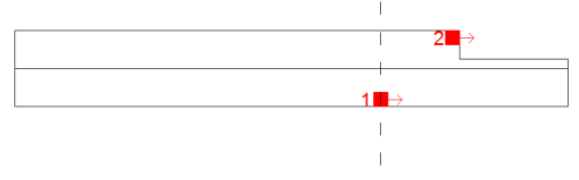

b) Configuration $\mathrm{C} 1$

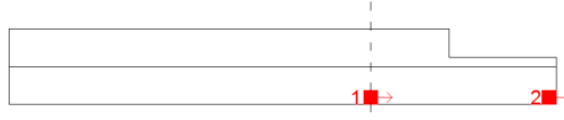

d) Configuration $\mathrm{C} 3$

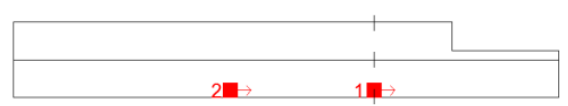

f) Configuration $\mathrm{C5}$

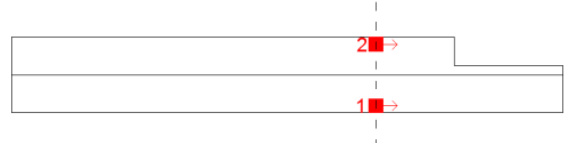

c) Configuration $\mathrm{C} 2$

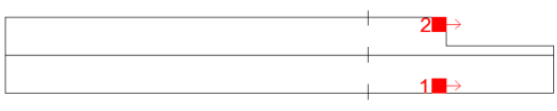

e) Configuration $\mathrm{C} 4$

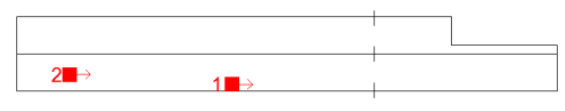

g) Configuration C6

Figure 6: Sketch of the existing part of the bridge and configurations used in the dynamic test.

Reference is made to this legend in the processing of the data, with regard to the directions of the detections:

N-S $1 \quad$ North-South microsismic 1

E-W $1 \quad$ East-West microsismic 1

v $1 \quad$ Vertical direction microsismic 1

N-S $2 \quad$ North-South microsismic 2

E-W 2 East-West microsismic 2

v 2 Vertical direction microsismic 2

In Figure 7, one of the three oscillograms of the three surveys carried out by the configuration $\mathrm{C} 1$ (Figure 6.a) is depicted. The abscissa shows the time, the ordinate the acceleration in $\mathrm{mm} / \mathrm{s}^{2}$. 


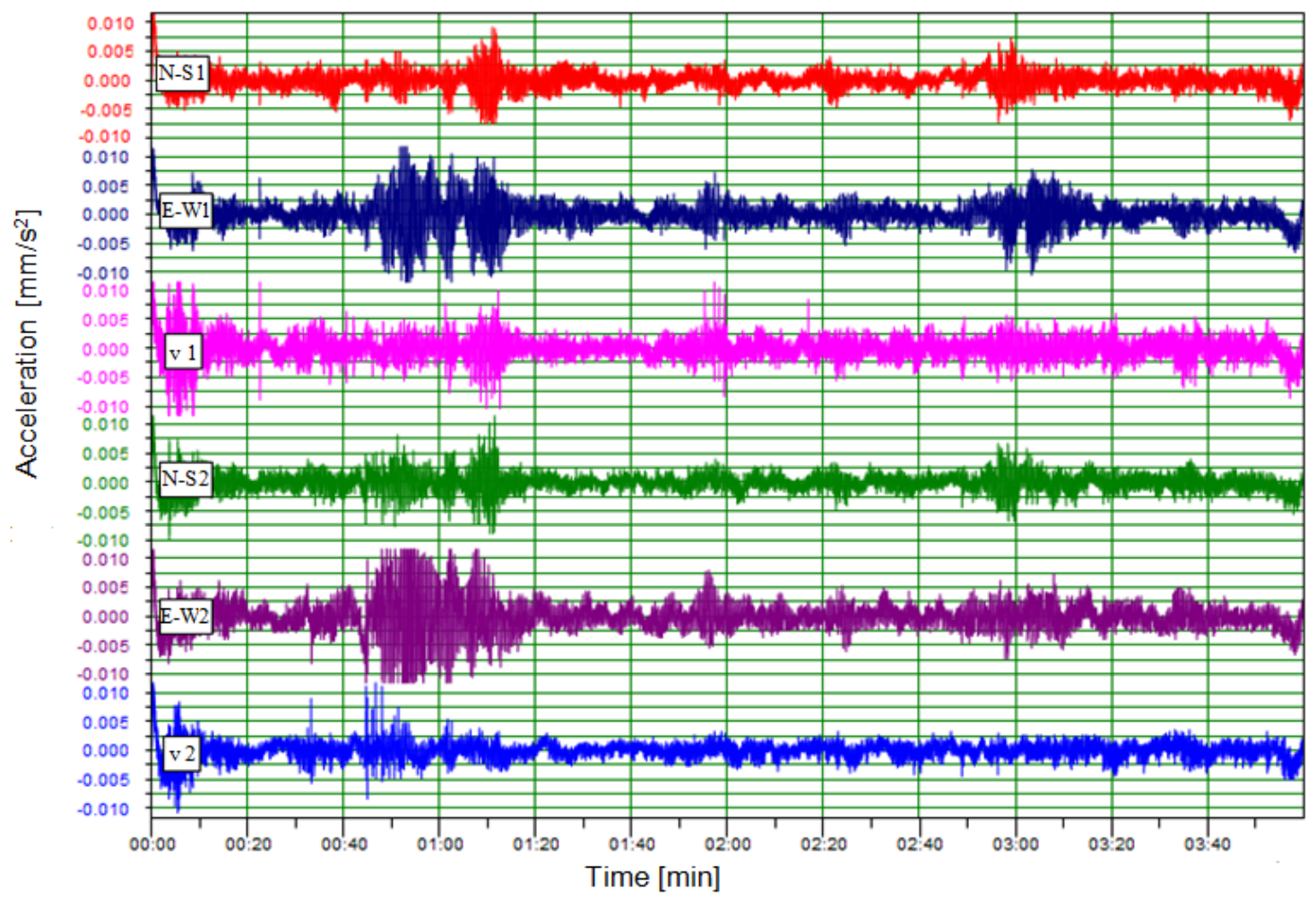

Figure 7: Oscillogram of $\mathrm{C} 1$ configuration

Figure 8 reports a time window of the same signal, filtered through Butterworth filter of $3 \mathrm{~Hz}$. The direction E-W 1 is in phase with the direction E-W 2, the frequency is $2.3 \mathrm{~Hz}$.

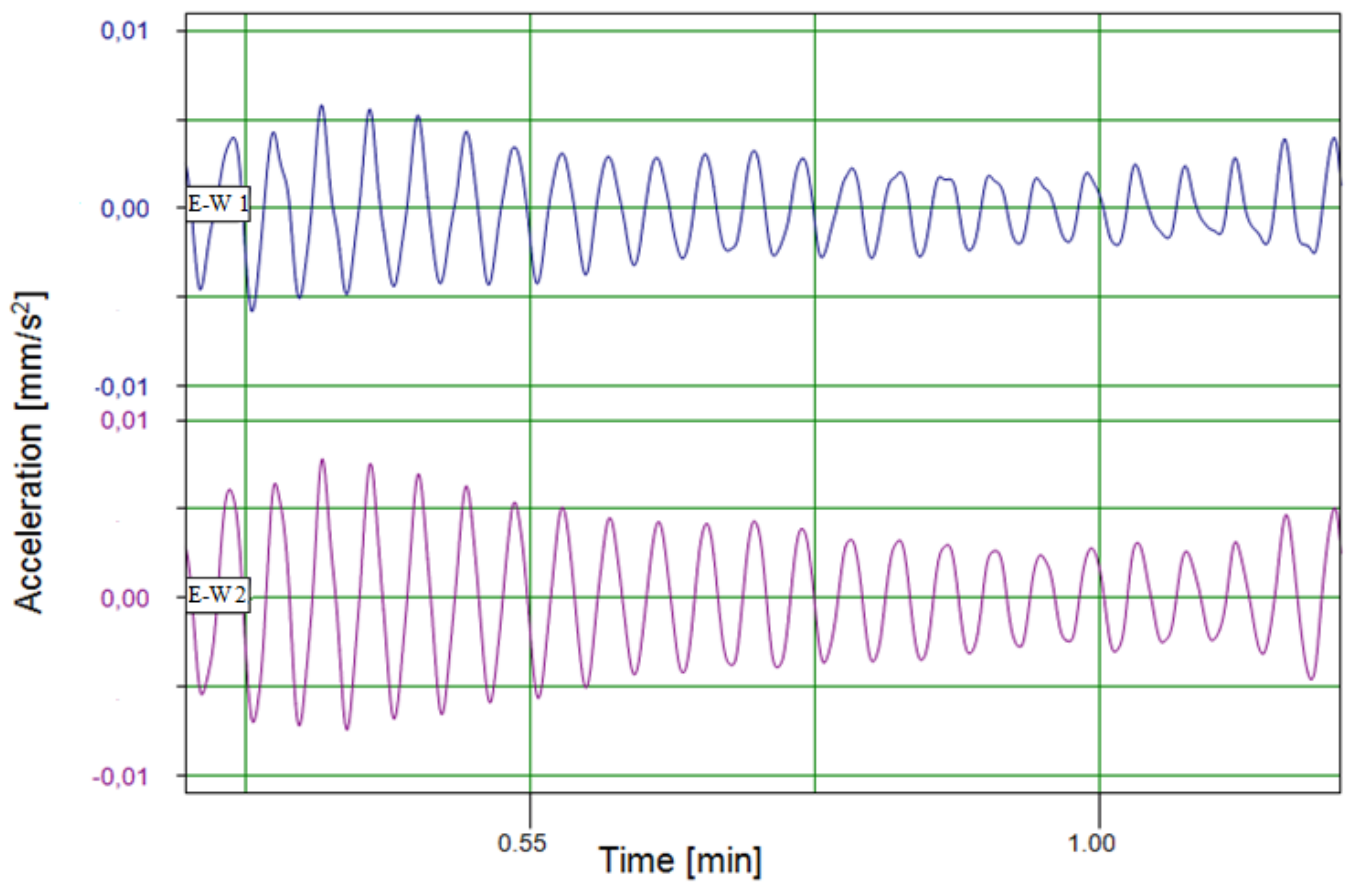

Figure 8: Time window with E-W 1 and E-W 2 signals

This elaboration is done for all the directions (N-S, E-W and v) for all the 3 samplings carried out for each configuration. 
The processing in the frequency domain of the configuration $\mathrm{C}$, obtained through the Fourier's transform, confirms the frequencies detected in the time domain. This processing provides the graph of Figure 9, where in the horizontal and vertical axes the frequency in $\mathrm{Hz}$ and the amplitude in $\mathrm{mm} / \mathrm{s}^{2}$ are reported respectively.

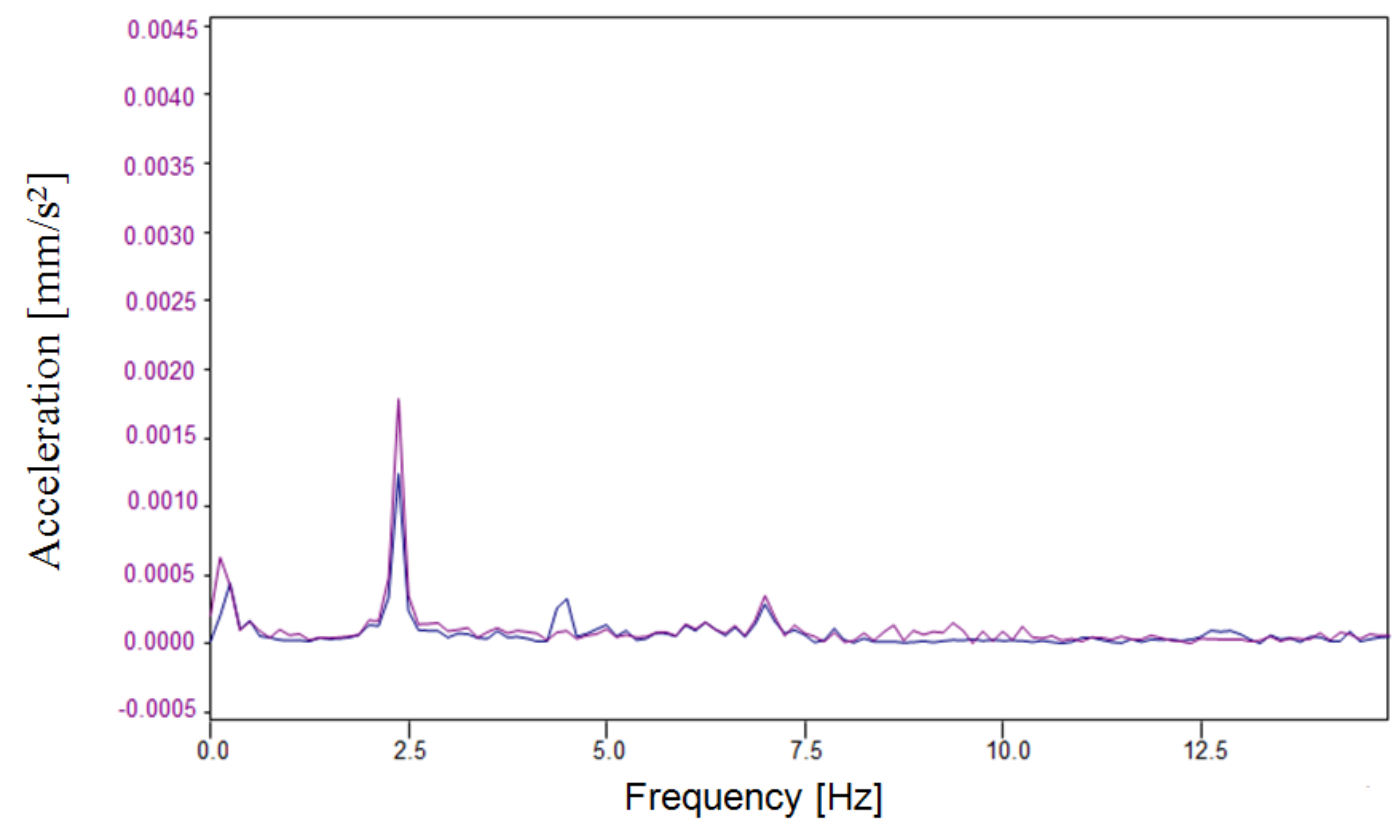

Figure 9: Spectrum E-W direction with peak frequency of $2.3 \mathrm{~Hz}$

Such elaboration is done for all the frequencies detected in the time domain.

At the end of all the signal elaborations, the frequencies of the first vibration modes in the three main directions are obtained. The values are summarized in Table 1.

Table 1 - Frequencies of the first vibration modes in the three main directions

\begin{tabular}{|c|c|}
\hline Frequency [Hz] & Direction \\
\hline 2.3 & East-West (transversal) \\
\hline 3.6 & North-South (longitudinal) \\
\hline 11.1 & Vertical direction \\
\hline
\end{tabular}

\section{5 - Geometrical and Numerical Model of the bridge}

In this Section, a brief summary of the geometry assumed in the numerical FE computations with the mechanical properties adopted is reported.

\section{1 - Geometrical modeling}

The analyses have been developed with reference to a FE model obtained from the geometry (Cecchi 2003) of the main part of the existing bridge (Figure 10), constituted the left abutment, the first arch and the first pier of the Ponte di Augusto. 


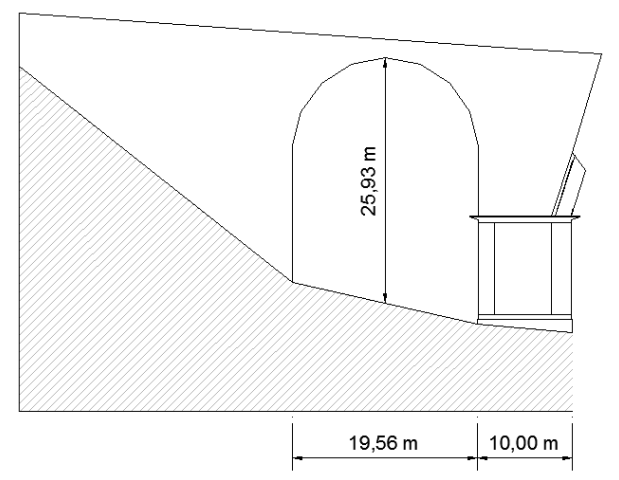

Figure 10: Geometric model of the still standing part of the Ponte di Augusto.

The geometry is exported from a CAD software into the commercial FE code Straus7 (Straus7 2004), where a model in 3 dimensions is created for the dynamic identification and into ABAQUS (Abaqus 2006) for the non-linear dynamic analyses and pushover analyses.

\section{2 - Geometric FE modeling}

Two FE models are conceived for the bridge, one for the still standing part and another for the entire structure as it was before the collapse of the central pillars.

The model of the still standing part of the Ponte di Augusto (Figure 1(i) and Figure 11) has been preliminarily validated through the numerical-experimental comparison obtained from the dynamic behavior observed in the dynamic test. This model is constituted by 14977 nodes, 12480 elements, of which 12247 8-noded bricks and 233 6-noded wedges.

The mechanical modeling has taken place by assigning to the different parts of the bridge the different mechanical properties due to the different materials used in construction (Table 2).

The restrains of the structure are fixed nodes at the base of the piers and abutments. 


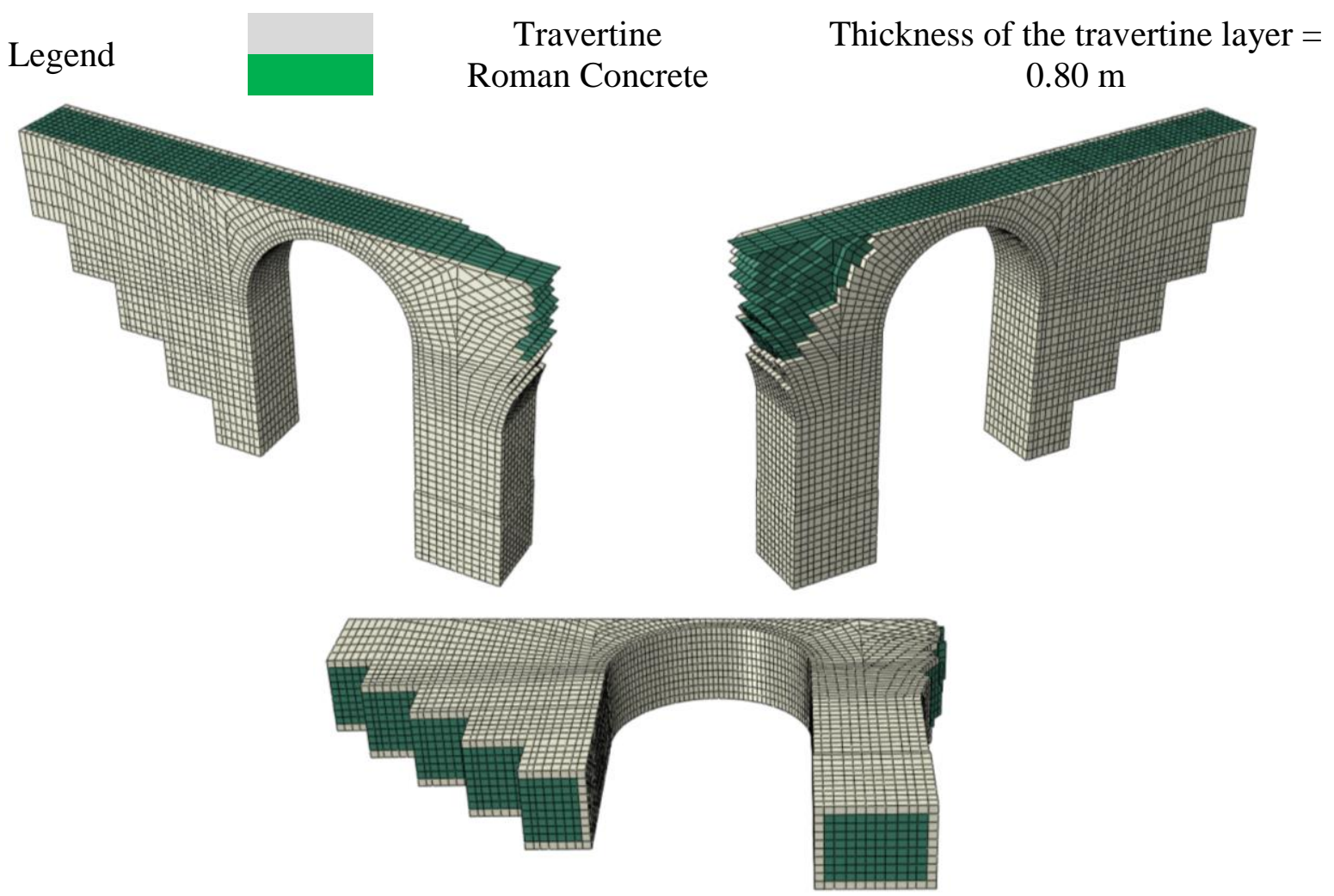

Figure 11: Numerical model of the still standing part of the Ponte di Augusto.

The model of the entire bridge is only hypothetical but based on consolidated historical research, as discussed in the previous Sections. The mesh used for the entire bridge is shown in Figure 12. The perforation introduced to allow railroad passage, see Figure 4, is obviously not considered. The model is constituted by 46342 nodes, 38136 elements, of which 37596 8-noded bricks and 5406 noded wedges. 


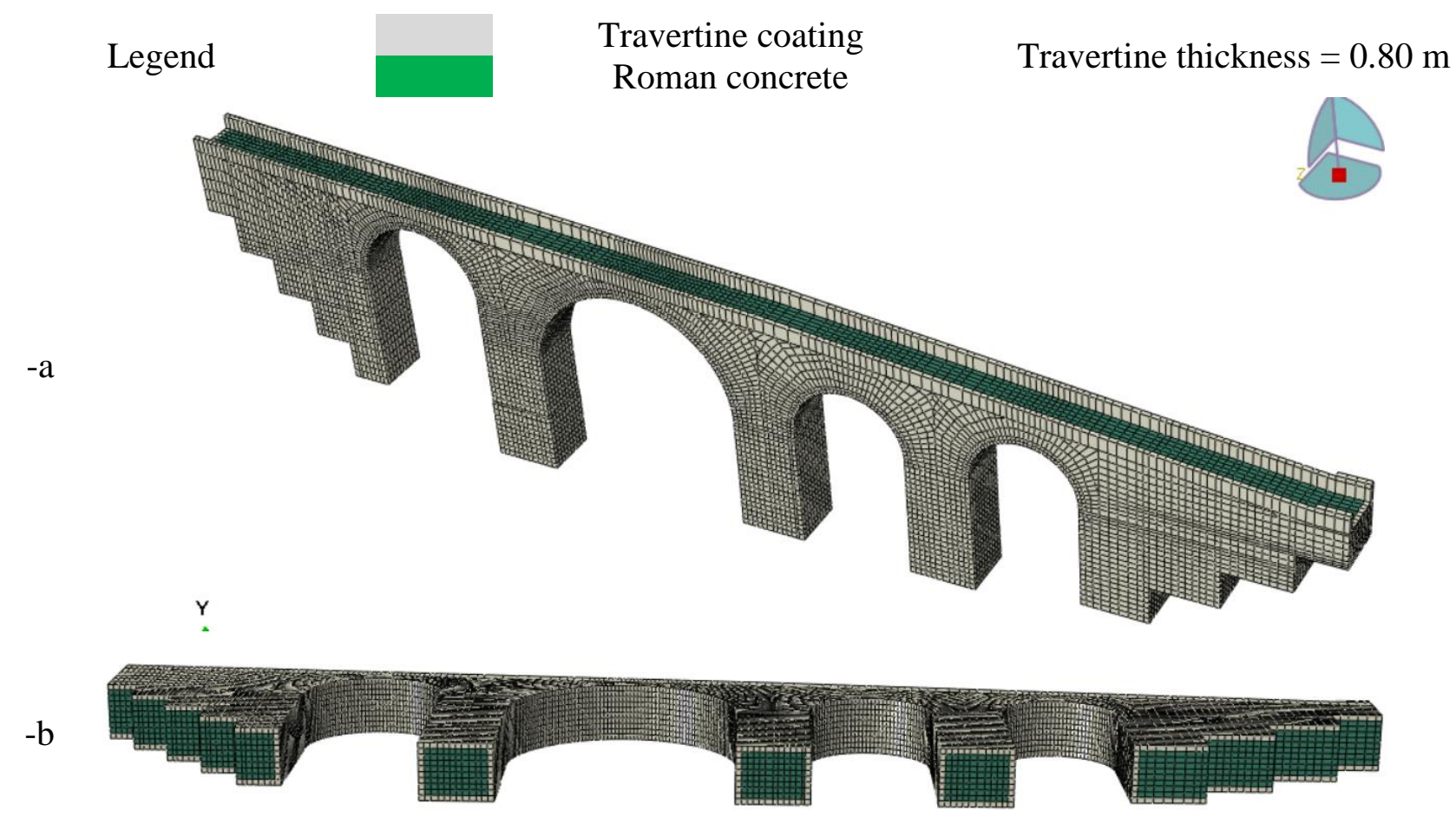

Figure 12: Geometric model of the entire Ponte di Augusto. -a: perspective view. -b: bottom view.

\section{2 - Material models}

Material models adopted for the different numerical analyses performed range from linear elastic (for the dynamic identification) to an isotropic damage-plasticity approach (for the non linear dynamic analyses and pushover), the latter quite suitable to properly simulate Roman Concrete where plasticity and damage with softening can occur in both tension and compression.

When dealing with elastic analyses, values adopted are in agreement with those used by Cecchi (2003) and are summarized in Table 2.

Table 2 - Mechanical properties of the materials used in the numerical model, according to Cecchi (2003)

\begin{tabular}{|c|c|}
\hline \multicolumn{2}{|c|}{ Travertine } \\
\hline Young Modulus [MPa] & 10000 \\
Poisson Modulus & 0.1 \\
Specific weight $\left[\mathrm{kg} / \mathrm{m}^{3}\right]$ & 2200 \\
\hline \multicolumn{2}{|c|}{ Roman concrete } \\
\hline Young Modulus [MPa] & 10000 \\
Poisson Modulus & 0.1 \\
Specific weight $\left[\mathrm{kg} / \mathrm{m}^{3}\right]$ & 2250 \\
\hline
\end{tabular}

The damage plasticity approach is available in the commercial FE code Abaqus and is also known as CDP (Concrete Damage Plasticity) model. It is based on the assumption of distinct scalar damage parameters for tension and compression and is particularly suited for applications in which the 
material exhibits damage, and therefore also for dynamic analyses. A different inelastic behavior in tension and in compression can be introduced, as shown in Figure 13.
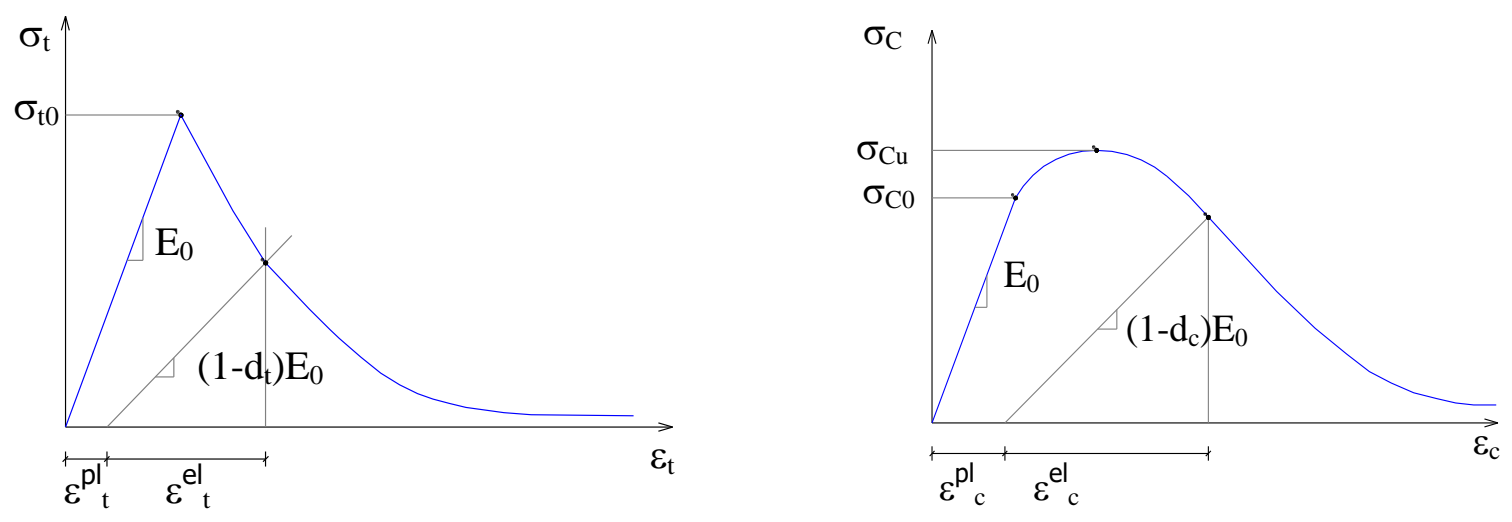

Figure 13: Tension (left) and compression (right) behavior in CPD model.

The damage variables in tension (index " $\mathrm{t}$ ") and compression (index "c") are defined by means of the following standard relations:

$$
\begin{aligned}
& \sigma_{\mathrm{t}}=\left(1-d_{\mathrm{t}}\right) E_{0}\left(\varepsilon_{\mathrm{t}}-\varepsilon_{\mathrm{t}}{ }^{\mathrm{ple}}\right) \\
& \sigma_{\mathrm{c}}=\left(1-d_{\mathrm{c}}\right) E_{0}\left(\varepsilon_{\mathrm{c}}-\varepsilon_{\mathrm{c}}{ }^{\mathrm{ple}}\right)
\end{aligned}
$$

Where the symbols have the following meaning:

- $\quad \sigma_{\mathrm{t}}$ and $\sigma_{\mathrm{c}}$ are uniaxial stresses in tension and compression, respectively;

- $\quad E_{0}$ is the virgin elastic modulus;

- $\quad \varepsilon_{\mathrm{t}}$ and $\varepsilon_{\mathrm{c}}$ are uniaxial total strains;

- $\quad \varepsilon_{\mathrm{t}}{ }^{\text {ple }}$ and $\varepsilon_{\mathrm{c}}{ }^{\text {ple }}$ are equivalent plastic strains;

- $\quad d_{\mathrm{t}}$ and $d_{\mathrm{c}}$ are damage parameters. 

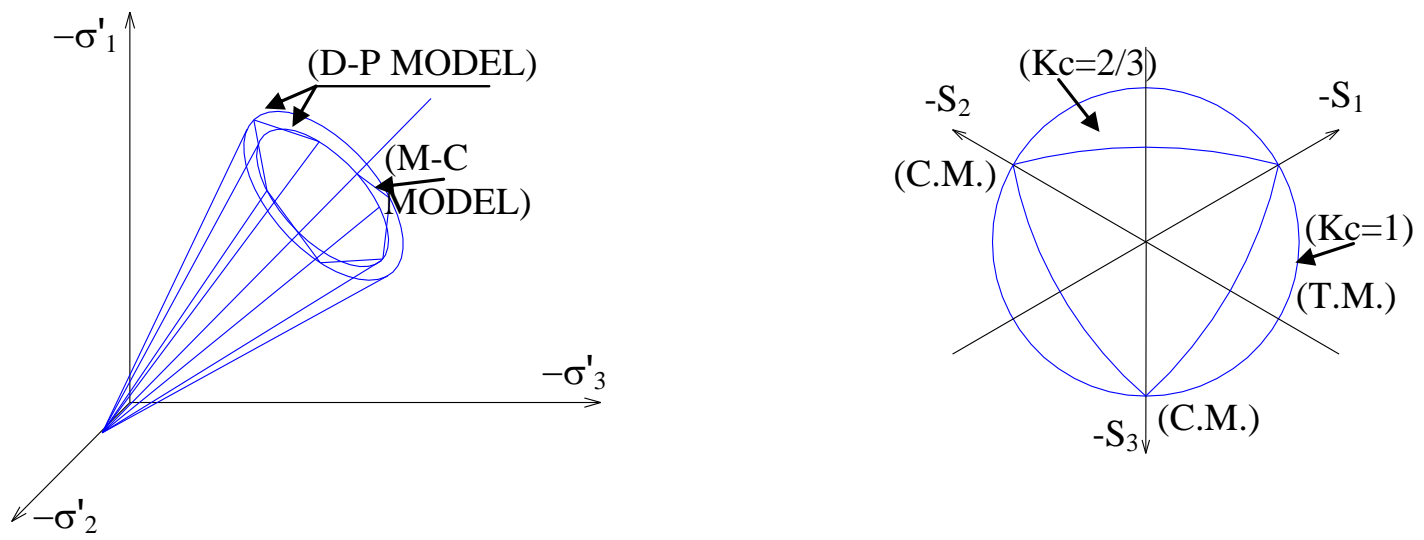

Figure 14: Drucker-Prager failure surface and effect of the application of the Kc parameter in the CDP model

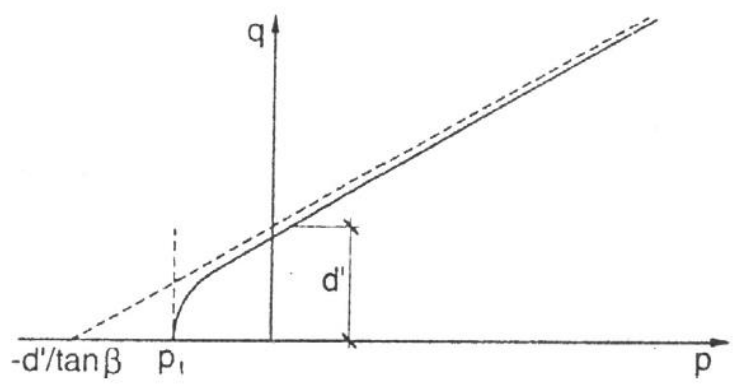

Figure 15: Vertex regularization of the Drucker-Prager failure criterion - eccentricity $=0.1$

As far as the three-dimensional behavior is concerned, CDP embeds a modification of the DruckerPrager failure criterion, see Figure 14. According to this modification, the failure surface in the deviatoric plane is not circular, but it is governed by a parameter $K_{c}$ that, if set equal to $2 / 3$ makes the strength domain closely approximates in a smooth fashion a Mohr-Coulomb failure criterion. CDP also takes into account the ratio between the ultimate compressive strength in a biaxial stress state and the one in uniaxial conditions. This ratio, which typically takes similar values for concrete, is reasonably set equal to 1.16 in the simulations.

Is then necessary the determination of the post-peak constitutive law of the material in the plastic range. For both compression and tension the post-peak behavior follows a softening rule, whose decaying is faster for tension than compression.

A value of $36^{\circ}$ is adopted for the dilatation angle, which seems reasonable for concrete material. This value is in agreement with the common practice which consider values between $36^{\circ}$ and $40^{\circ}$. To avoid numerical convergence issues, a vertex regularization is performed: the tip of the conical Drucker-Prager strength domain is smoothed using a hyperbola (Figure 15). The software ABAQUS allows smoothing the strength domain by means of an eccentricity parameter, which in the $p-q$ plane represents the distance between the points of intersection with the $p$-axis of the cone and the hyperbola, where $p$ represents the pressure component of the stress matrix while $q$ represents its deviatoric component. A value of 0.1 is adopted in the model for the parameter e (eccentricity).

A summary of the most important parameters utilized in the analyses is summarized in Table3. 
Modifications highlighted in color YELLOW

Table3 - CDP parameters

\begin{tabular}{|c|c|c|c|}
\hline Symbol & Name & Description & Value \\
\hline$\psi$ & Dilatance angle & $\begin{array}{r}\text { Angle due to a variation in volume of the material following } \\
\text { the application of a shear force }\end{array}$ & $36^{\circ}$ \\
\hline $\mathrm{e}$ & Eccentricity & $\begin{array}{c}\text { Distance between the points of intersection with the } p \text {-axis of } \\
\text { the cone and the hyperbola (in the } p \text { - } q \text { plane) }\end{array}$ & 0.1 \\
\hline $\mathrm{f}_{\mathrm{b} 0} / \mathrm{f}_{\mathrm{c} 0}$ & Strength ratio & Ratio between the biaxial and uniaxial compression strength & 1.16 \\
\hline $\mathrm{K}_{\mathrm{c}}$ & - & $\begin{array}{c}\text { Ratio between distance from the hydrostatic axis of the } \\
\text { maximum compression and traction respectively }\end{array}$ & 0.667 \\
\hline
\end{tabular}


Tension
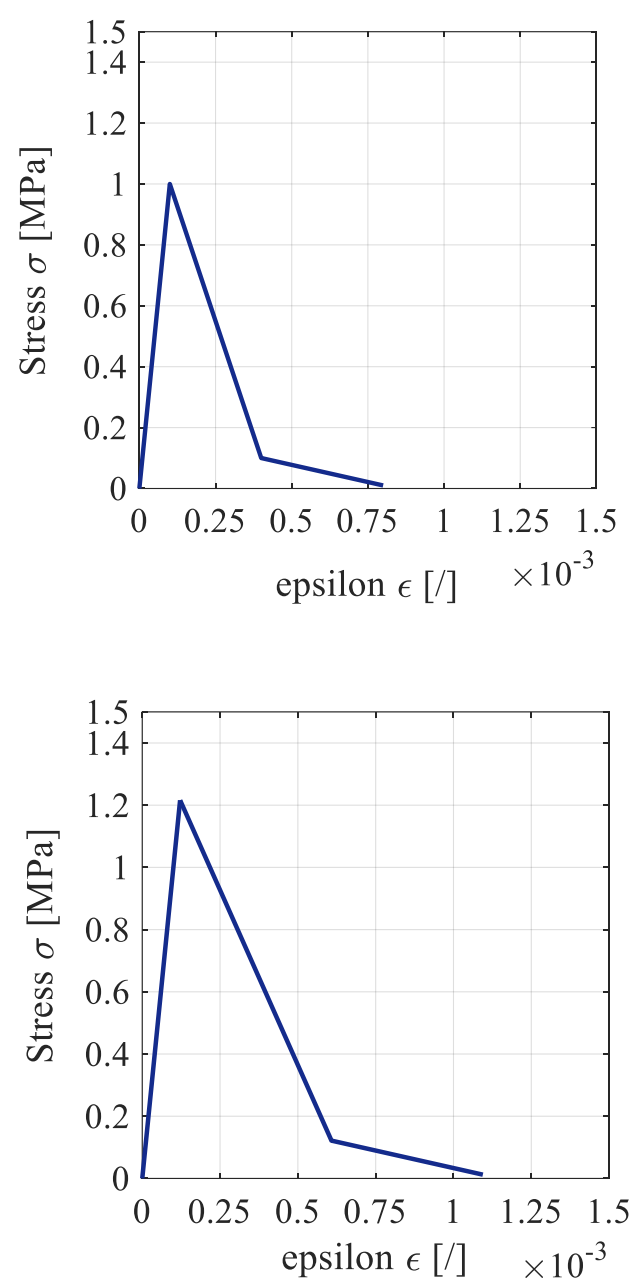

Compression

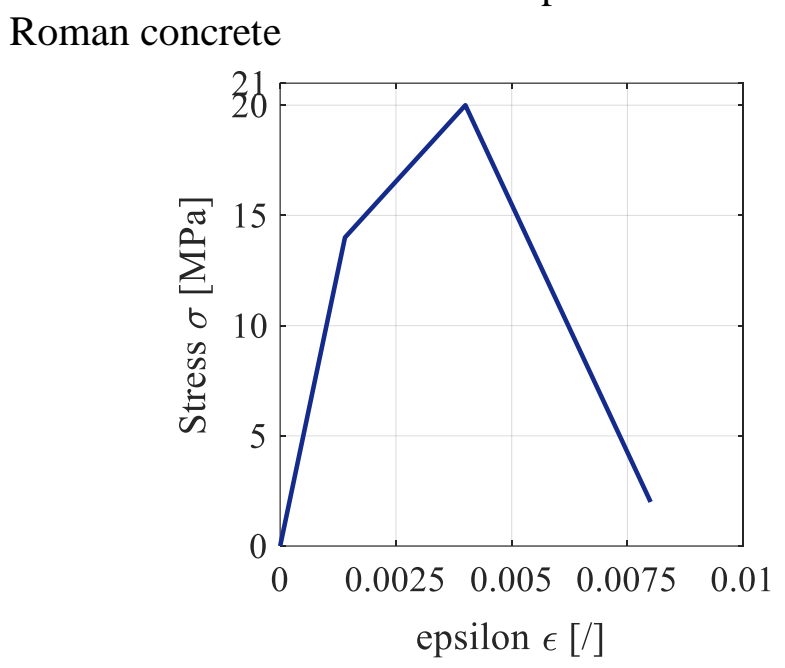

Travertine

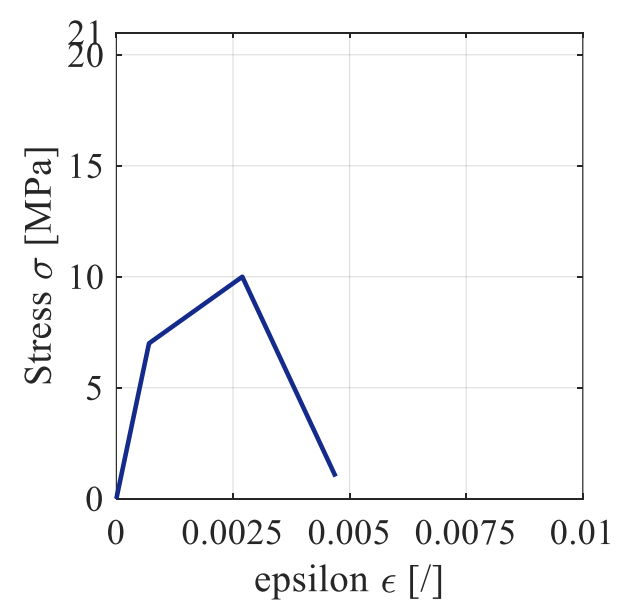

Figure 16: Uniaxial stress-strain behavior adopted for Roman Concrete and travertine.

It is also necessary to define a damage variable which was set equal to 0 for null deformations and equal to 0.95 for a deformation of $5 \%$. According to the previous considerations, deformation reaches a critical threshold, where the value of the elastic modulus $E$ of the material is cut down of $95 \%$.

\section{6 - Numerical analysis}

In this section, the results of the different numerical simulations carried out are reported and discussed in detail. Preliminary elastic modal analyses are carried out to calibrate the numerical model with reference to the dynamic tests presented in the previous Section. Then, either an elastic perfectly plastic obeying a cohesive-frictional failure load or a damage plasticity nonlinear model exhibiting softening and limited tensile and compressive strength are adopted for masonry and concrete filling, in order to perform non-linear static (pushover) and non-linear dynamic analyses, respectively. 


\section{1 - Modal analysis and calibration of the numeric model}

Particular attention was paid during the phase of calibration, as underlined in Sevim et al. (2011). FE simulations performed during the dynamic identification are carried out with the commercial code STRAUS7 (2004). A sensitivity analysis is performed varying the elastic modulus of the two materials (Roman concrete and travertine) of a quantity of $\pm 10 \%$ of the value of Table 2 .

In Table 4 the frequencies of the numerical model according to the different sets of parameters and the natural frequencies of the dynamic test are shown.

Table 4 - Frequencies for the set of mechanical parameters

\begin{tabular}{|c|c|c|c|c|}
\hline $\begin{array}{c}\text { Elastic modulus of } \\
\text { Roman concrete } \\
{[\mathrm{MPa}]}\end{array}$ & $\begin{array}{c}\text { Elastic modulus } \\
\text { of Travertine } \\
{[\mathrm{MPa}]}\end{array}$ & $\begin{array}{c}\text { Frequency } \\
\text { longitudinal } \\
\text { direction (X axis) } \\
{[\mathrm{Hz}]}\end{array}$ & $\begin{array}{c}\text { Frequency } \\
\text { transversal } \\
\text { direction (Y axis) } \\
{[\mathrm{Hz}]}\end{array}$ & $\begin{array}{c}\text { Frequency } \\
\text { vertical direction } \\
\text { (Z axis) }[\mathrm{Hz}]\end{array}$ \\
\hline 10000 & 9000 & 3.7 & 2.4 & 12.8 \\
\hline 10000 & 10000 & 3.7 & 2.5 & 13.1 \\
\hline 10000 & 11000 & 3.9 & 2.6 & 13.3 \\
\hline 9000 & 9000 & 3.6 & 2.4 & 12.4 \\
\hline 9000 & 10000 & 3.7 & 2.4 & 12.7 \\
\hline 9000 & 11000 & 3.7 & 2.5 & 12.9 \\
\hline 11000 & 9000 & 3.7 & 2.5 & 13.2 \\
\hline 11000 & 10000 & 3.9 & 2.6 & 13.5 \\
\hline 11000 & 11000 & 3.9 & 2.6 & 13.7 \\
\hline \multicolumn{2}{|l|}{ Experimental (dynamic test) } & 3.6 & 2.3 & 11.1 \\
\hline
\end{tabular}

The values shown in Table 4 allow to establish that the choice of the parameters of Table 2 corresponds with a good approximation to the experimental reality of the dynamic test.

The good accordance between the experimental dynamic behavior and the numeric dynamic behavior, obtained with a model that employs the mechanical properties of the materials reported in Cecchi (2003), confirms that the Roman concrete filling has properties close to the ones deduced from the tests on the materials. It also allow to believe that considering the travertine integral with the internal concrete (without relative sliding), corresponds to a correct modeling hypothesis and therefore it constitutes a validation of the numerical model. Such hypothesis, moreover, is quite consistent with Roman construction techniques, which, as is in the case of the Ponte di Augusto, provided the anchoring of the blocks of travertine between themselves and with the concrete filling using metal stirrups (Cecchi 2003).

\section{2 - Pushover analysis and N2 method}

A pushover analysis, see also Acito et al. (2013), is a nonlinear static analysis that allows evaluating in a conventional way the response of a structure during a seismic event, assuming non-linear mechanical properties for the constituent materials, eventually with softening. Such simplified procedure consists in the application of the loads on the structure as nodal forces, which are incremented at each step of calculation up to the activation of a failure mechanism. In case of global softening, an arc-length procedure is adopted, thus allowing following up the behavior of the 
structure in the softening branch. In general, the analysis stops once a value of maximum shear at the base of the structure or a value of maximum displacement of the control point is reached.

The control point (Figure 17) is the point on which the "displacement" is read during the execution of the analysis and it is chosen in order to be representative of the overall behavior of the entire structure. The result of the pushover analysis consists of a graph with the displacement of the control point on the $\mathrm{x}$-axis and the shear at the base of the structure on the y-axis.

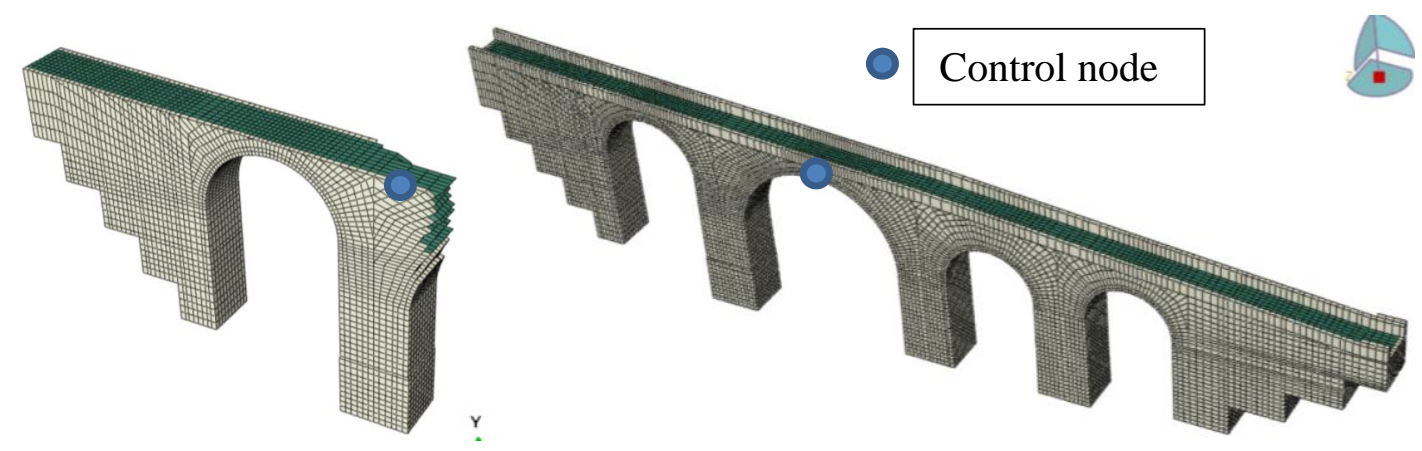

Figure 17: Control points of the still standing part (left) and the whole bridge (right)

According to the Italian code (NTC 2008, Circolare 2009, Circolare 2010), two different load conditions must be considered in the pushover analysis: G1 distribution, proportional to the mass and to the height of each node of the structure, and G2 distribution, proportional only to the mass.

The curve extrapolated from the numeric analysis is representative of a sort of global constitutive law of the structure. According to Circolare (2009) a 1 degree of freedom system equivalent to the real one is needed, so a change from a MDOF (Multi Degree Of Freedom) system to a bilinear SDOF (Single Degree Of Freedom) system is performed.

The aim of this kind of analysis is to verify if the capacity of the structure (in terms of displacement) is sufficient with respect to the demand (in terms of spectral action).

The curve resulting from the pushover analysis is then scaled by means of the modal participation factor $\Gamma=\frac{\varphi^{\mathrm{T}} \cdot \mathrm{M} \cdot \tau}{\varphi^{\mathrm{T}} \cdot \mathrm{M} \cdot \varphi}$, where the vector $\tau$ is the dragging vector corresponding to the direction of the earthquake considered, the vector $\varphi$ is the fundamental mode of vibration of the real system normalized and the matrix $\mathrm{M}$ is the mass matrix of the real system. Assuming then $\mathrm{F}^{*}$ bu the actual base shear of the structure, the scaled value is $\mathrm{F}^{*}=\frac{\mathrm{F}_{\mathrm{bu}}^{*}}{\Gamma}$.

According to the Italian code, the bilinear curve is obtained imposing two conditions:

- The elastic part of the bilinear curve must pass for the point corresponding to $0,6 \mathrm{~F}^{*}{ }_{\mathrm{bu}}$ of the SDOF capacity curve.

- The total area under the bilinear curve must be equal to the area of the SDOF capacity curve. It is also necessary to define the mass $\mathrm{m}^{*}$ of the equivalent system and the natural period of oscillation $\mathrm{T}^{*}$ as: $\mathrm{m}^{*}=\sum_{i} \mathrm{~m}_{\mathrm{i}} \varphi_{\mathrm{i}}$, where $\mathrm{T}^{*}=2 \pi \sqrt{\frac{\mathrm{m}^{*}}{\mathrm{k}^{*}}}$, where $\mathrm{k}^{*}$ is the stiffness of the equivalent system (slope of the elastic section of the bilinear curve). 
The ductility of the bilinear curve $\mu$ is defined as the ratio between the ultimate displacement and the yield displacement. Once known the natural period of oscillation, the Italian code allows to estimate the displacement demand $\mathrm{d}^{*}$ t using the elastic displacement spectrum of the Narni site (lifesafety limit state: SLV, reference period: $V_{R}=100$ years), obtained from the spreadsheet of the Italian CSLLPP (High Council of Public Works) based on the Italian Code (Circolare 2009, Circolare 2010).

\section{3 - Results of the pushover analysis on the still standing part}

Pushover curves obtained in case of the still standing part and the whole bridge (G1 distribution), along with the corresponding deformed shapes (where tensile damage patch is superimposed to make the failure mechanism active clear) are depicted in Figure 18 and Figure 19, assuming respectively for Roman concrete a strength defined by parameters $\mathrm{f}_{\mathrm{t}}=1.0 \mathrm{MPa}$ and $\mathrm{f}_{\mathrm{c}}=20 \mathrm{MPa}$ and $\mathrm{c}=0.14 \mathrm{MPa}$ and $\varphi=36^{\circ}$. Obviously, mechanical properties assumed for travertine are scaled accordingly, so that $\mathrm{f}_{t}=1.216 \mathrm{MPa}$ and $\mathrm{f}_{\mathrm{c}}=10 \mathrm{MPa}$ in the first case and $\mathrm{c}=0.17 \mathrm{MPa}$ with $\varphi=36^{\circ}$ in the second.

As can be noted, the active failure mechanism for the still standing part is constituted by the formation of a horizontal cylindrical hinge at the base of the pier and a sliding hinge at the crown of the arch. The behavior is basically an overturning of the pier, because of the limited thickness of the arch at the crown and the relatively reduced cohesion of the Roman concrete.

The behavior of the whole bridge is slightly different, because there is a clear formation of an arch effect along the out-of-plane direction, favored by the continuity of the deck and the sufficient outof-plane thickness of the bridge. Again, the formation of cylindrical hinges at the base of the central piers is worth noting. Finally, it is worth mentioning that the qualitative behavior at failure of the entire bridge is very similar to that described by Pelà et al. (2009) for two masonry arch bridges in central Italy. A further remark should be done for the material: Roman concrete exhibits much less damage than the material that mimics a masonry infill, with mechanical properties assumed as per Italian code, meaning that -if Roman bridges were made only by masonry- they would be hardily able to pass the so called "history exam", the majority collapsing after a moderate single earthquake and in any case showing diffused damage even only after the application of the gravity loads.

Pushover curves so obtained are synoptically depicted in Figure 20. Such curves are obtained assuming a G1 distribution of the horizontal loads and both the cases of the still standing part and the entire bridge are depicted, assuming for the infill either a Roman concrete or masonry material. Results are represented in terms of normalized acceleration $\mathrm{ag} / \mathrm{g}$. It is interesting to notice that - as expected- the still standing part shows quite high normalized collapse accelerations, because of the fact that the structure is quite squat and monolithic. The entire bridge appears much more vulnerable under horizontal loads, even in presence of strong Roman concrete infill. This could partially justify that the collapse of the central part could be a consequence of a seismic event or repeated earthquakes. In case of infill with poor mechanical properties (similar to those used by the Italian code to represent a common masonry material), the ultimate acceleration of the bridge is particularly low, with diffused damage observed even after the application of the self weight only. 


\begin{tabular}{|l|l|}
\hline Still standing part & Entire bridge \\
\hline \multicolumn{2}{|c|}{ Damage in tension, Roman concrete } \\
\hline
\end{tabular}
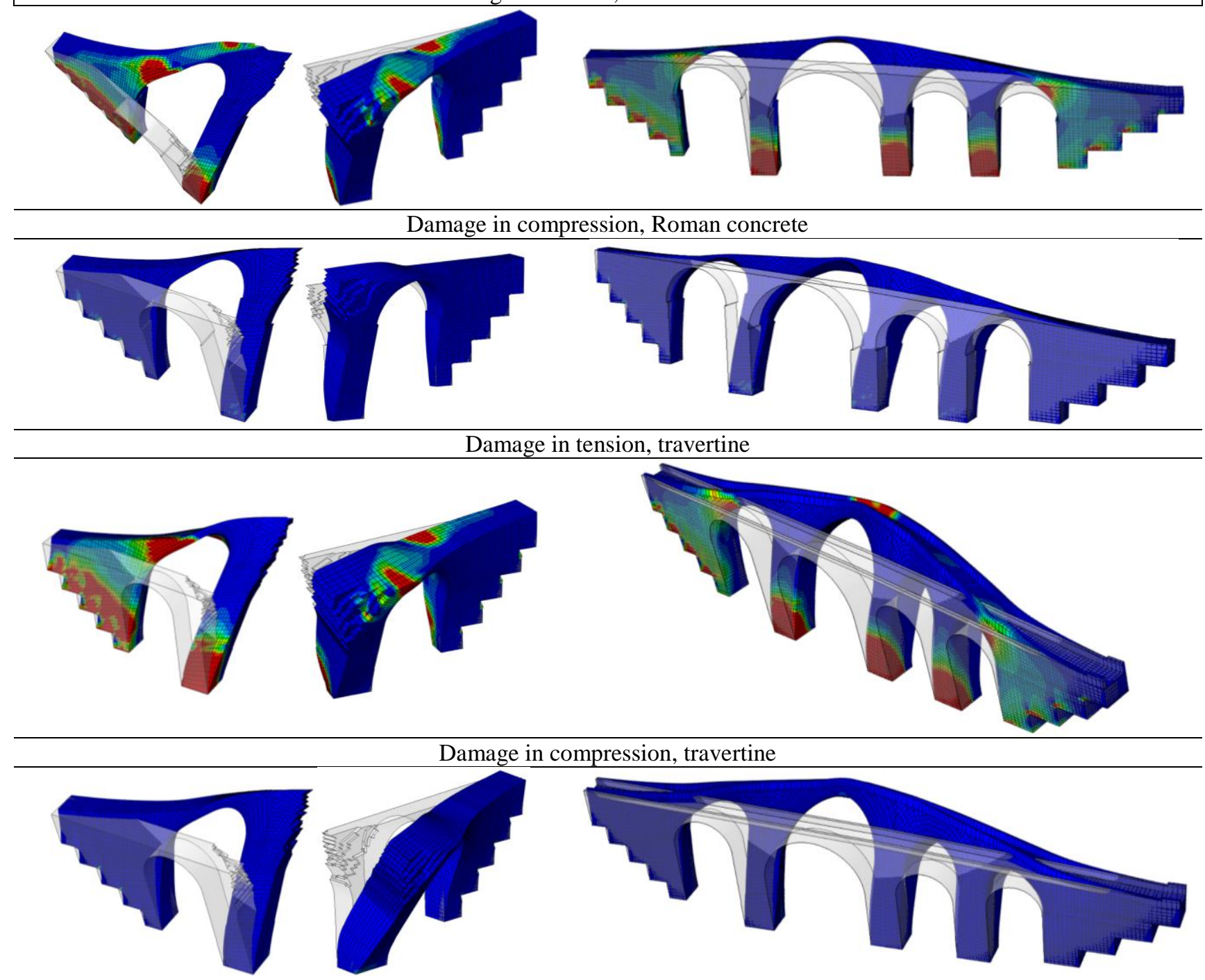

$-\mathrm{a}$

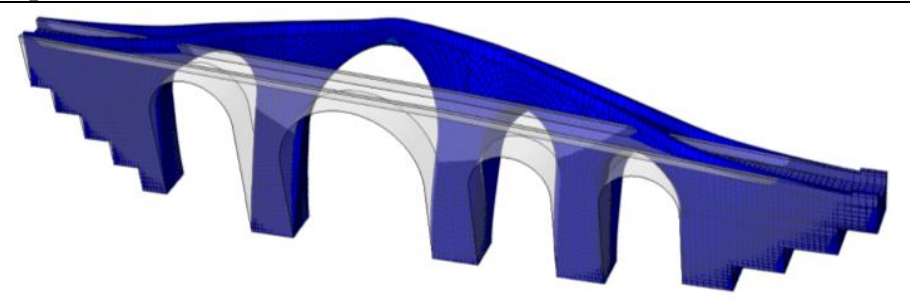

$-b$

Figure 18: Damage (in tension and compression) plus deformed shapes at collapse obtained for the still standing part (a) and the whole bridge (-b), G1 load distributions. Mechanical properties assumed for the travertine: $\mathrm{f}_{\mathrm{t}}=1.216 \mathrm{MPa}$ and $\mathrm{f}_{\mathrm{c}}=10 \mathrm{MPa}$ 


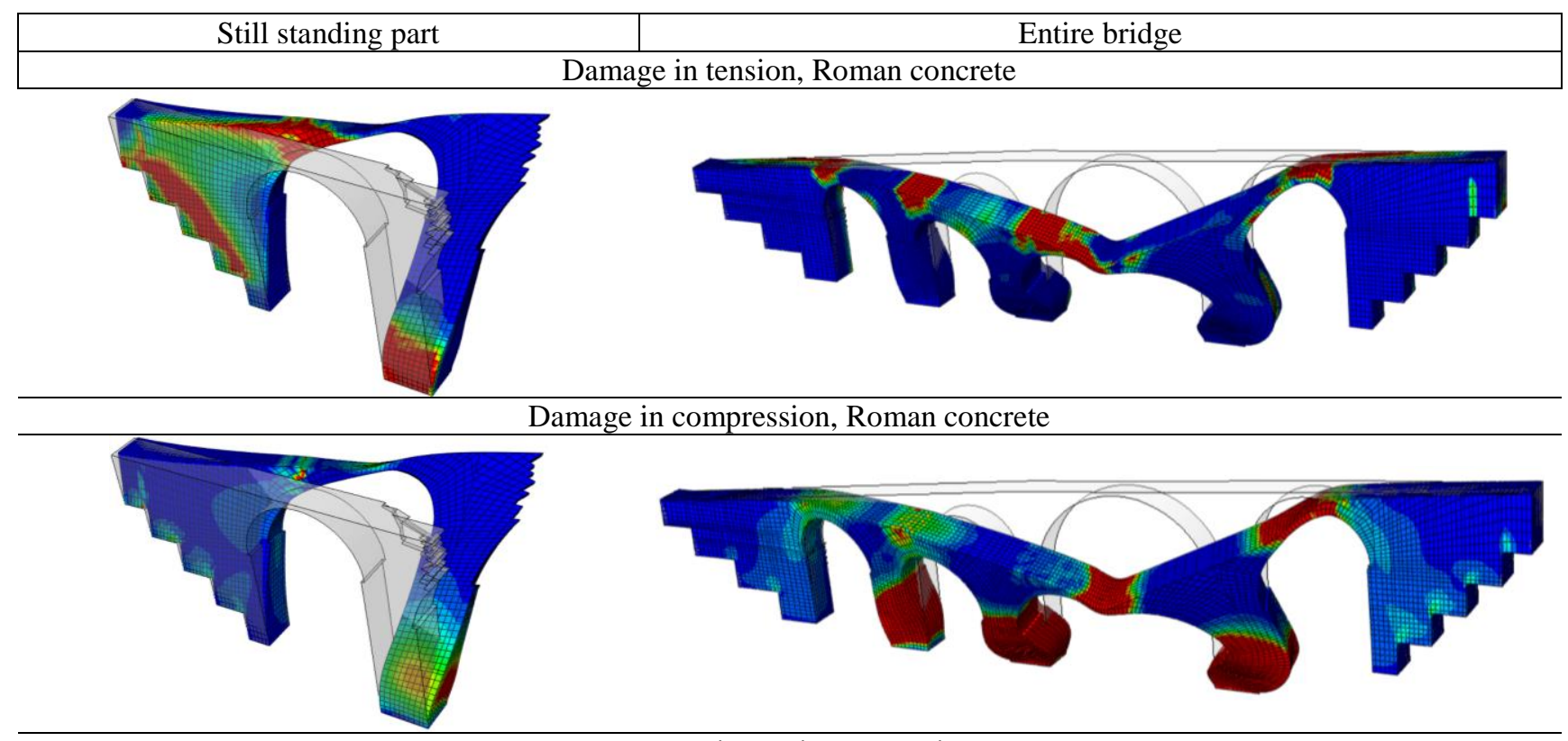

Damage in tension, travertine
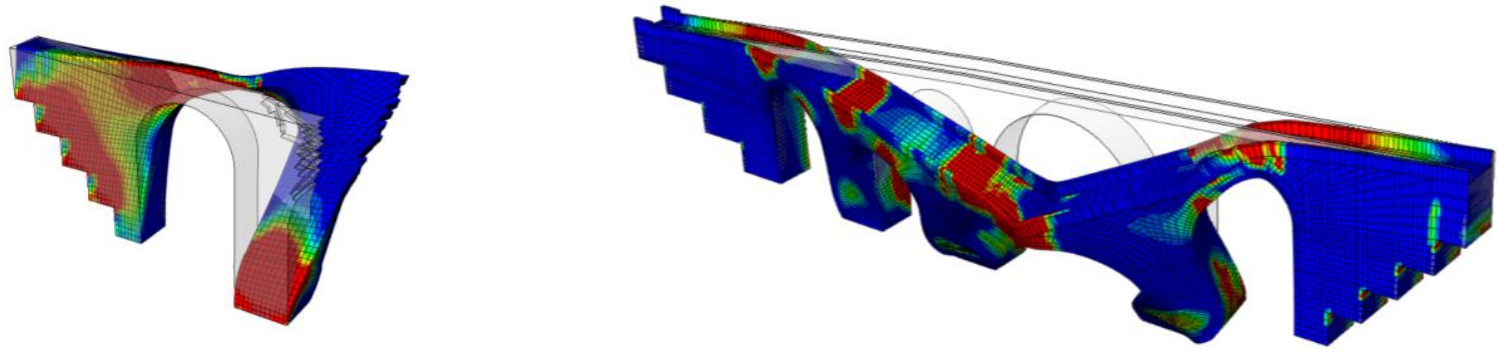

Damage in compression, travertine

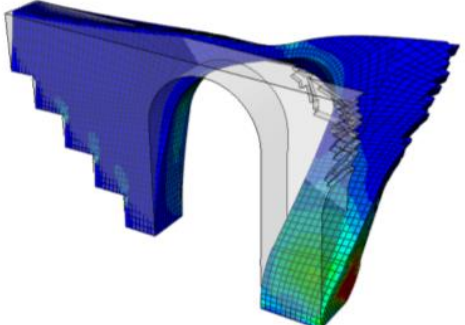

-a

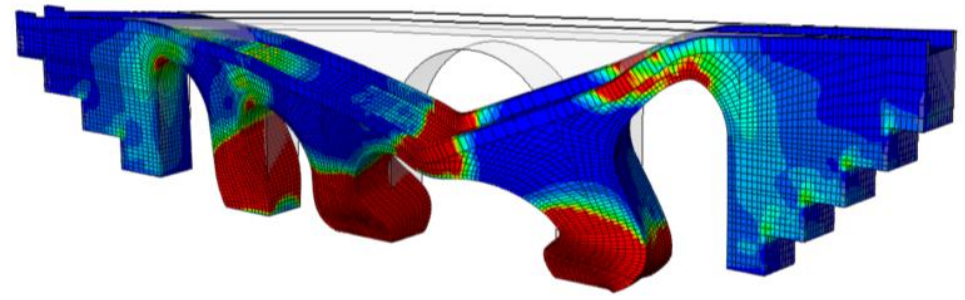

$-b$

Figure 19: Damage (in tension and compression) plus deformed shapes at collapse obtained for the still standing part (a) and the whole bridge (-b), G1 load distributions. Mechanical properties assumed for the travertine: $c=0.17 \mathrm{MPa}$ and $\varphi=36^{\circ}$. 


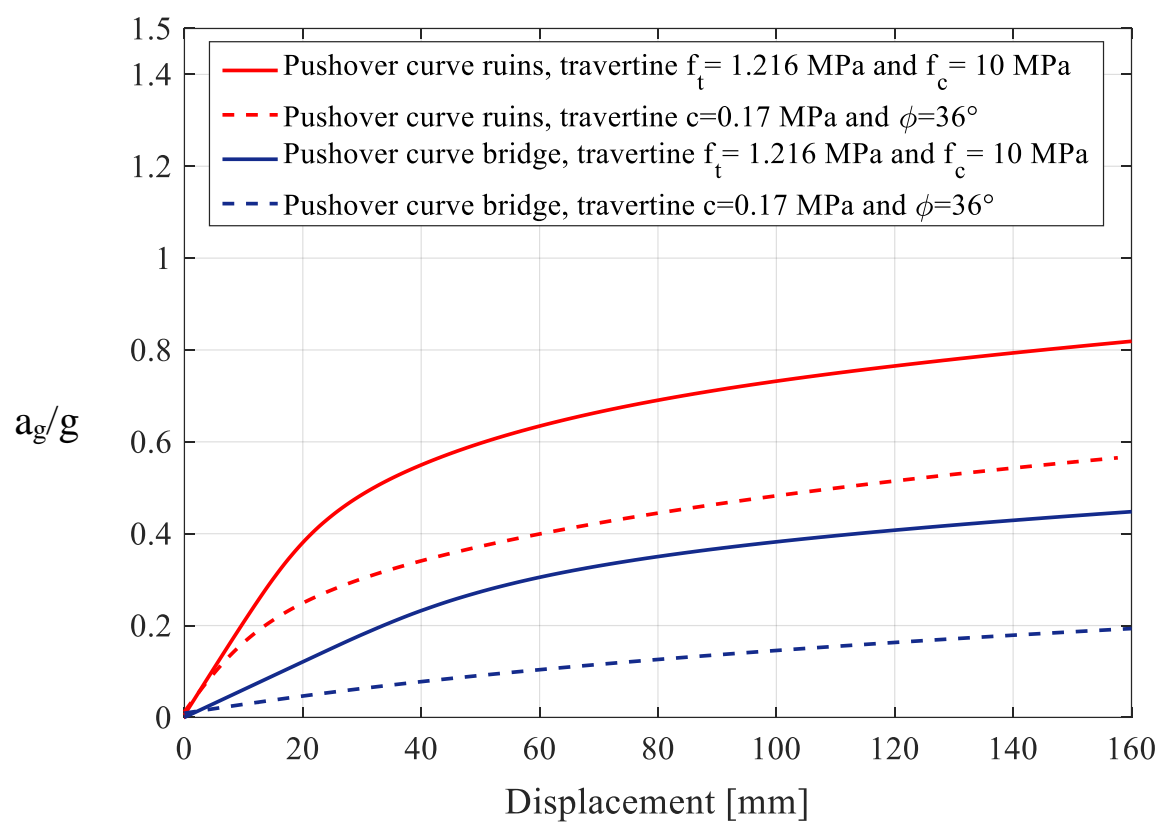

Figure 20: Pushover curves obtained assuming a G1 distribution of the horizontal loads, still standing part and entire bridge assuming for the infill either Roman concrete or masonry. Results are depicted in terms of normalized acceleration $\mathrm{ag} / \mathrm{g}$.

In Figure 21 the graphical representation of the N2 method check is reported. Only the case of the still standing part is shown, because N2 gives a quantitative indication of the seismic vulnerability, which is indeed required only for the present condition. Values from the Italian code are adopted, i.e. $c=0.17 \mathrm{MPa}$ and $\varphi=36^{\circ}$ for the travertine in order to be consistent with the approach proposed by the code for existing masonry structures. 
Combination G1_X

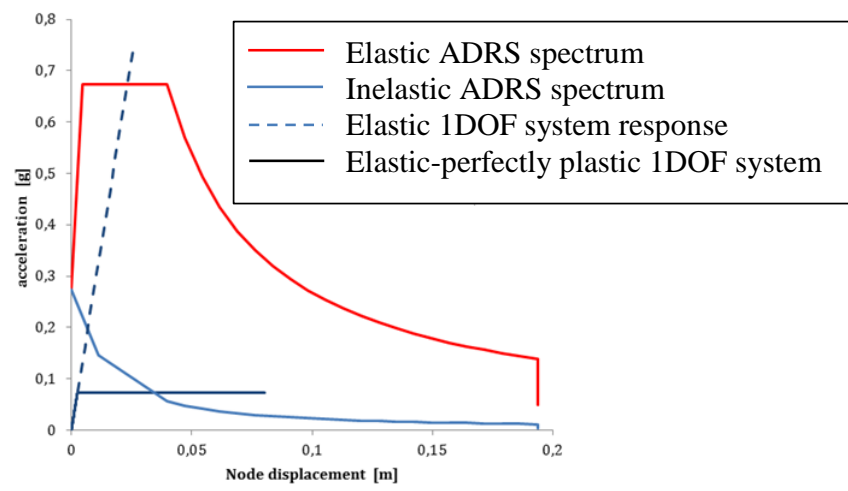

Combination G1_Y

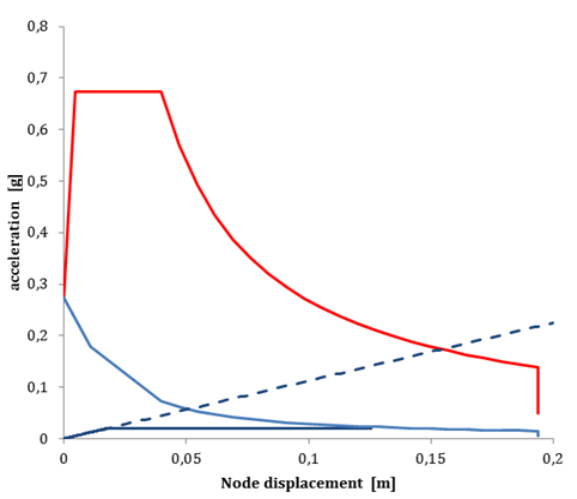

Combination G2_X

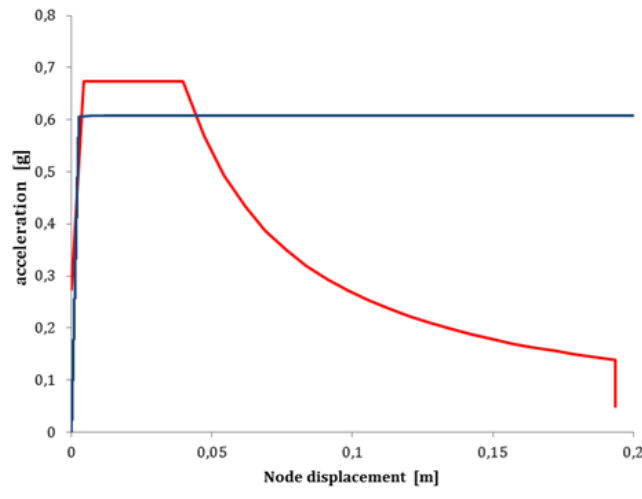

Combination G2_Y

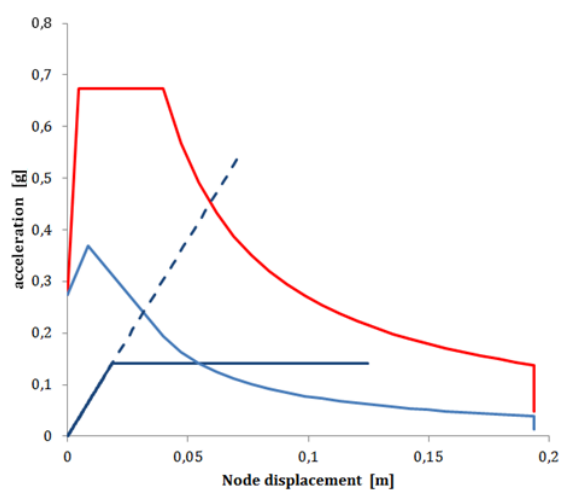

Combination G1_-X

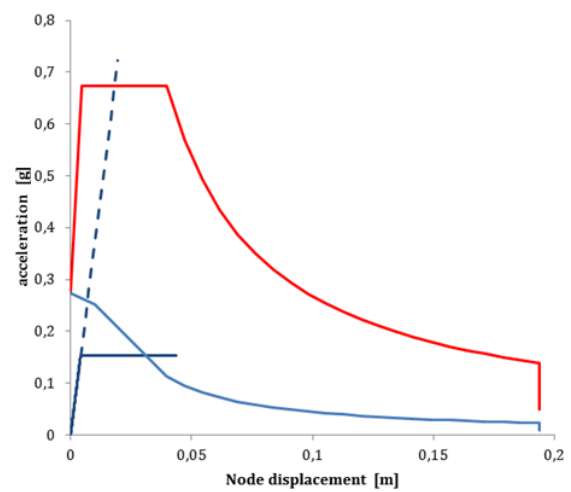

Combination G1_-Y

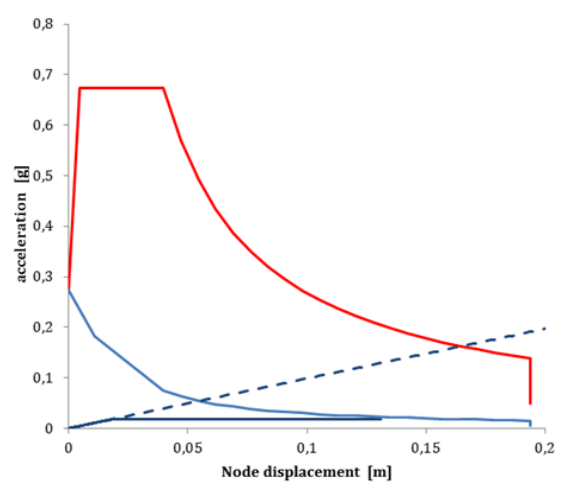

Combination $\mathrm{G} 2$ - $\mathrm{X}$

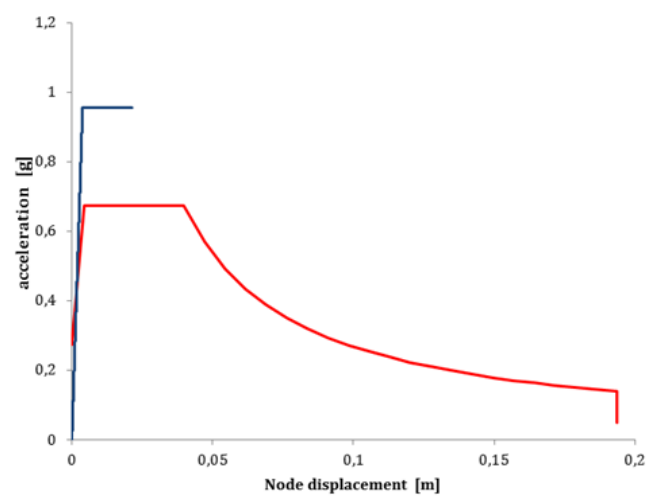

Combination G2_-Y

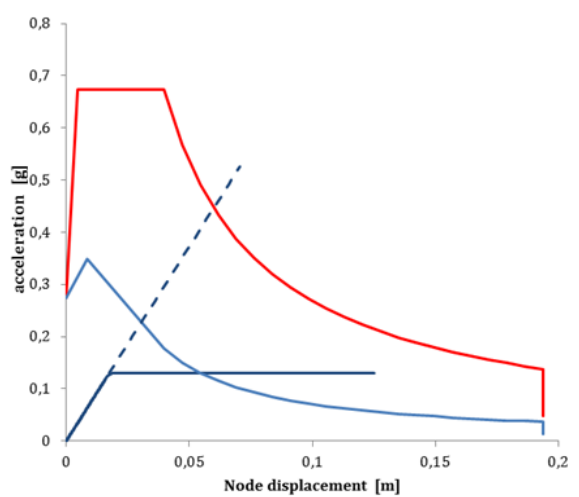

Figure 21: Graphic results of the pushover analyses on the still standing part of the Ponte di Augusto 
As it usually occurs, G1 distribution is always more critical than G2 distribution; as a matter of fact the safety assessment for G2 combination is always positive, as occurs in the X direction of G1 combination, while it is negative in $\mathrm{Y}$ direction (in accordance with the expectations and the physical reality).

The conclusions from the point of view of the vulnerability, as regards the analysis of pushover, consist in the fact that the bridge is verified for the load combination G2 and not for the combination G1. Table 5 summarizes the results of pushover analyses.

\begin{tabular}{|cc|cc|}
\multicolumn{4}{|c|}{ Table 5 - Summary of pushover analyses } \\
\begin{tabular}{|cc|cc|}
\hline Still standing part of the Ponte di Augusto \\
\hline G1_X & verified & G2_X & verified (elastic field) \\
G1_X & verified & G2_-X & verified (elastic field) \\
G1_-Y & Not verified & G2_Y & verified \\
\end{tabular}
\end{tabular}

The obtained results, within the applicability limits of the pushover procedure to the case of arch bridges, seem to confirm a certain seismic vulnerability of the existing residual part of the Ponte di Augusto and probably underlies the choice to reinforce the pier by inserting Titanium bars anchored in the rock below the pier (Salvatore et al. 2005).

\section{4 - Settlement of the central pillar}

In order to have an insight into the possible causes of the collapse of the central part (Pier II), two are the most popular hypotheses formulated, namely (i) a settlement of the central pillar (Pier II), maybe due to particular ground conditions caused by floods and (ii) effect of the seismic action.

In the present Section, the action of floods is investigated applying a differential settlement on the central pier, see Figure 22 and performing non-linear static analyses with the CDP model in ABAQUS.

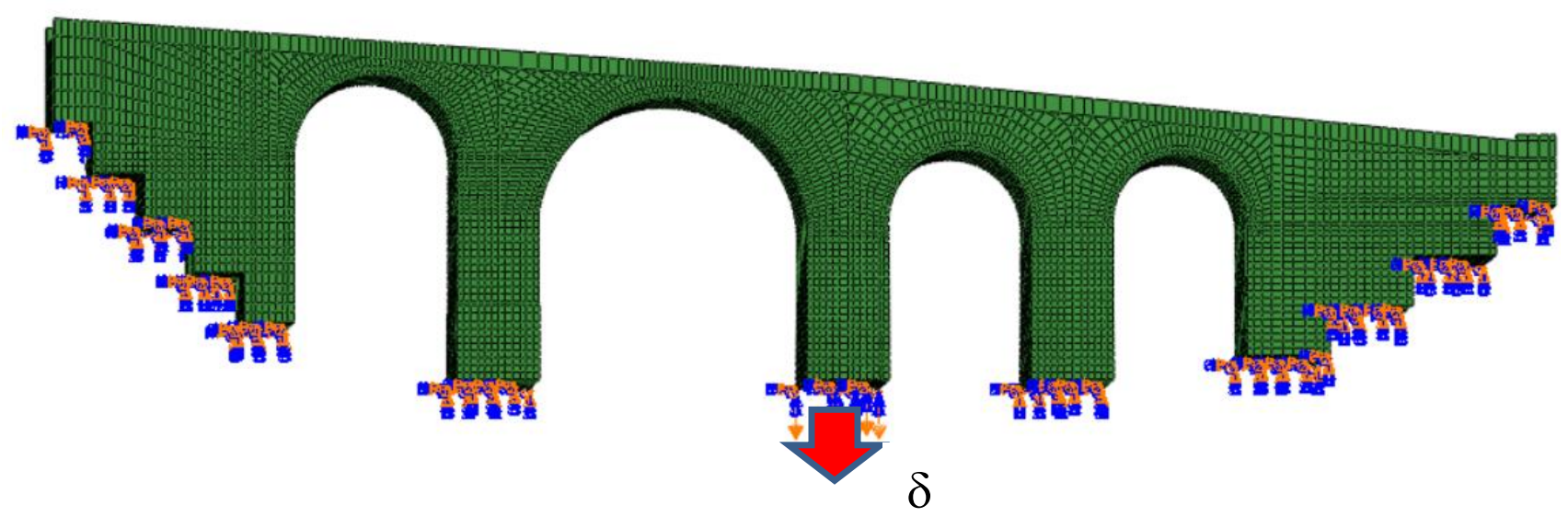

Figure 22: Analyses with imposed vertical displacement of the central pillar. 


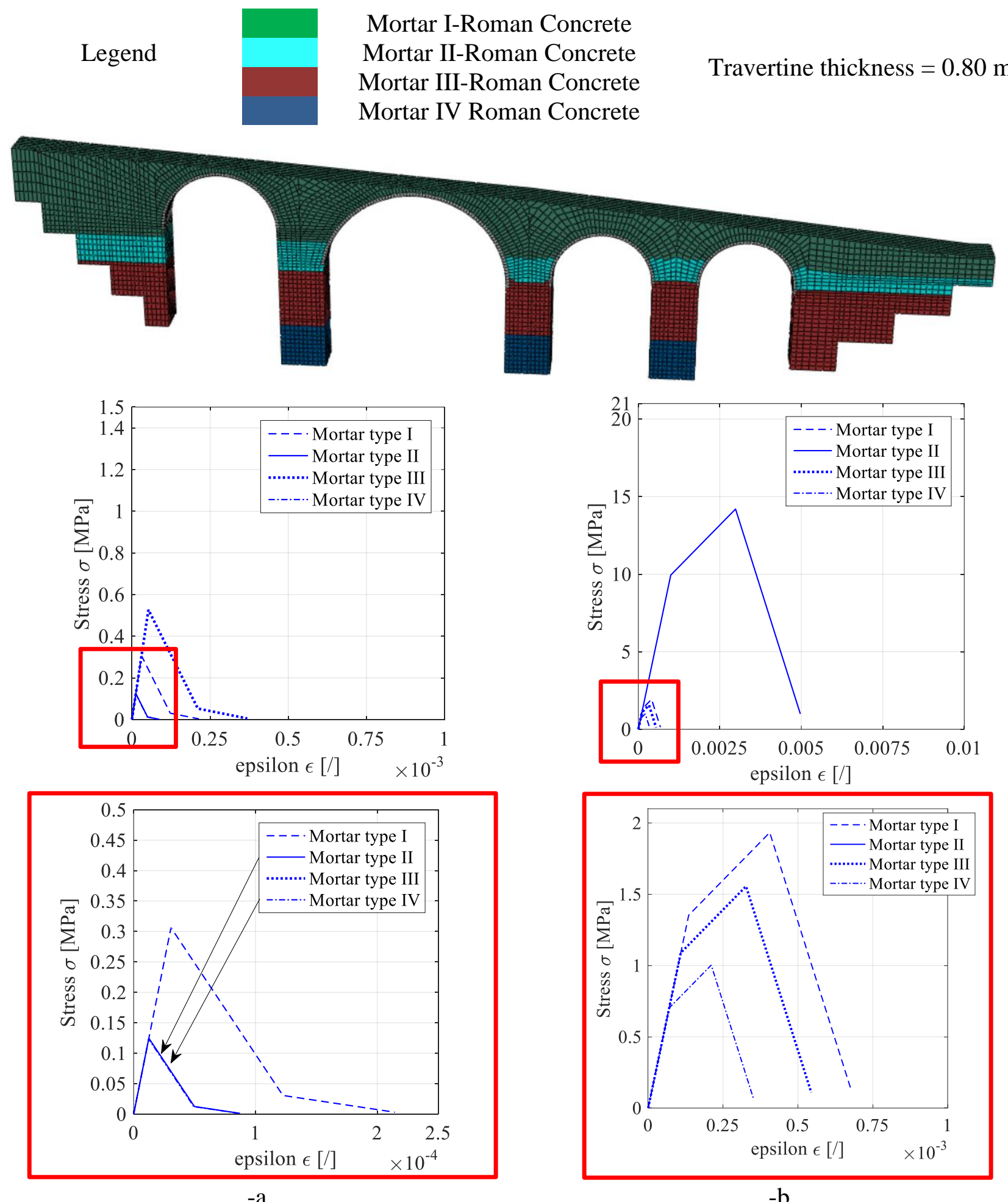

Figure 23: Mechanical properties adopted for Roman concrete in Model II. -a: tensile regime. -b: compression regime. 


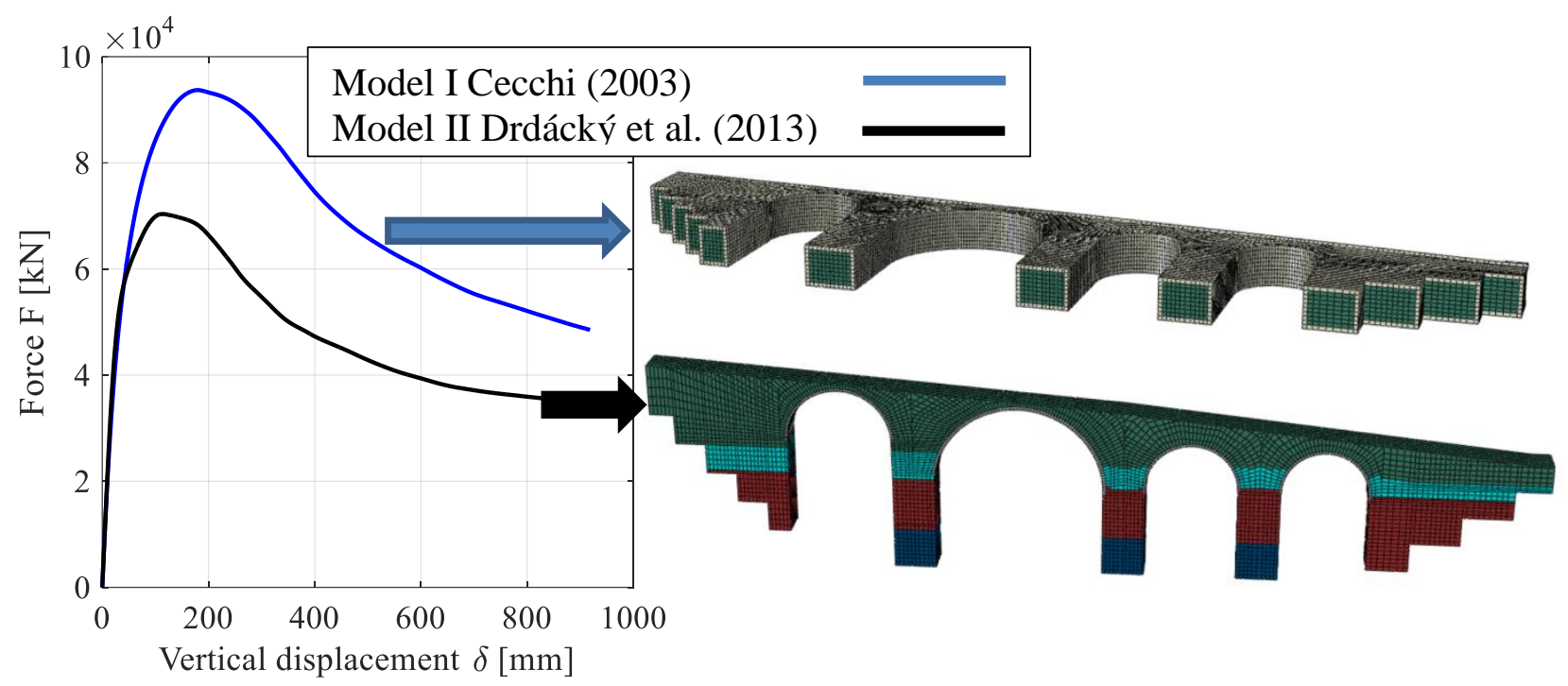

Figure 24: Force displacement curves obtained with the two different material models adopted.

Two different hypotheses on the mechanical properties of the Roman concrete are done, one assuming homogeneous properties for the material along the height of the pillars as in Figure 16, i.e. in agreement with Cecchi (2003), the other assuming the experimental values found by Drdácký et al. (2013) on specimens sampled by probing, extracted from the still standing Pier I and later tested in the lab. In particular, Drdácký et al. (2013) identify four different layers with fairly homogeneous mechanical properties as indicated in Figure 23, where uniaxial stress-strain relationships adopted in the corresponding ABAQUS model are depicted. As can be seen, mechanical properties of the different layers are quite different especially in compression. It is however worth noting that data found by Drdácký et al. (2013) maybe affected by a certain scatter because in some cases samples exhibited very reduced geometrical dimensions, meaning that maybe mortar strength was measured instead of the mixture of cement and aggregates, as it occurs in standard strength tests for common modern concrete. This is the reason why in Figure 23 different layers are labeled as "Mortar" from I to IV.

On the other hand, it is worth remembering that Model I mechanical properties are fully in agreement with indications given by Cecchi (2003).

After proper non-linear FE analyses performed in ABAQUS, the resultant force-displacement curves obtained with the two different material models adopted are depicted in Figure 24, whereas final damage maps in tension and compression for travertine and Roman concrete are shown in Figure 25 and Figure 26 respectively.

From an overall analysis of the aforementioned figures, the following remarks can be done:

1) In both cases, i.e. both for Model I and II, failure mechanisms found are fully compatible with the real shape of the still standing part, being failure due to the formation of plastic hinges at the crowns of the arches near the central pillar subjected to settlement;

2) The resultant peak load of Model I is about 1.35 times higher than that found for Model II. This is not surprising, because the mechanical properties adopted for Mortar I, where part of the damages in both tension and compression occurs, are lower than those adopted for Model I.

3) The utilization of different mechanical properties for the Roman concrete obviously does not affect the formed failure mechanism, which remains independent from material models but strictly related to the geometric features of the structure.

4) Mechanical properties of travertine, as experienced by authors re-running the analyses with different mechanical properties for the coating material, have little effect on the structural 
behavior of the bridge, also thanks to the limited thickness when compared with the Roman concrete.

All things considered, it appears therefore suitable for the non-linear dynamic simulations, to adopt homogeneous mechanical properties for the Roman concrete, as in Cecchi (2003), and to give to travertine a suitable tensile strength (not excessively low), being the role played by coating almost negligible and so increasing at the same time numerical stability and efficiency. 
Modifications highlighted in color YELLOW

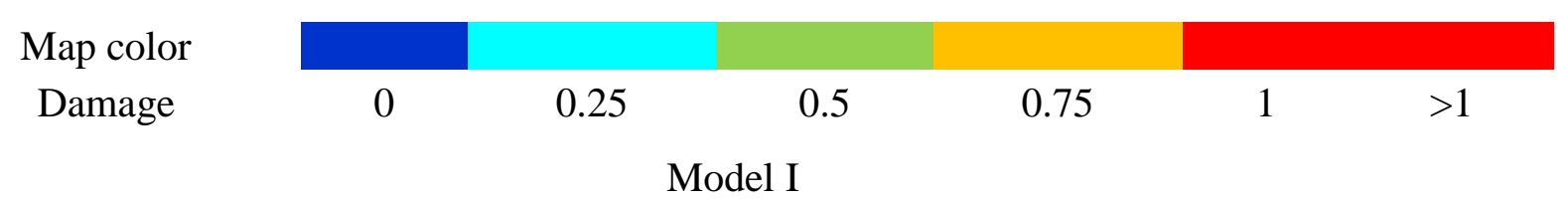

$-a$

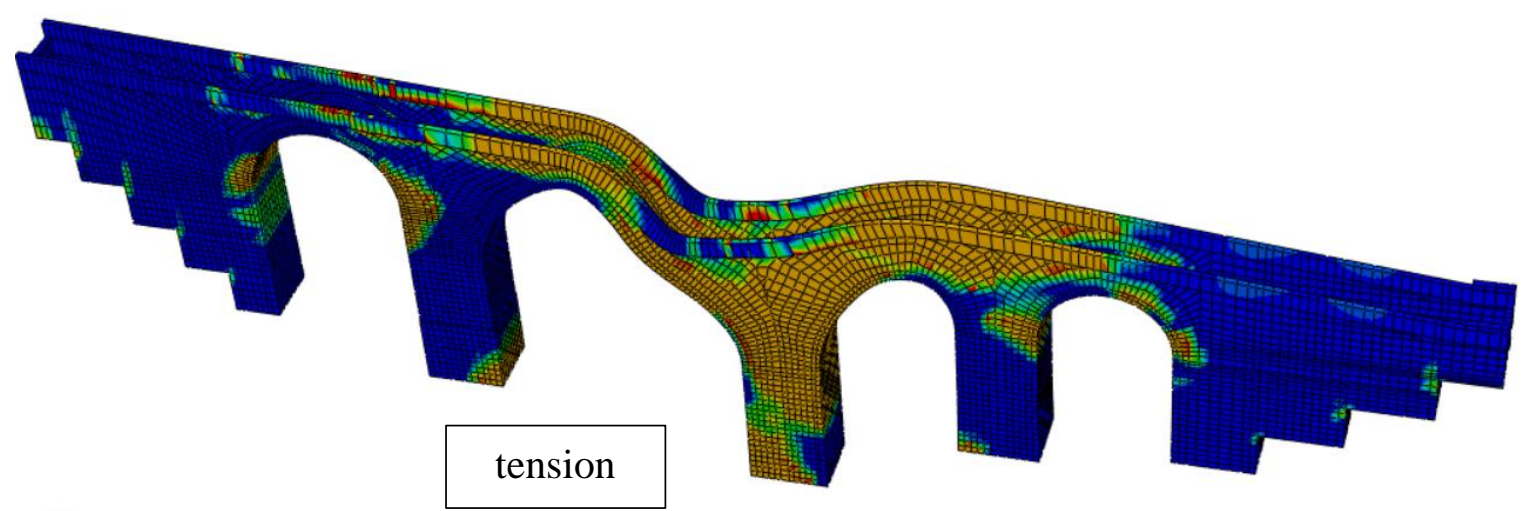

$-b$

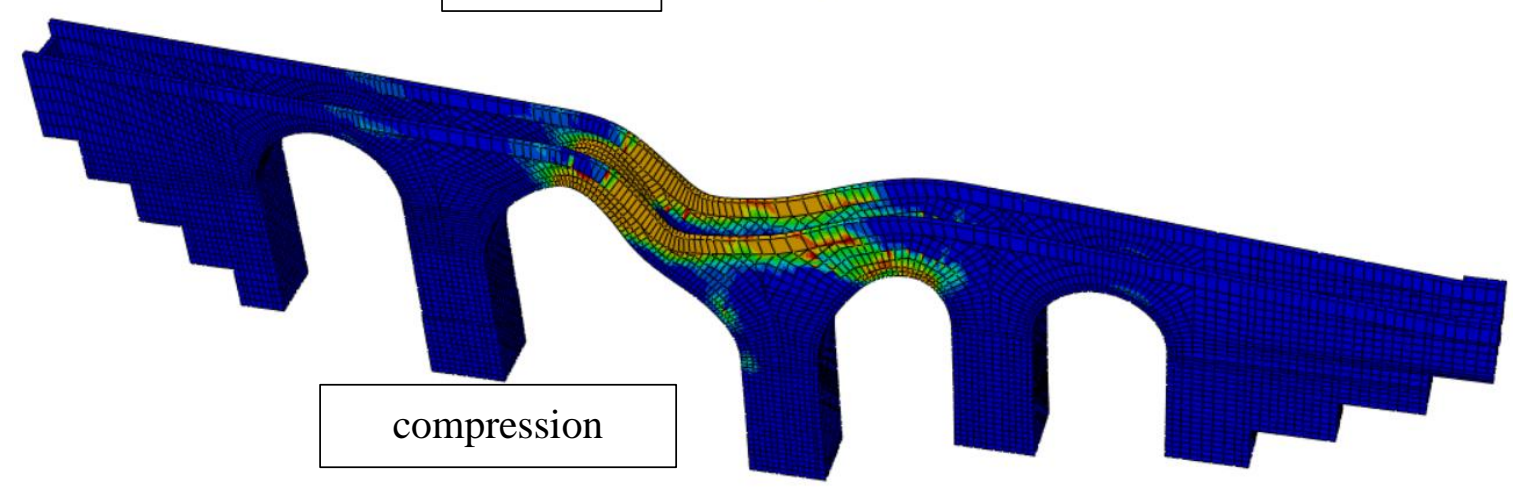

Model II
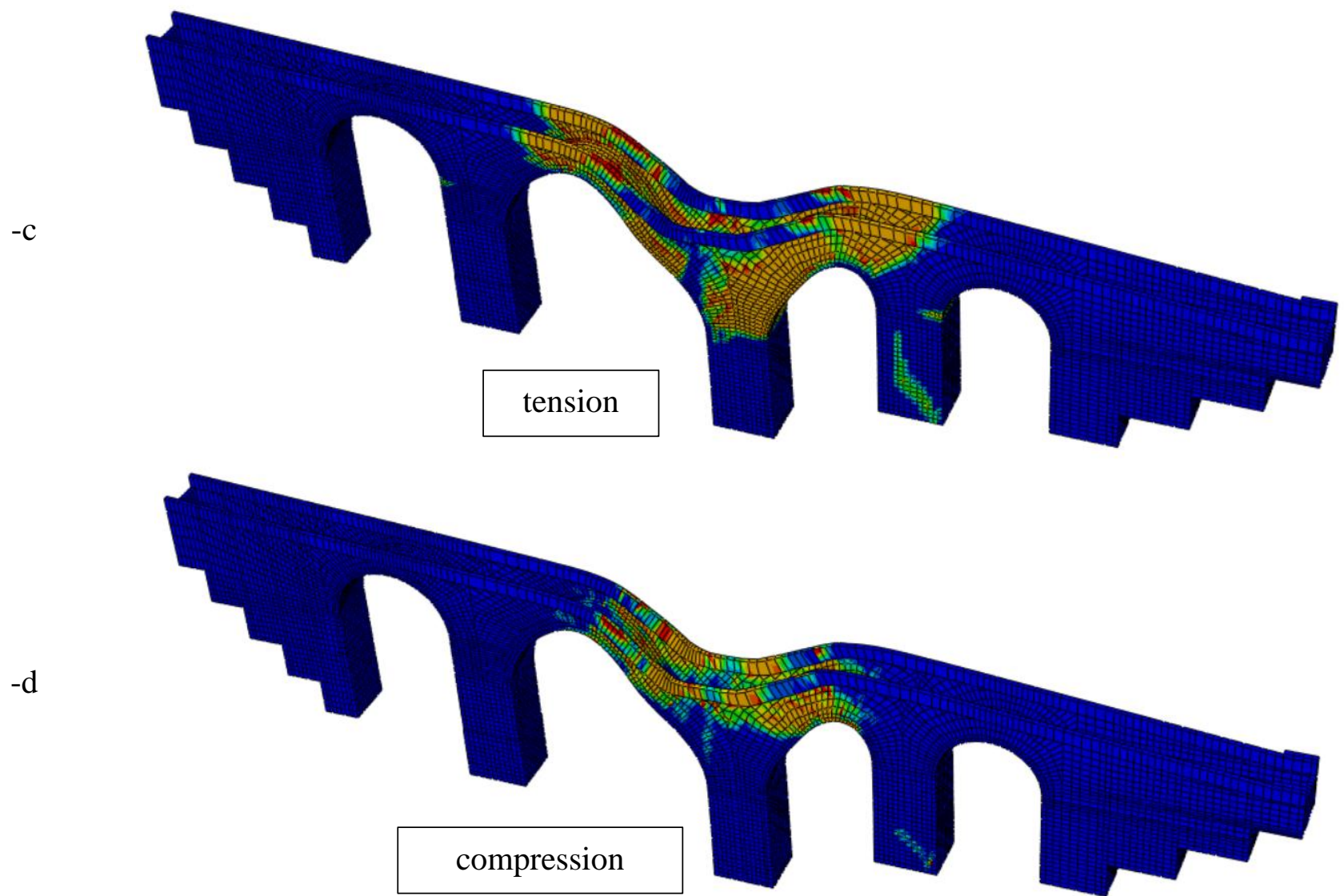

Figure 25: Compression damage Travertine. -a: model I, compression. -b: model I, tension. -c: model II, compression. -d: model II, tension. 
Modifications highlighted in color YELLOW
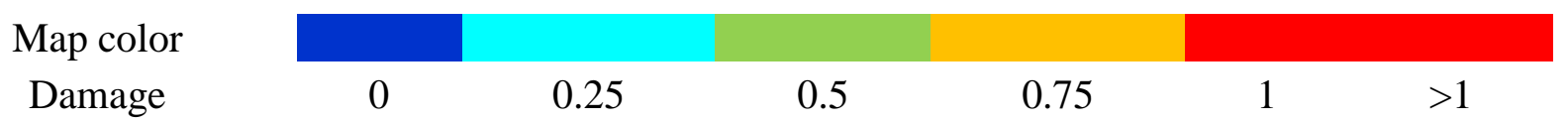

Model I
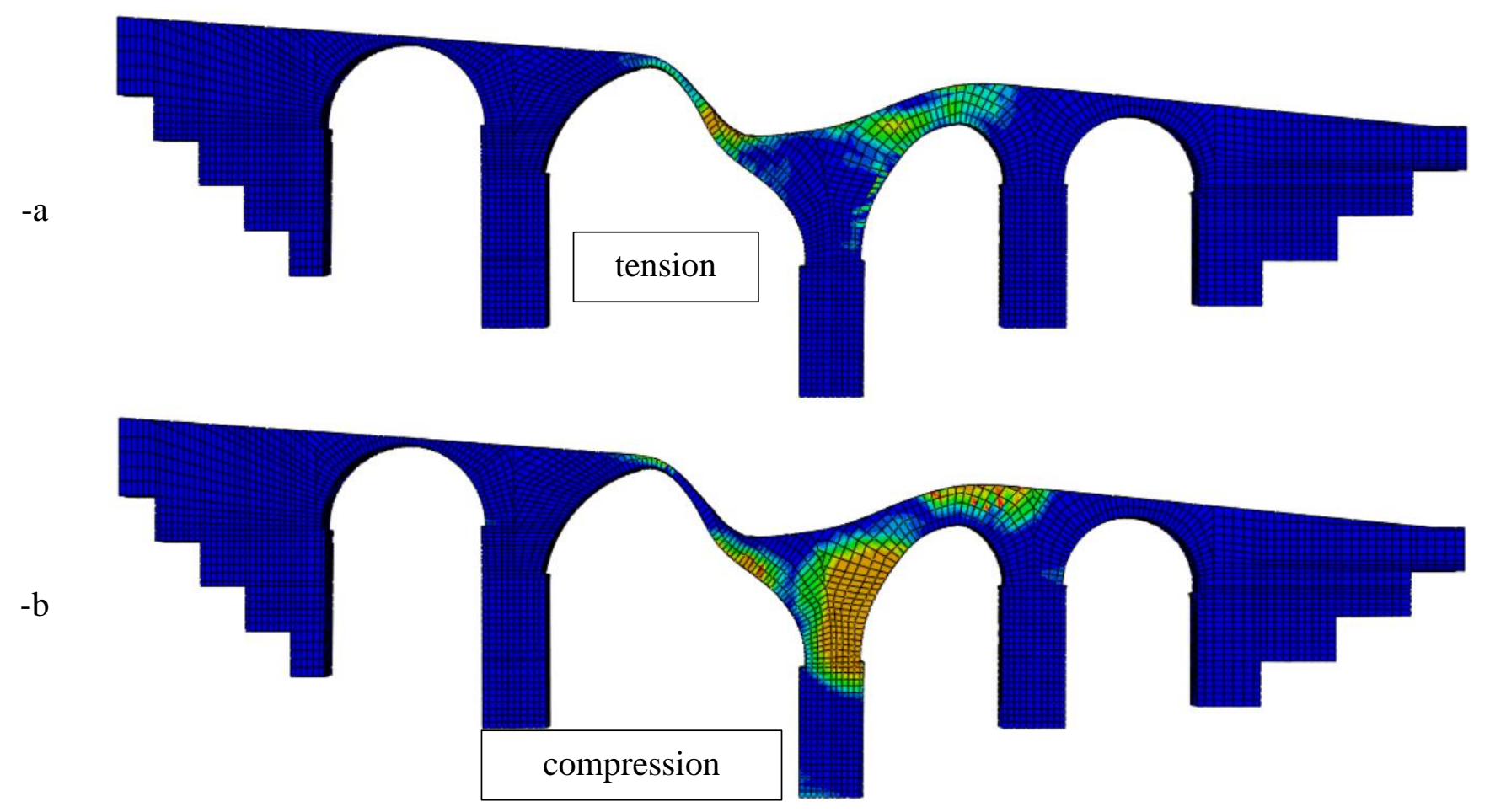

Model II
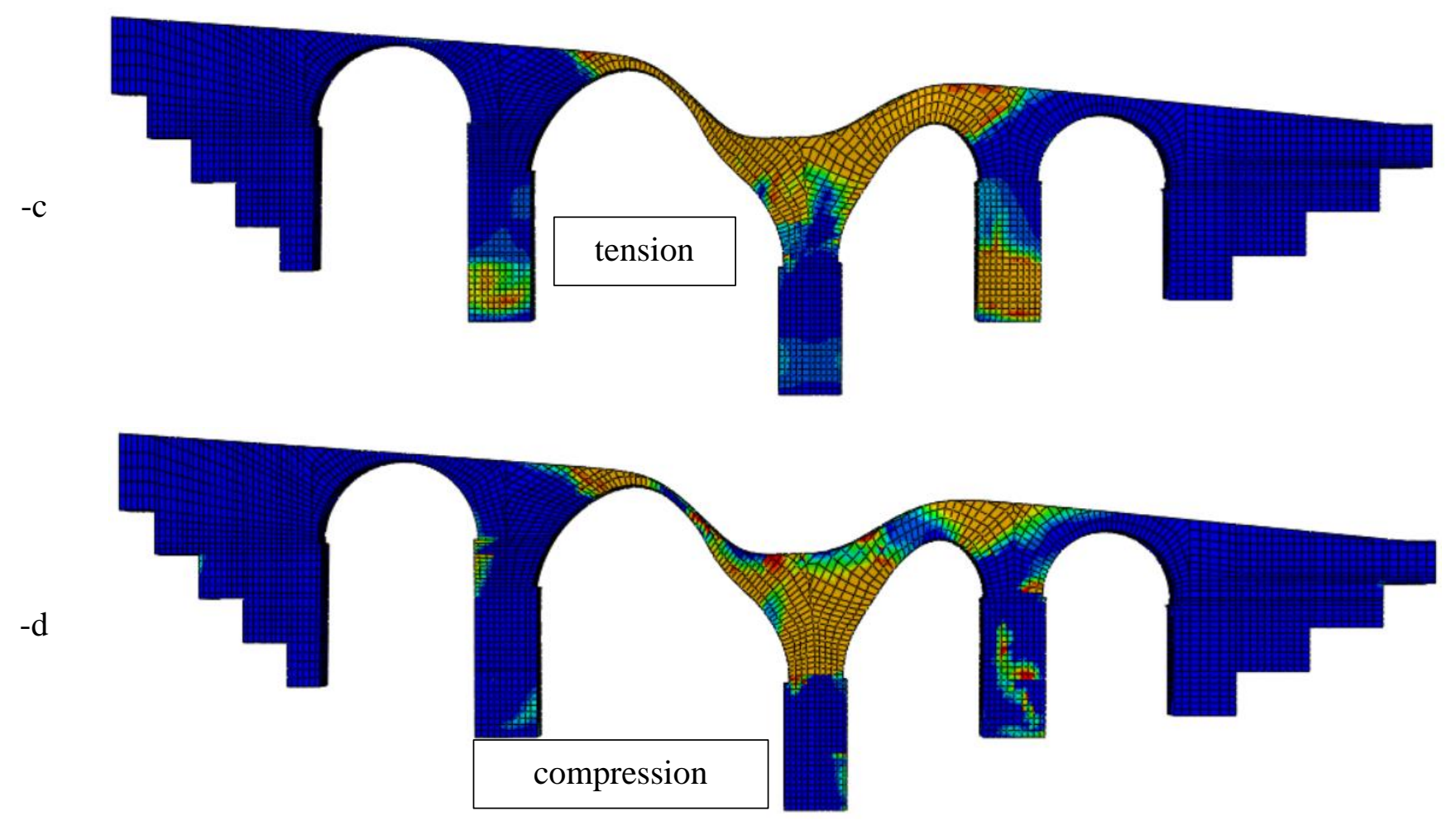

Figure 26: Compression damage Roman concrete. -a: model I, compression. - b: model I, tension. -c: model II, compression. $-\mathrm{d}$ : model II, tension. 


\section{5 - Dynamic analyses}

The goal of non-linear dynamic analyses is a very realistic evaluation of the structural response in case of a seismic event. For the still standing part, the interpretation of the results may help in understanding better the vulnerability of the structure in case of future earthquakes (in terms of both damage evolution and expected residual displacements), whereas for the whole structure it can provide information on the reason why the bridge collapsed in its central part.

For both the still standing part and the whole bridge, a spectrum-compatible accelerogram generated by the response spectrum expected (life-safety limit state: SLV, reference period: $V_{R}=100$ years) for the Narni site is used. Both a horizontal component (along the bridge out-of-plane direction) and a vertical one, see Figure 27, are applied. The accelerogram was generated with SIMQKE_GR (Vanmarcke et al. 1999) starting from the spectrum provided by the Italian Code for the site of Narni.

Dynamic analyses (Kmiecik \& Kaminski 2011) are again performed within ABAQUS (Abaqus 2006), because CDP is particularly suited in case of load-unload processes. A classic viscous damping equal to $5 \%$ is adopted in the simulations.
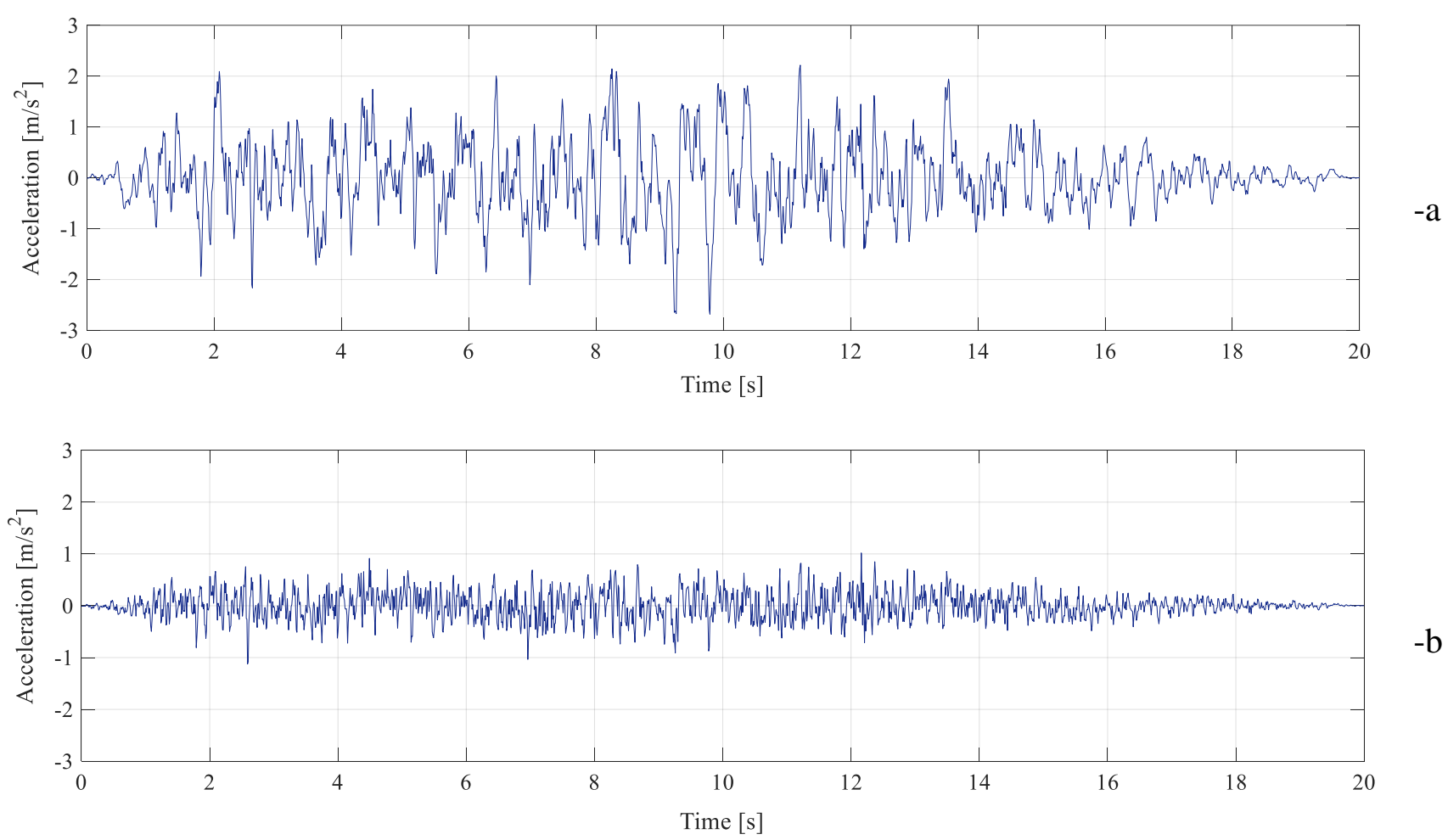

Figure 27: Spectrum compatible accelerograms used for the non-linear dynamic analyses. -a: horizontal component. -b: vertical component. 

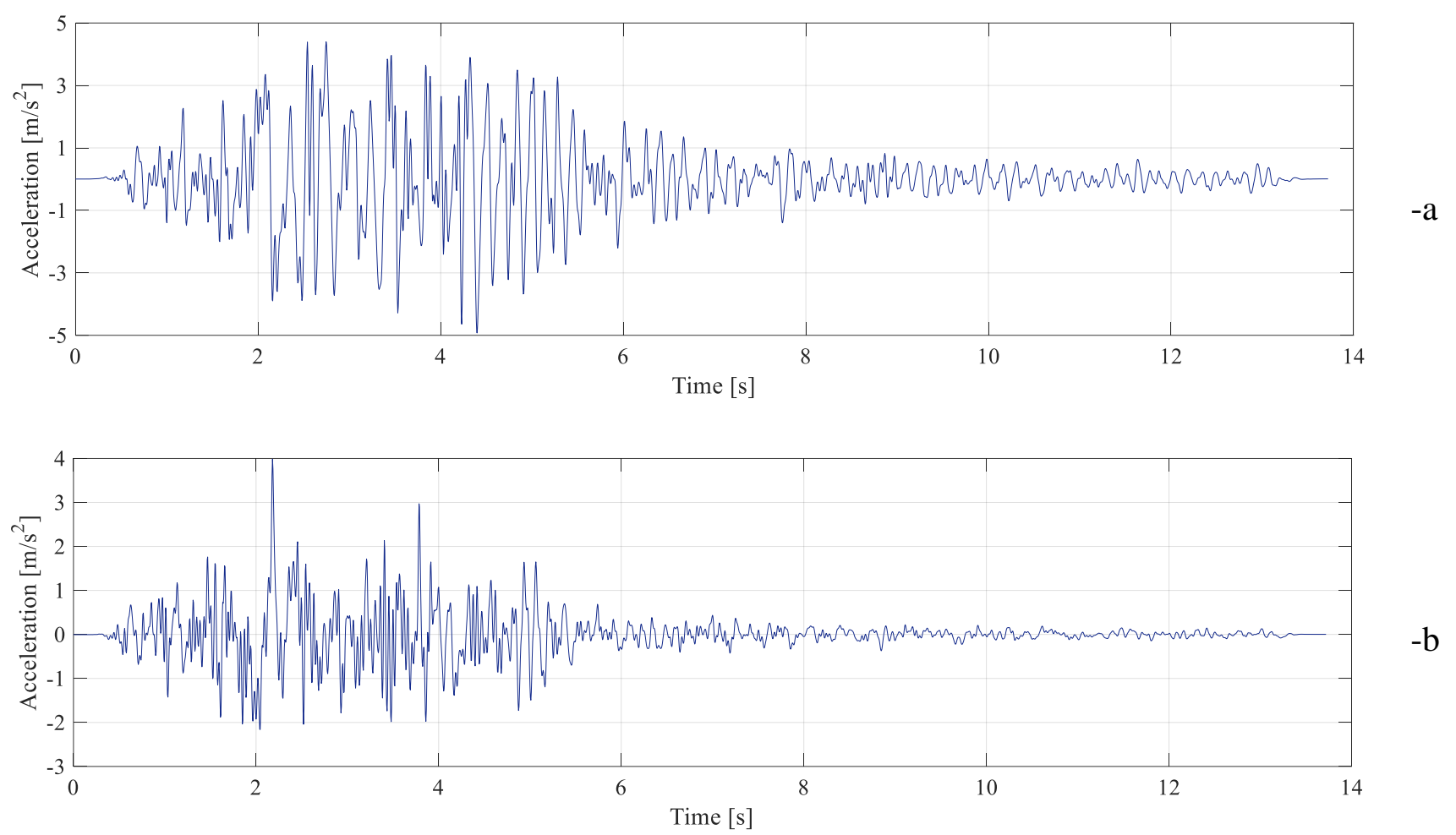

Figure 28: Umbria-Marche (1997) accelerogram used to perform a second set of non-linear dynamic analyses on the whole bridge. -a: horizontal component. -b: vertical component.

Results obtained for the still standing part are summarized in Figure 29 and Figure 30. In particular, Figure 29 collects the relative out-of-plane displacement histories of the pier top and keystone nodes. Reference is made to a node located at the base of the pier. The abscissa shows the time axis; the simulations are conceived in such a way that the static-step is applied in the first second.

As a consequence, in Figure 29, in the X-axis range from 0 to 1 the displacements of the static-step (i.e. displacements under self-weight) are presented, whereas from 1 to 21 seconds the displacements related to the 20 seconds of the earthquake are depicted.

As can be seen, the residual displacement of the pier top and the keystone when compared with the base nodes does not exceed $2-2.5 \mathrm{~cm}$. From one side, the result suggests that some damage occurred inside the bridge as a consequence of the application of the accelerogram, but from the other the absolute value indicates that the displacement is quite moderate, meaning that a failure mechanism is still not active. Considering an isolated pier, for instance, the Italian Code suggests as ultimate displacement a value equal to $0.4 \%$ of the height, in this case about $6 \mathrm{~cm}$ i.e. 3 times the obtained maximum relative displacement. Figure 30 shows the tensile damage map at the end of the simulations. It is evident the localization of damage at the bottom of the pier and at the keystone, which is certainly in agreement with the obtained residual displacements but not sufficient to fully activate a failure mechanism. 


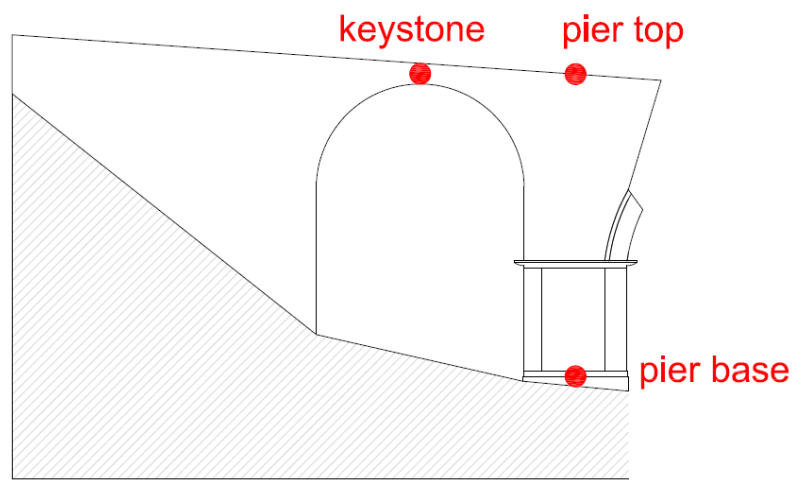

$-a$

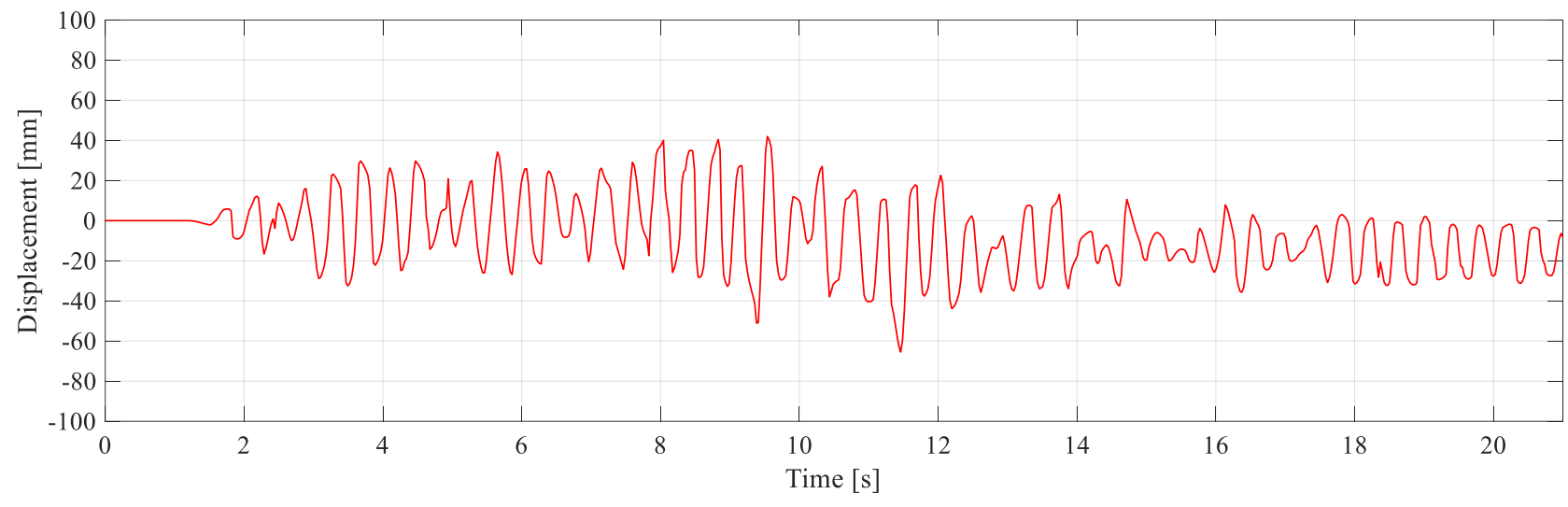

$-b$

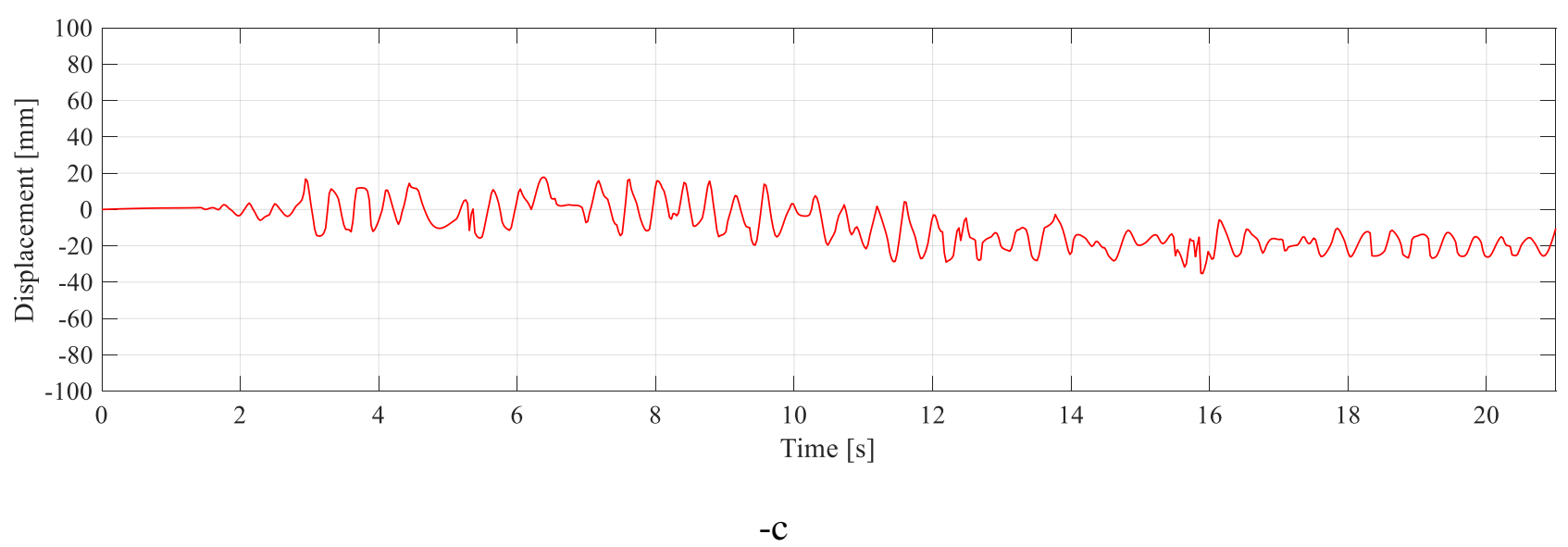

Figure 29: -a Points where the displacement is read. -b: Out-of-plane relative displacement of the pier top node. -c: Out-of-plane relative displacement of the keystone. 


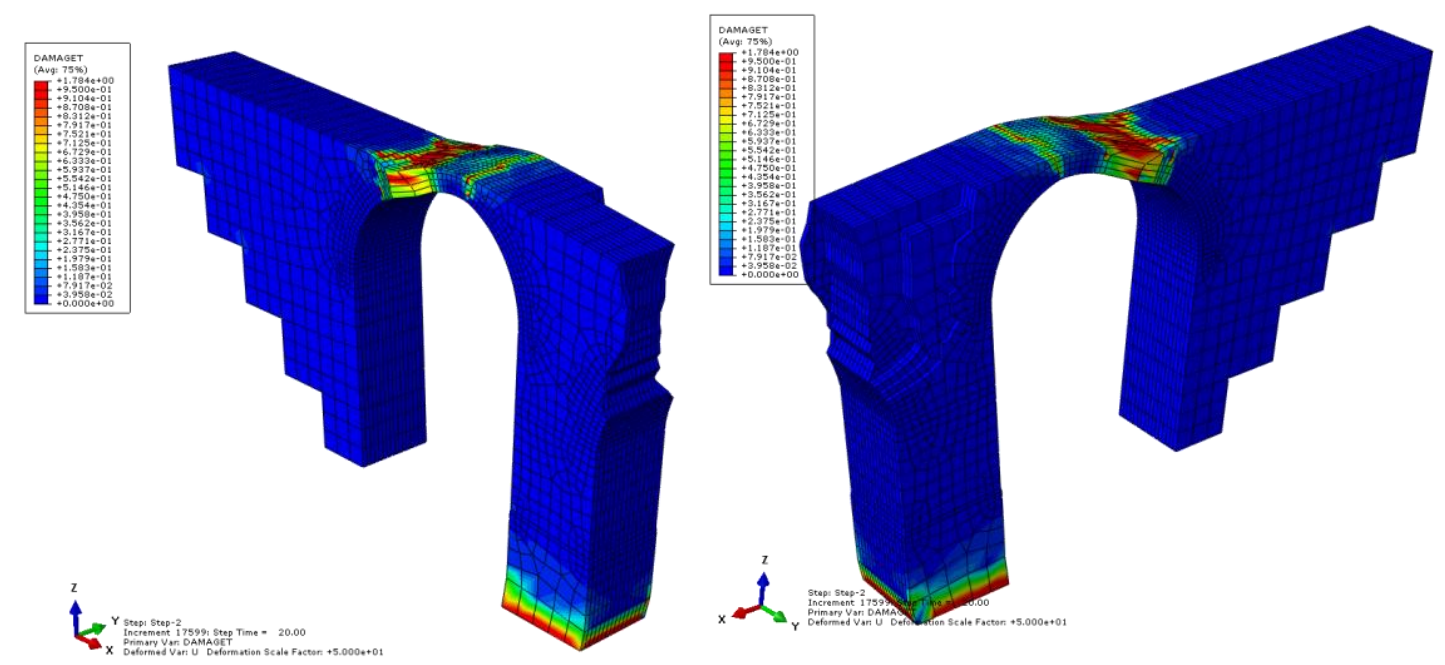

Figure 30: Tensile damage map. View from North (left) and from South (right)

Non linear dynamic simulations on the entire bridge led to the results shown in Figure 31 (differential displacement histories of some meaningful points with respect one node belonging to the base) and Figure 32 (evolution of damage in both tension and compression).

The accelerogram used is the same as that utilized for the still standing part. Authors experienced that the utilization of five different spectrum compatible accelerograms leads to similar results. For this reason only the results obtained with an accelerogram are reported for the sake of conciseness. Again it is interesting to notice that damage found is compatible with a possible failure of the central part of the bridge, an outcome which fully justifies one of the hypotheses done for the partial collapse, i.e. that it was a consequence of an earthquake. However, residual displacements seem again relatively small (less than $5 \mathrm{~cm}$ on point B), meaning that the activation of the failure mechanism, albeit fully compatible with the actual situation of the ruins, is not yet occurred. A further level of refinement about the idea that earthquakes could have caused the partial collapse of the bridge is linked to the concept of application of repeated accelerograms, which is really fascinating and realistic. As a matter of fact, several earthquakes occurred in that region during the last centuries, which realistically could be at the base of a progressive damage of the structure up to the total activation of a collapse mechanism on the central part. The investigation of the behavior of the structure under repeated accelerograms is not an easy task, because one should know the real accelerograms registered during the last seismic events (in practice impossible) and suitably modify the signal in agreement with the exact location of the epicenter.

Whilst this latter issue is clearly outside the scopes of the present paper, it is interesting to evaluate the non-linear dynamic performance of the structure when subjected to a real accelerogram, as that registered not far from Narni in occasion of the devastating Umbria and Marche seismic sequence occurred in 1997/98, see Figure 28.

Results obtained in terms of differential displacement histories of some meaningful points with respect to one node belonging to the base and evolution of damage in both tension and compression are shown respectively in Figure 33 and Figure 34. 
As can be seen, again damage found is compatible with a possible failure of the central part of the bridge, but residual displacements seem still relatively small (around $2 \mathrm{~cm}$ on both point B and point C). From repeated simulations, it appears clear that the failure mechanism is still not fully active and therefore the idea that the partial collapse of the bridge is due to an earthquake can be reasonably supported only thinking about repeated seismic sequences.

The situation is different when four layers of distinct mechanical properties as in Figure 23 are considered, according to the recent experimentation carried out by Drdácký and co-workers. In such case, indeed, the very low compressive strength of some soft layers (especially \#4) leads to a much higher vulnerability under horizontal loads and diffused damage at the base of the central piers even after the application of gravity loads.

Again results obtained in terms of differential displacement histories of some meaningful points with respect to the base and evolution of damage in both tension and compression are shown respectively in Figure 35 and Figure 36.

It is particularly interesting to point out that residual displacements observed are sufficiently large (in some cases more than $20 \mathrm{~cm}$ with a diverging trend) to suggest an out-of-plane collapse of the central part. Crushing of the central pier is also quite visible even at the beginning of the application of the accelerogram, an outcome which makes this last hypothesis on the materials very suited to explain the collapse of the central part after the application of a single accelerogram. It is finally noted that damage at the end of the simulations is so diffused to involve basically all the bridge. 


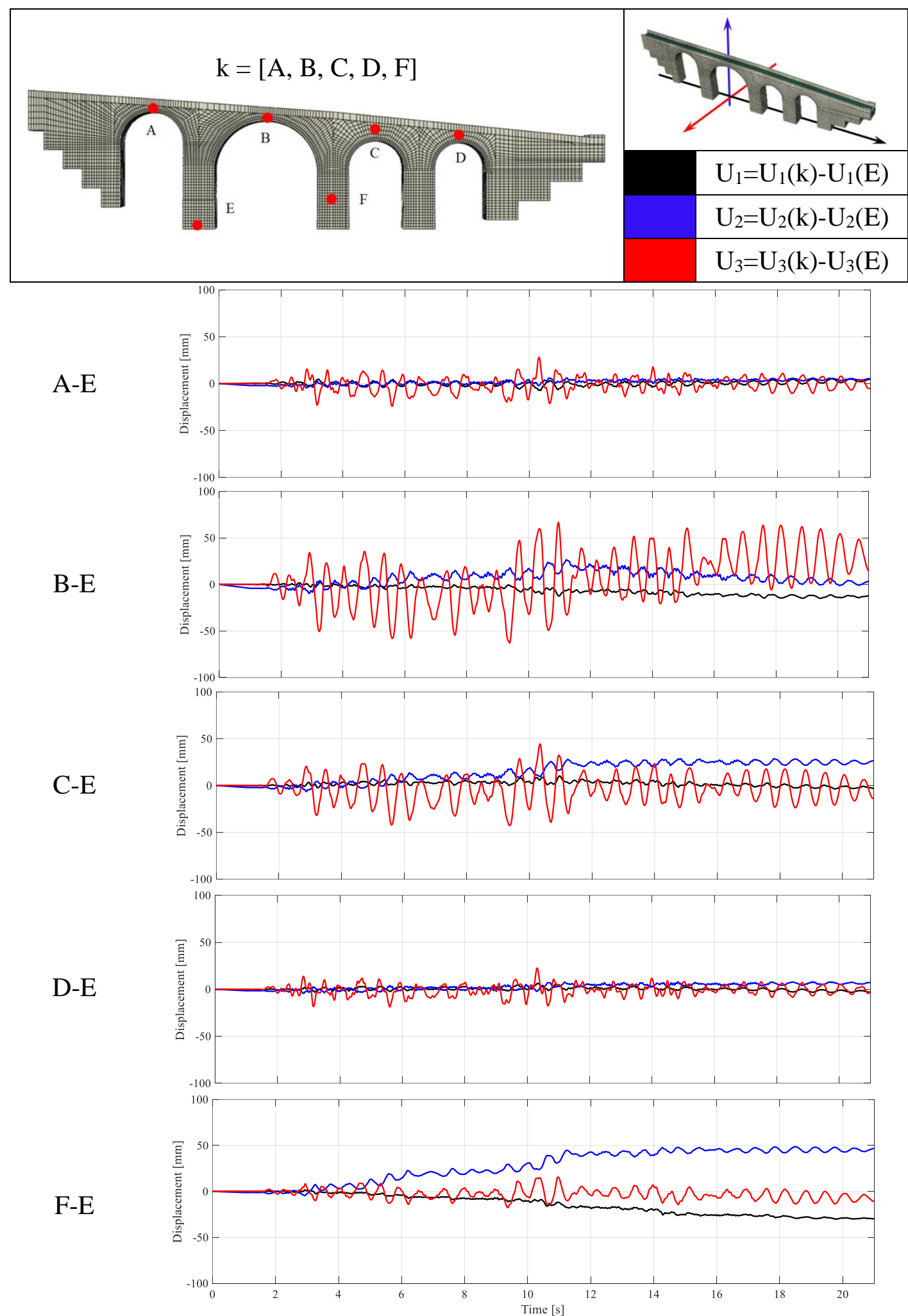

Figure 31: Spectrum compatible accelerogram. Differential displacement histories of meaningful points on the bridge. 
Modifications highlighted in color YELLOW

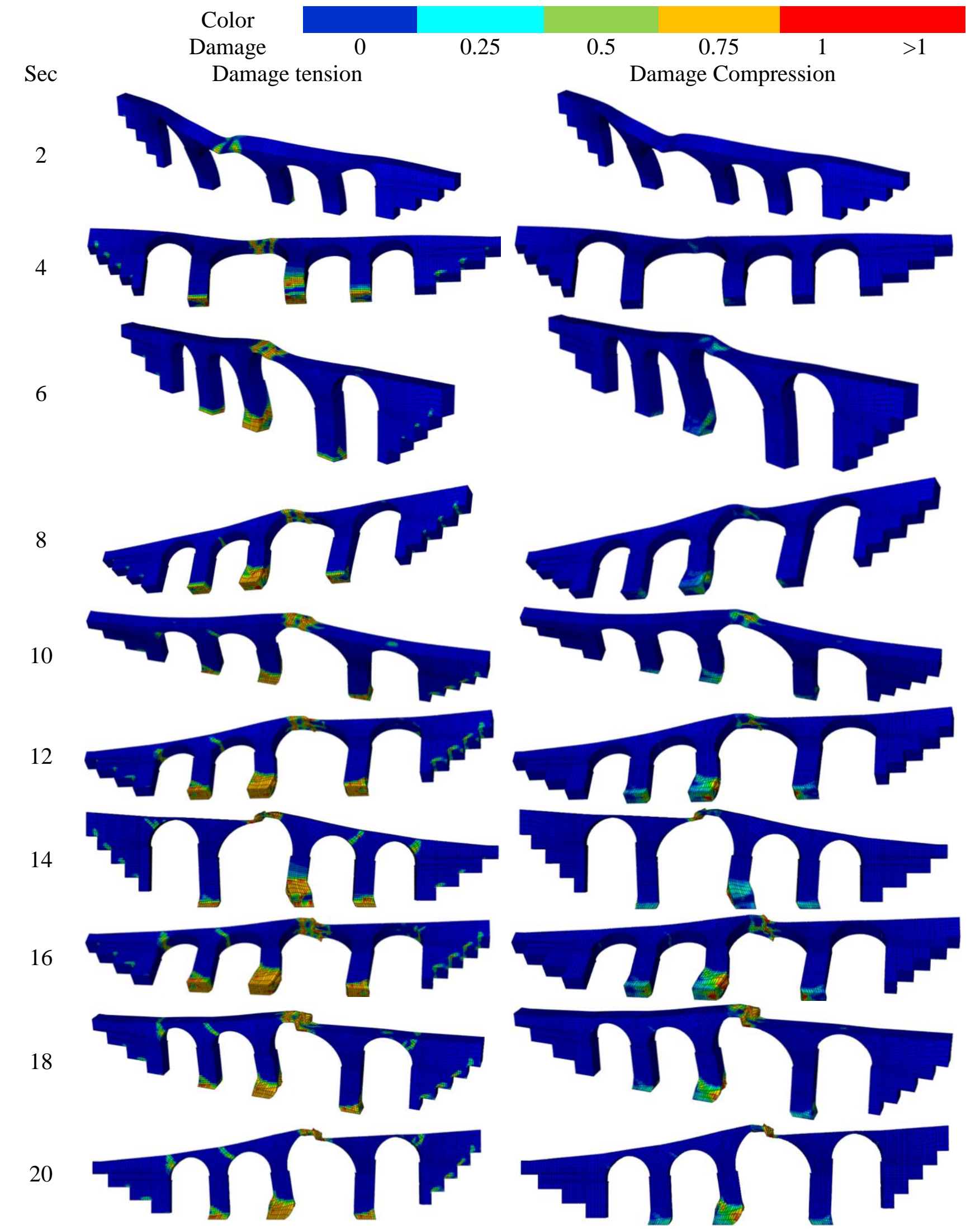

Figure 32: Spectrum compatible accelerogram. Damage propagation at different instants. 


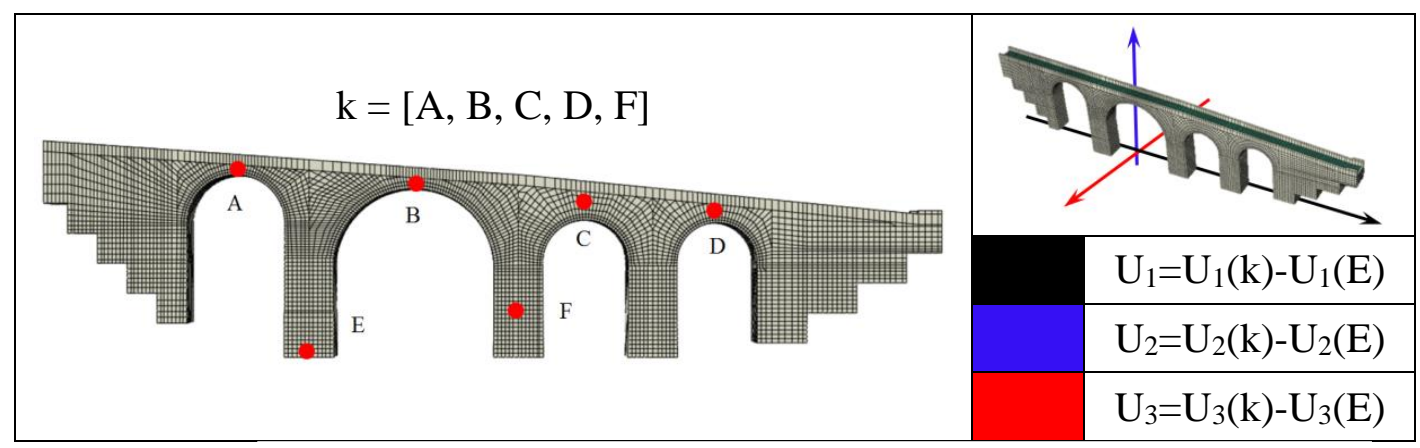

A-E

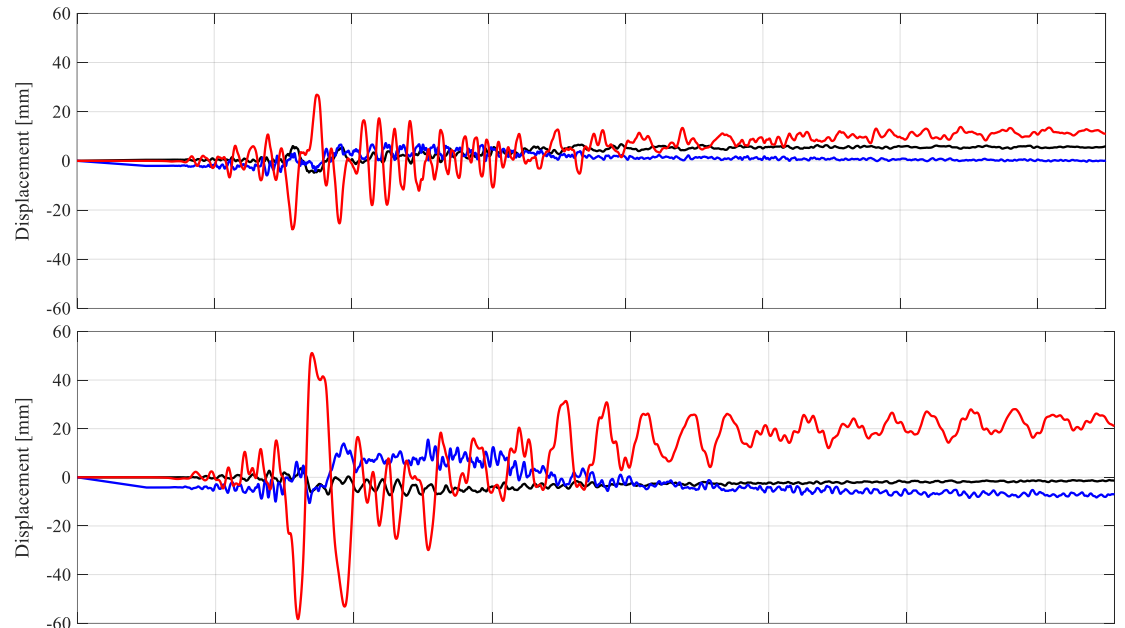

B-E

C-E

D-E
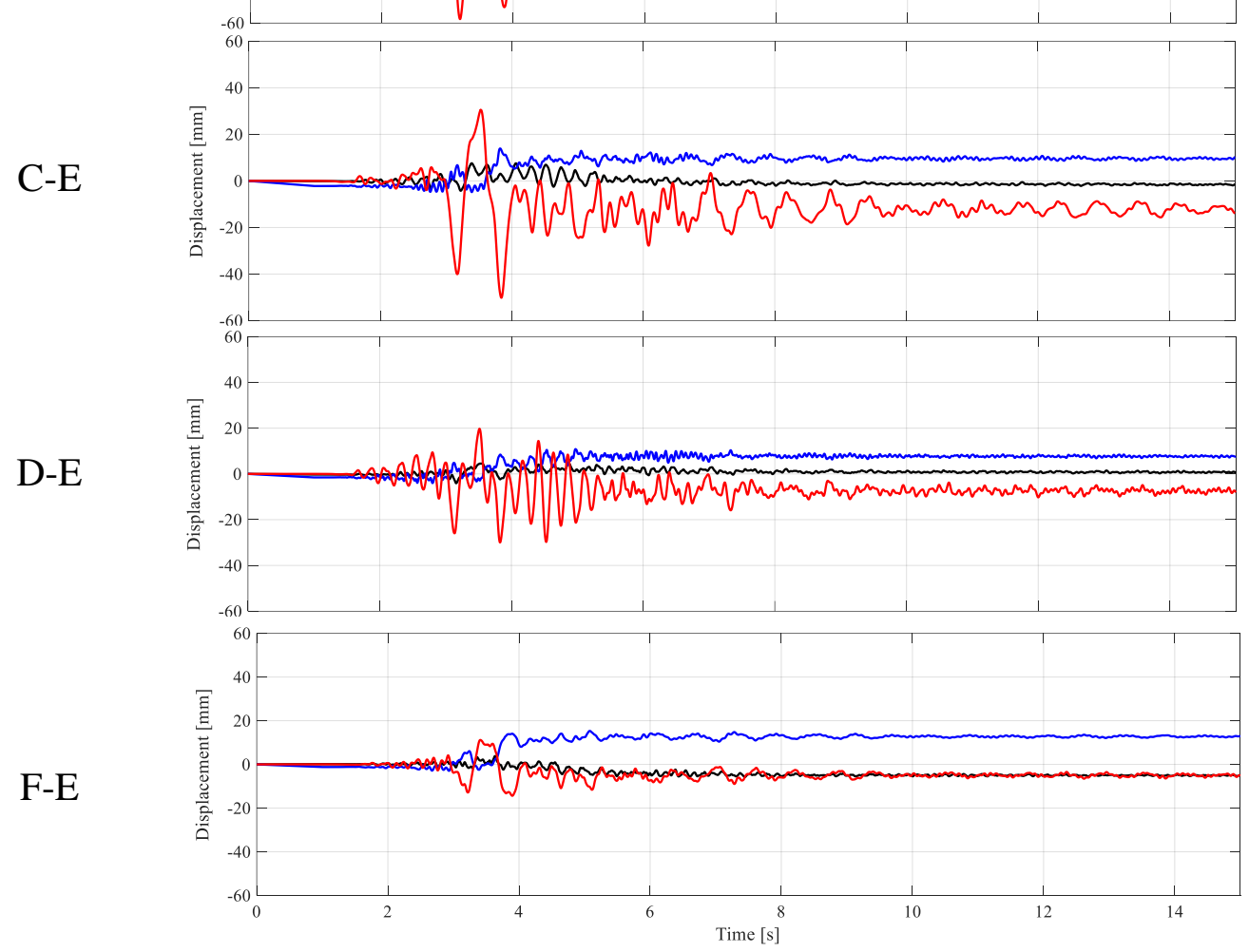

Figure 33: Umbria-March (1997) accelerogram. Differential displacement histories of meaningful points on the bridge. 


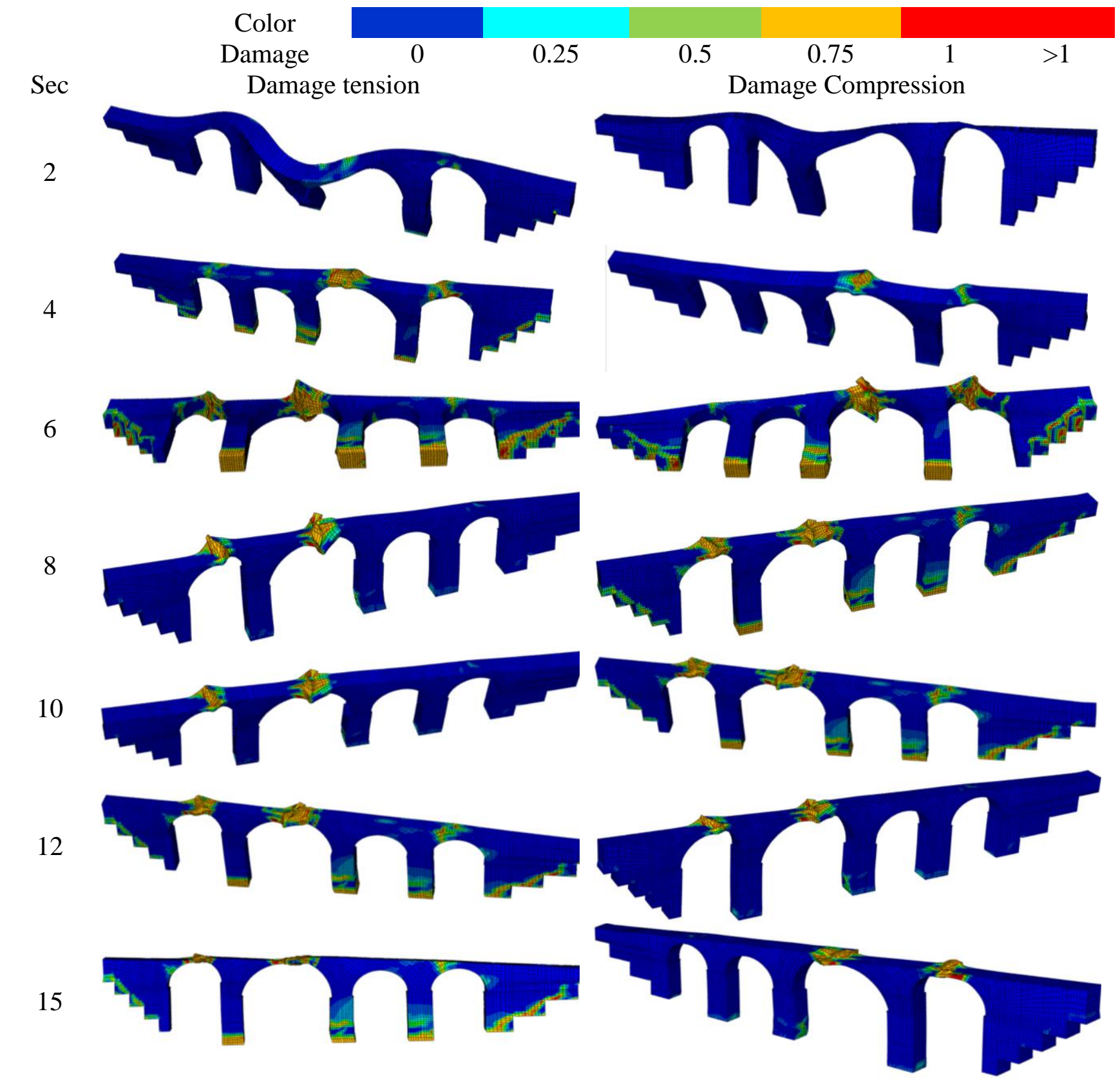

Figure 34: Umbria-March (1997) accelerogram. Damage propagation at different instants. 


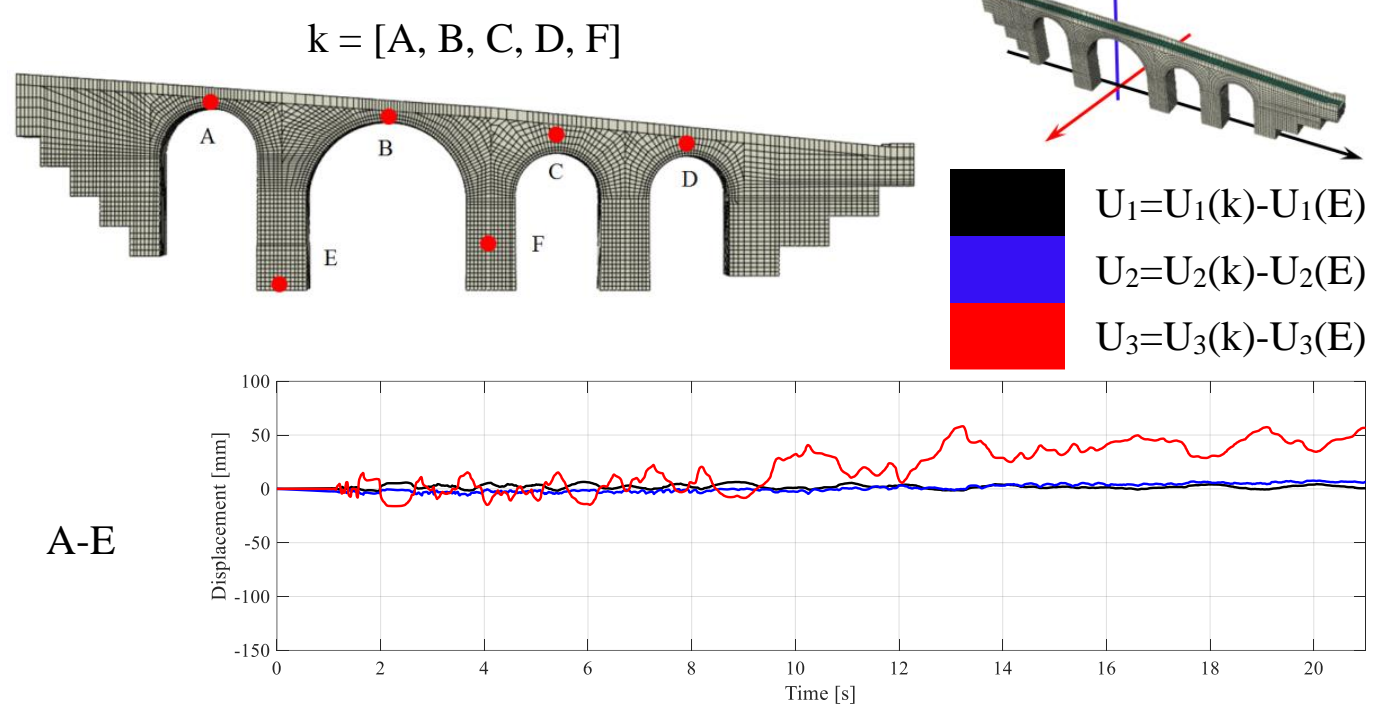

B-E

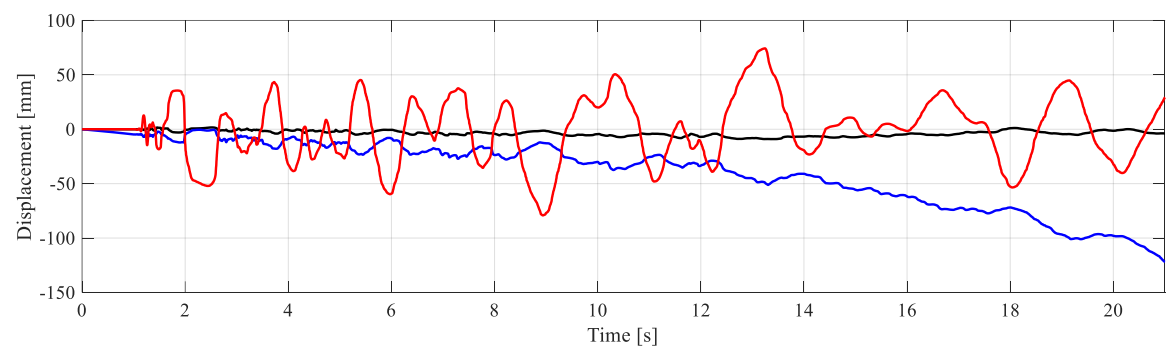

C-E
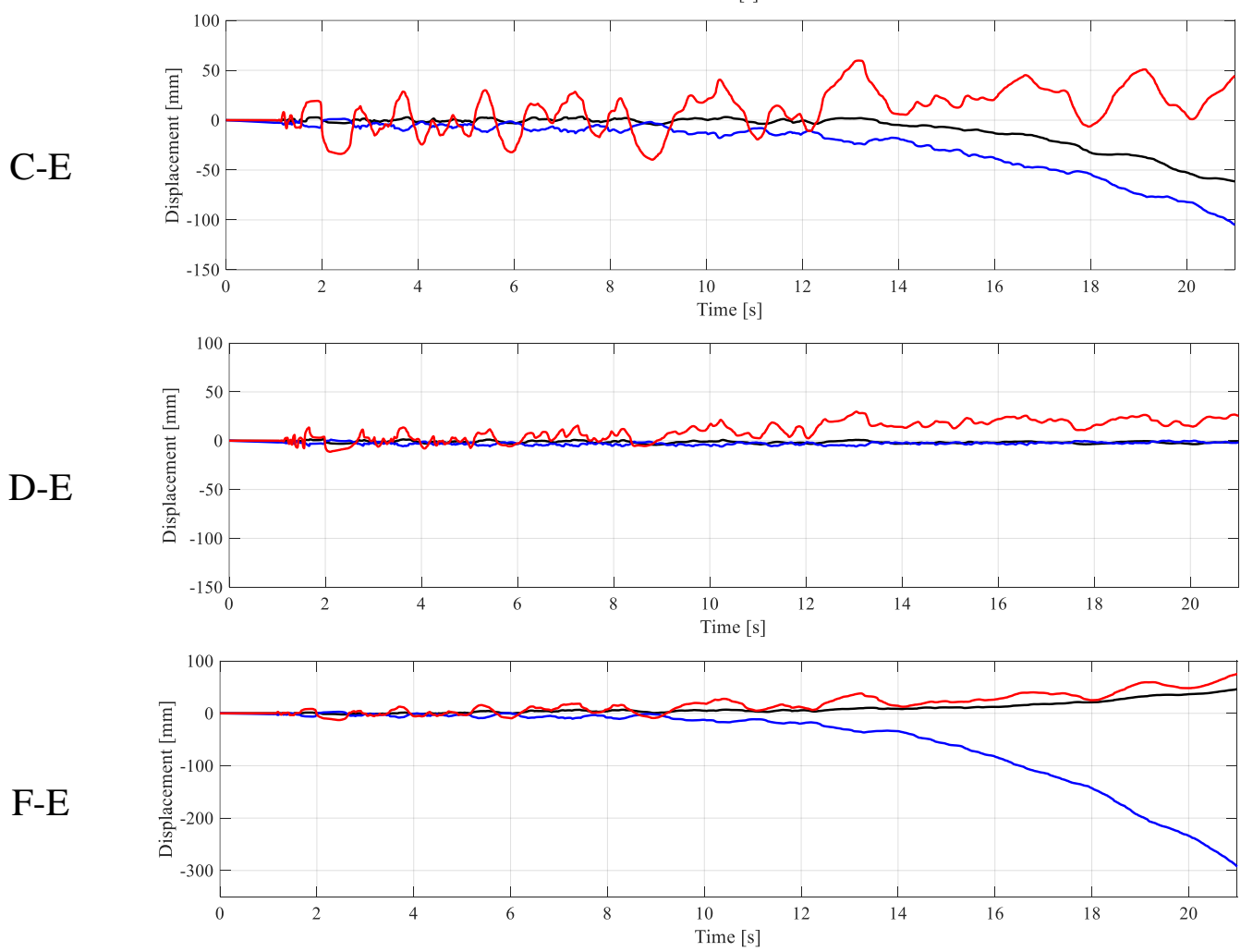

Figure 35: Spectrum compatible accelerogram, model with four layers. Differential displacement histories of meaningful points on the bridge. 


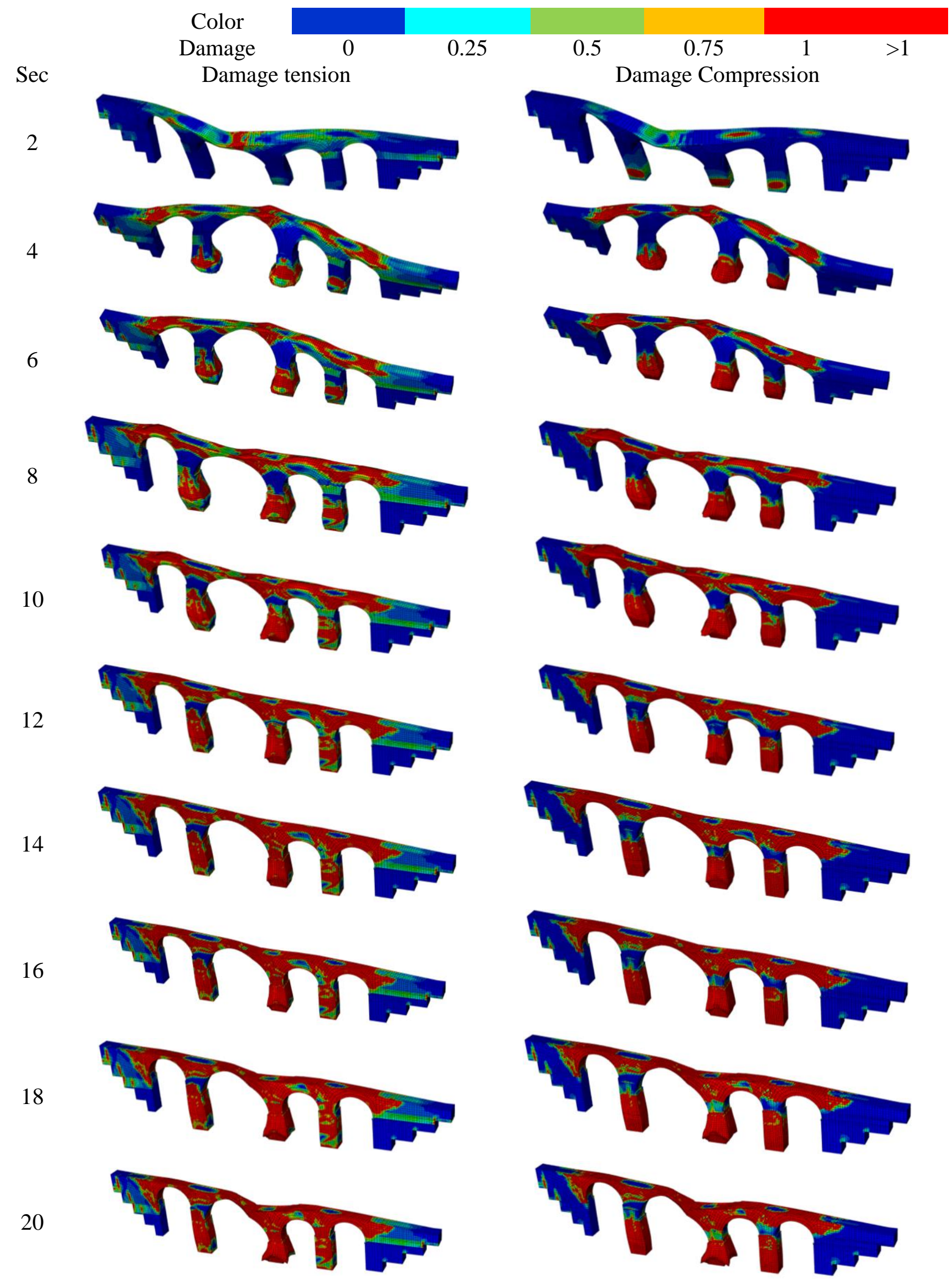

Figure 36: Spectrum compatible accelerogram, model with four layers. Damage propagation at different instants. 


\section{7 - Conclusions}

The Ponte di Augusto is one of the most impressive structures ever built in the whole Roman bridge production. As a matter of fact, thanks to the size of the object, the amplitude of the arches and the height of the structure, it is surely one of the masterpieces of ancient Roman engineering that deserves to be studied with advanced numerical techniques.

The present paper was aimed at providing answers on several different open questions that awaited a quantitative clarification, namely the causes of collapse of the central part, the role played by Roman concrete on increasing the stability also against earthquake excitation and obviously an analysis of the actual vulnerability of the still standing part, being the preservation of the ruins a fundamental task, especially in that area where recently the seismic activity proved to be particularly high.

As far as the causes of the partial collapse concern, detailed non-linear static and dynamic analyses performed on a 3D FE model of the whole structure assuming for the Roman concrete a softening behavior with damage, shown that the most reasonable hypothesis justifying the failure is maybe a foundation settlement of one of the central piers, which probably proceeded slowly over the centuries. The hypothesis of collapse due to a single seismic event appears less convincing but still possible, because the results of the non-linear dynamic analyses addressed a state of residual deformation not fully compatible with the activation of a failure mechanism. Indirectly, such latter results provide interesting insight into the surprisingly high resistance of such kind of structures against earthquakes, which is obviously a consequence of the Roman concrete high strength. A further hypothesis that still makes the collapse for seismic action possible is the effect of the application of repeated accelerograms, with failure due to cumulated damage over time.

Another important issue is related to the role played by Roman concrete on the seismic resistance of arch bridges. For the present case study, several experimental data are already available thanks to tests conducted on samples of concrete extracted directly from the bridge in the recent past (Cecchi 2003, Cantisani et al. 2002, Drdácký et al. 2013). Such authors speculated that the exceptionally high strength found (i.e. the hydraulicity in the conglomerate) can be attributed to calcification of stones of impure limestone, and not by the insertion of any particular additives (Cantisani et al. 2002), such as dusts and shards of terracotta and/or by the addition of sand and pebbles of volcanic origin (pozzolan), generally used in all Roman buildings. From non-linear dynamic simulations, it has been shown that Roman concrete increases the overall strength of the structure, also against earthquakes. The utilization of weaker mechanical properties, assuming for instance values from indications provided by the Italian code for existing masonry, addresses a largely insufficient capacity of the whole bridge to cope with transversal actions mimicking an earthquake. Pushover simulations show a high vulnerability of the entire building, corroborating the hypothesis that the collapse of the central part could be a consequence of a seismic event, but only under the hypothesis of mechanical strength of the Roman concrete much smaller than that found experimentally on the still standing part. As a matter of fact, analyses carried out assuming several mechanical properties of the filling material, revealed an even greater seismic vulnerability gradually assuming properties of the filling similar to those of an ordinary masonry; pointing out that similar structures have an insufficient load carrying capacity even with respect to the only vertical loads if realized with a masonry filling and not with Roman concrete. 
Concerning the structural behavior of the bridge, the good accordance between the experimental dynamic behavior and the numeric dynamic behavior, obtained with a model that employs the mechanical properties of the materials reported in Cecchi (2003), confirms that the Roman concrete filling seems to exhibit properties close to the ones deduced from the tests on the materials.

Another interesting issue is the efficacy of the connection between travertine and infill. From historical studies, it is nowadays common opinion that in the initial state, the connections between the two materials were effective. However, in the present ruined state, detachment and relative sliding may be possible. It would be interesting to model such relative sliding, introducing joint elements in the numerical model, but this would make the non-linear numerical models more complex and the analyses even more demanding. Postponing this particular issue to a future research, the choice made here was to suitably decrease travertine tensile strength, in order to reasonably take into account, despite in an approximate way, the possibility of detachment due to inefficient connection.

Concerning the seismic-resistant behavior of the still standing part, the obtained results (both nonlinear static and dynamic) seem to confirm a certain seismic vulnerability of the ruins and probably underlies the choice to reinforce the pier by inserting Titanium bars anchored in the rock below the pier (Salvatore et al. 2005). 


\section{Acknowledgements}

The authors gratefully acknowledge the support of 4EMME Service S.p.A. for carrying out the dynamic test on the Ponte di Augusto at Narni, the Municipality of Narni and the Superintendence for Archaeological Heritage of Umbria.

\section{References}

ABAQUS®, Theory Manual, Version 6.6, 2006.

Acito, M., M. Bocciarelli, C. Chesi and G. Milani. 2013. Collapse of the Clock Tower in Finale Emilia after the May 2012 Emilia-Romagna earthquake sequence: numerical insight. Engineering Structures 72: 70-91.

Audenaert, A. and J. Beke. 2010. Applicability analysis of 2D-models for masonry arch bridge assessment: Ring, Archie-M and the elasto-plastic model. WSEAS Transactions on applied and theoretical mechanics 5(4): 221230.

Audenaert, A., P. Fanning, L. Sobczak and H. Peremans. 2008. 2-D analysis of arch bridges using an elasto-plastic material model. Engineering Structures 30: 845-855.

Cantisani, E., A. Cecchi, I. Chiaverini, F. Fratini, C. Manganelli del Fa, E. Pecchioni and S. Rescic. 2002. The binder of the «Roman Concrete» of the Ponte di Augusto at Narni (Italy). Periodico di Mineralogia 71: 113-123.

Cavicchi, A. and L. Gambarotta. 2005. Collapse analysis of masonry bridges taking into account arch-fill interaction. Engineering Structures 27(4): 605-615.

Cavicchi, A. and L. Gambarotta. 2006. Two-dimensional finite element upper bound limit analysis of masonry bridges. Computers \& Structures 84(31-32): 2316-2328.

Cecchi A. 2003. Il Ponte di Augusto a Narni: metodi informatici per il rilievo delle rovine, la ricostruzione virtuale, la modellazione solida con il metodo degli elementi finiti. Quaderni di Leonardo N.2. Leonardo Società di Ingegneria,

Circolare 2009. Circolare n. 617 del 2 febbraio 2009 Istruzioni per l'Applicazione Nuove Norme Tecniche Costruzioni di cui al Decreto Ministeriale 14 gennaio 2008. Rome, Italy.

Circolare 2010. Circolare n. 26 del 2 dicembre 2010. Linee guida per la valutazione e riduzione del rischio sismico del patrimonio culturale allineate alle Nuove Norme Tecniche per le costruzioni. Ministero per i Beni e le Attività Culturali. MiBAC, Rome, Italy.

De Felice, G. and S. De Santis. 2010. Experimental and numerical response of arch bridge historic masonry under eccentric loading. International Journal of Architectural Heritage 4(2): 115-137.

Drdácký, M., F. Fratini, D. Frankeová and Z. Slížková. 2013. The roman mortars used in the construction of the Ponte di Augusto (Narni, Italy) - A comprehensive assessment. Construction and building Materials 38: 1117-1128.

Drosopoulos, G. A., G. E. Stavroulakis and C. V. Massalas. 2006. Limit analysis of a single span masonry bridge with unilateral frictional contact interfaces. Engineering Structures 28(13): 1864-1873.

Fanning, P. J. and T. E. Boothby. 2001. Three dimensional modelling and full scale testing of stone arch bridges. Computers and Structures 79(29-30): 2645-2662.

Fanning, P. J., T. E. Boothby and B. J. Roberts. 2001. Longitudinal and transverse effects in masonry arch assessment. Construction and Building Materials 15: 51-60.

Galliazzo V. 1994. I ponti romani, Volumes I \& II. Canova, Treviso, Italy.

Gilbert M. 2006. Limit analysis of masonry block structures with non-associative frictional joints using linear programming. Computers and Structures 84: 873-887.

Gilbert, M. and C. Melbourne. 1994. Rigid-block analysis to masonry arches. Structural Engineering 72: $356-361$. 


\section{Modifications highlighted in color YELLOW}

Kmiecik, P. and M. Kaminski. 2011. Modelling of reinforced concrete structures and composite structures with concrete strength degradation taken into consideration. Archives of Civil and Mechanical Engineering 11(3): 623-636.

Lamprecht, H. O. 1986. Opus Caementicium: Costruzioni in calcestruzzo Romano. L'Industria Italiana del Cemento 7-8.

Martín-Caro, J. A. and G. Morales. 2007. Numerical analysis of a load test on a skewed masonry arch bridge. ARCH'07: 5th International Conference on Arch Bridges, Multicomp, Lda Publishers, Madeira: 569-576.

Milani, G. and P. B. Lourenço. 2012. 3D non-linear behavior of masonry arch bridges. Computers \& Structures 110111: 133-150.

NTC 2008. Nuove norme tecniche per le costruzioni. Ministero delle Infrastrutture (GU n.29 04/02/2008). Rome, Italy, 14/01/2008.

Oliveira, D. V., P.B. Lourenço and C. Lemos. 2010. Geometric issues and ultimate load of masonry arch bridges from the northwest Iberian Peninsula. Engineering Structures 32(12): 3955-3965.

Pelà, L., A. Aprile and A. Benedetti. 2009. Seismic assessment of masonry arch bridges. Engineering Structures 31(8): 1777-1788.

Pippard A. J. S. 1948. The approximate estimation of safe loads on masonry bridges. Civil engineer in war: Institution of Civil Engineers, 1: 365.

Reccia, E., G. Milani, A. Cecchi and A. Tralli. 2014. Full 3D homogenization approach to investigate the behavior of masonry arch bridges: The Venice trans-lagoon railway bridge. Construction \& Building Materials 66: 567-586.

Salvatore, M., L. Lombardi, L. Bonomi Ponzi, V. Angeletti, C. Fiove Fantozzi, F. Carli and G. Ranaulo. 2005. Il ponte di Augusto a Narni. Quadro archeologico, vicende costruttive, restauro.

Sevim, B., A. Bayraktar, A. Can Altunişik, S. Atamtürktür and F. Birinci. 2011. Finite element model calibration effects on the earthquake response of masonry arch bridges. Finite Elements in Analysis and Design 47(7): 621634.

STRAUS7®, Theoretical manual-theoretical background to the Strand7 finite element analysis system, 2004.

Vanmarcke, E. H., G. A. Fenton and E. Heredia-Zavoni. SIMQKE-II, conditioned earthquake ground motion simulator: user's manual. 1999.

Zeman, V., J. Nováka, M. Šejnoha and J. Šejnoha. 2008. Pragmatic multi-scale and multi-physics analysis of Charles Bridge in Prague. Engineering Structures 30(11): 3365-3376. 